cytosolic

fatty

acid-

binding

proteins

René J.A. Paulussen 

FATTY ACID-BINDING PROTEINS 



\title{
CYTOSOLIC FATTY ACID-BINDING PROTEINS
}

\author{
een wetenschappelijke proeve
}

op het gebied van de geneeskunde en tandheelkunde

\section{Proefschrift}

ter verkrijging van de graad van doctor aan de Katholieke Universiteit te Nijmegen, volgens besluit van het college van decanen

in het openbaar te verdedigen op maandag 27 november 1989 des namıddags te 330 uur

door

René Josephus Antonius Paulussen geboren op 2 september 1958 te Rotterdam 
promotor prof dr JH Veerkamp

The investigations described in this thesis were carried out at the Department of Biochemistry, Faculty of Medicine, of the University of Nijmegen, The Netherlands, under the direction of Prof $\mathrm{Dr} \mathrm{JH}$ Veerkamp 
Chapter 1 .

General introduction.

Chapter 2 .

Intracellular fatty acid-binding proteins.

An overview.

Chapter 3

Materials and general procedures.

Chapter 4

Purification, characterization and binding properties of the FABPs from human, pig and rat heart.

Chapter 5 .

Fatty acid-binding capacity of cytosolic proteins of various rat tissues. Effect of postnatal development, starvation, sex, clofibrate feeding and light cycle.

Chapter 6

Immunochemical quantitation of fatty acid-binding proteins. I. Tissue and intracellular distribution, postnatal development, and influence of physiological conditions on rat heart and liver FABP

Chapter 7

Immunochemical quantitation of fatty acid-binding proteins. II. Distribution of liver and heart FABP types in human and porcine tissues.

Chapter 8 .

survey and summary.

Samenvatting

References

Appendices

List of publications $\quad$. $\quad . \quad$. $\quad . \quad$. 123

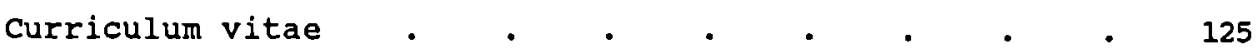


studies as described here never are the work of just one person. I would like to express my gratitude to all who have contributed, in one way or another, to the accomplishment of this thesis.

The support of Canberra Packard Benelux NV, and of the state Institute for Quality Control of Agricultural Products (RIKILT), Wageningen, The Netherlands, is gratefully acknowledged.

$\mathbf{v i}$ 


$\begin{array}{ll}\text { ANS } & \text { 1-anilino-8-naphthalene sulphonate } \\ B_{\max } & \text { maximal binding capacity } \\ \text { BSA } & \text { bovine serum albumin } \\ \text { COA } & \text { coenzyme A } \\ \text { CM } & \text { carboxymethyl } \\ \text { CRBP } & \text { cellular retinol-binding protein } \\ \text { DEAE } & \text { diethylaminoethyl } \\ \text { DOCA } & \text { deoxycorticosterone acetate } \\ \text { EDTA } & \text { ethylenediamine tetra-acetate } \\ \text { ELISA } & \text { enzyme-linked immunosorbent assay } \\ \text { FABP(s) } & \text { fatty acid-binding protein(s) } \\ \text { IgG } & \text { immunoglobulin G } \\ \mathrm{K}_{\mathrm{d}} & \text { dissociation constant } \\ \text { MDGI } & \text { mammary-derived growth inhibitor } \\ \text { Mr } & \text { relative molecular mass } \\ \text { NMR } & \text { nuclear magnetic resonance } \\ \text { PBS } & \text { phosphate buffered saline } \\ \text { SCP } & \text { sterol carrier protein } \\ \text { SD } & \text { standard deviation } \\ \text { SDS-PAGE } & \text { sodium dodecylsulfate- } \\ \text { SET } & \text { polyacrylamide gel electrophoresis } \\ \text { TG } & \text { sucrose-EDTA-Tris buffer } \\ \text { VLDL } & \text { triacylglycerols } \\ & \text { very-low-density lipoproteins }\end{array}$





\subsection{INTRODUCTION.}

The complex structure of higher organisms, with organs and tissues that perform highly specialised functions, requires an effective mechanism for the inter- and extracellular targeting of compounds. The organism has to accurately direct all kinds of regulatory substances, biosynthetic building blocks, and energy containing compounds towards their specific sites of action or utilization. In the last decades, a large number of carrier proteins have been ldentified, that are involved in the transfer of a variety of molecules to specific sites within the body. Carrier proteins have also been found within the cell, involved in the trafficking of compounds towards intracellular compartments and in the transcellular transport.

Many transport proteins have been found in the blood. The binding proteins for peptide hormones as somatotropin and somatomedins are involved in the regulation of distribution and metabolic clearance rate of these factors [1,2]. Blood also contains a number of proteins that transfer steroids and related compounds: sex hormone-binding globulin (SHBG), corticosteroid-binding protein ( $C B G$ ) and progesterone-binding globulin (PBG) (3). Like with the peptide hormones, these proteins markedly influence the metabolism of their ligands $(3,4)$. Furthermore, binding proteins have been identified for vitamins $A$ and $D$, plasma retinol-binding protein [4] and vitamin D-binding protein $[4,5]$. The plasma retinolbinding protein circulates in a complex with transthyretin, a thyroid hormone-binding protein [4].

Serum albumin is considered to be a more general carrier protein, with affinity for many lipophilic substances $(4,6,7$. It plays a major role in the transport of free fatty acids through 
the cardiovascular system. Apolipoproteins form structural and functional components of chylomicrons and various types of lipoproteins, which are involved in transport of triacylglycerols, phospholipids, cholesterol and cholesterolesters [8-11]. Plasma lipid-transfer proteins play a role in the exchange of lipids between lipoproteins [12].

The cytoplasm forms a barrier between the plasma membrane and intracellular organelles, in which lipophilic molecules are metabolized or have specific functions. To facilitate the intracellular and also the transcellular passage, the cytosol contains several specific carrier proteins, with affinities for distinct classes of hydrophoblc ligands. Cellular retinol-binding proteins $[5,13]$, and $\alpha$-tocopherol-binding protein [14] are involved in intracellular transport of vitamins $A$ and $E$, respectively. The cytoplasm also contains specific binding proteins for steroids [15], glycolipids [16], and bile acids [17]. Two sterol-carrier proteins $\left(\mathrm{SCP}_{1}\right.$ and $\left.\mathrm{SCP}_{2}\right)$ have been described, that participate in different steps of cholesterol synthesis and its transfer and utilization within the cell $[18,19]$. The latter of the two is identical to a protein named nonspecific-lipid transfer protein (ns-LTP) that is capable of phospholipid exchange between membranes [18,19]. Several other types of cytosolic phospholipid transfer proteins have been isolated that may catalyze the flow of phospholipids between membranes [20-22]. In fetal and newborn plasma, alpha-fetoprotein is an important carrier for unsaturated fatty acids, and in some species also for estrogens $[23,24]$.

Fatty acid-binding proteins (FABPs) form a group of cytosolic proteins that are believed to be involved in the intracellular transport of fatty acids, and acyl-COA and-carnitine esters [25.261. Since their discovery at the end of the 1960's, much knowledge has been obtained regarding this group of lowmolecular-mass cytosolic proteins. The investigations described in this thesis aimed at the structure of these proteins, their characteristics, and their functions in various tissues of rat, man, and pig.

\subsection{OUTLINE OF THIS THESIS.}

This thesis starts with an overview of the current knowledge on FABPs (Chapter 2). It also includes the data that have been gathered during the investigations that are described in the following chapters. 
Chapter 3 gives a detailed description of the materials and practical procedures that have been applied.

The purification and characterization of FABPs from heart of man, pig and rat is described in chapter 4. The characteristics of these proteins are compared to those of FABPs from other tissues. They clearly demonstrate the existence of distinct types of this protein, related to different tissues.

Chapter 5 deals with the influence of various physiological conditions, postnatal development, and clofibrate treatment on the cytosolic fatty acid-binding capacity of rat tissues, determined by a radiochemical binding assay. In chapters 6 and 7 the cytosolic FABP content of tissues from rat, man, and pig is assessed by an enzyme-linked immunosorbent assay, using specific antibodies against distinct FABP types. The fatty acid-binding capacity is compared with these data (Chapter 6).

A summary of the results of the investigations described in chapters 4-7 is given in Chapter 8 . 



\subsection{EXTRACELLULAR TRANSPORT OF FATTY ACIDS.}

Fatty acids are distributed by the bloodstream to peripheral tissues where these molecules are utilized for energy production, in biosynthetic pathways, or are (temporarily) stored. Transport of fatty acids in plasma occurs in the form of triacylglycerols in chylomicrons and very-low-density lipoproteins, or noncovalently bound to serum albumin. On their route from the capillary to the intracellular organelles fatty acids have to pass a series of aqueous spaces and membrane barriers (Fig. 2.1). Endothelial cells of the capillary wall may transfer monomeric fatty acids from the blood to the interstitial space, but also albuminfatty acid complexes are able to pass the endothelial walls [29]. specific albumin-binding proteins have been identified in the capillary endothelium (30), that may be instruments in a carriermediated uptake and transcytosis of albumin and its ligands. As in the bloodstream, albumin probably also functions in fatty acid transport through the interstitial fluid and the delivery of fatty acids directly to the cell [313. By keeping the extracellular free fatty acid concentration low, albumin may prevent cytotoxic effects of fatty acids.

Scow and coworkers [32,33] proposed another model, based on electron microscopy. In this view, fatty acids are transported from the capillaries to the sites of utilization by lateral movement in membranes, that form a continuum across the capillary endothelium and within cells.

- This chapter was adapted from Paulussen and Veerkanp [28]. 


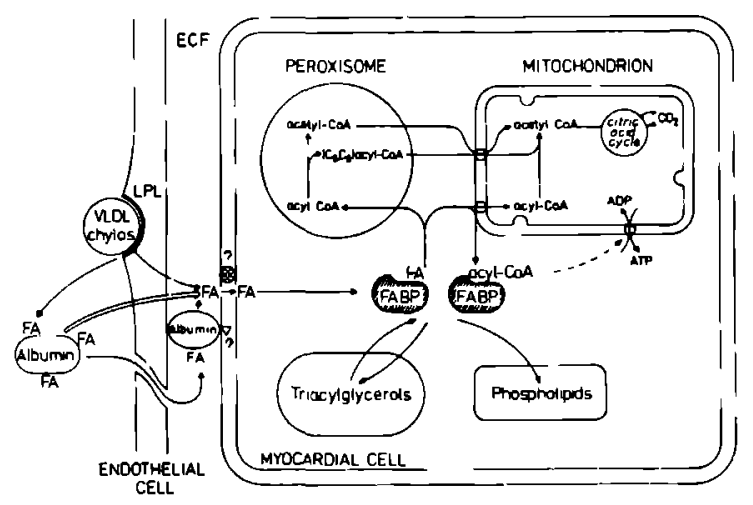

Fig. 2.1. Extra- and intracellular transport of fatty acids.

Abbreviations: FA, fatty acid; VLDL, very-lou-density lipoproteins; chylos, chylomicrons; LPL, llpoprotein lipase; ECF, extracellular fluid; $\nabla$, albumin receptor; 8 - plasma membrane fotty ocid-binding protein.

\subsection{CELLULAR FATTY ACID UPTAKE.}

Total cellular fatty acid uptake is dependent on the rate of fatty acid metabolism, and on the extra- and intracellular fatty acid concentrations. The extracellular free fatty acid concentration is determined by the total fatty acid concentration and the albumin-fatty acid ratio $[34,35]$. In cultured and isolated heart cells, uptake apparently is related to the total fatty acid concentration [36,37], but in Ehrlich ascites cells [38], perfused rat liver [39], rat hepatocytes [40], and in cultured human leukaemic myeloid cells [41] it depends on the free fatty acid concentration.

The different models that have been postulated for cellular fatty acid uptake are sumarized in Fig. 2.2. In the passive diffusion model (Fig. 2.2-A), fatty acids from the aqueous phase enter the outer leaflet of the plasma membrane, and spontaneously flip-flop to the inner-half [42]. At physiological pH the flipflop rate may be rather high, since approximately $50 \%$ of the fatty acids in membranes are unionized [43]. The maximal rate of fatty acid uptake will be determined by the rate of dissociation of fatty acids from albumin, or the transport of fatty acids 
from the capillary to the plasma membrane. The serum-tissue concentration gradient that was found in heart of rat, dog and man [44,45] supports a role for uptake by diffusion, but pure passive diffusion cannot explain the sex differences in fatty acid uptake in perfused rat liver [46].

Plasma membranes derived from male liver showed a lower affinity for fatty acids as palmitic and oleic acid versus plasma membranes from female liver, but the rates of uptake in perfused male and female liver were identical when the concentrations of fatty acids in the plasma membranes of male and female liver were the same [47]. This indicates important differences in the interactions between fatty acids and livers from male and female rats, besides different affinities of the plasma membranes for fatty acids.

Kinetic studies of single-pass hepatic uptake of fatty acids [48] suggested that uptake is mediated primarily by interaction of the albumin-ligand complex with a component on the hepatocyte surface, rather than by the small fraction of unbound fatty acid (Fig. 2.2-B). In more recent studies, catalysis of the dissociation of oleic acid from albumin by an albumin receptor could not be established. Dissociation from albumin could be the ratelimiting step in ligand transport. Thus, uptake apparently becomes dependent on the bound ligand [49]. The $\mathrm{pH}$ and the acyl chain-length are important factors in the regulation of fatty acid transfer from albumin to membranes $[43,50,51]$. According to Noy et al. [52], uptake in the perfused liver is not limited by kinetic factors, but is determined by the equilibrium distribution of fatty acids between albumin and the plasma membrane. A change of the molar fatty acid/albumin ratio therefore has a marked influence on fatty acid uptake. The intrahepatic pool sizes for palmitic acid predicted on basis of this model correspond well with the measured values at palmitate/albumin ratios of two and four [53]. Recent studies with perfused rat liver indicate that a portion of oleic acid uptake occurs by an electrogenic, sodiumcoupled transport mechanism [54].

The saturation of uptake of fatty acids alone is not sufficient evidence for a specific transport system [52,53], and studies on the presence of an albumin receptor in plasma membranes of liver and adipocytes are not equivocal [55.57]. Influx kinetics indicated a membrane-associated fatty acid transport system in adipocytes [58-60], hepatocytes [61-63], cardiomyocytes [64,65], and jejunal mucosa cells [66], and also the inhibition of fatty acid uptake by phloretin and by trypsin suggested the involvement of a carrier protein (Fig. 2.2-C, D,E). Uptake in rat hepatocytes [62] 
and basolateral liver plasma membrane vesicles $[67$ was potentialsensitive, sodium-coupled, and could be inhibited by ouabain and metabolic inhibitors, in contrast to uptake in adipocytes [58-60] and cardiac myocytes $[64,65]$. Heat- and trypsin-sensitivity of oleic acid-binding to plasma membranes of liver 168,691 , jejunum [70], and heart ${ }^{664}$ ] indicated the involvement of a membraneassociated protein. A basic $40 \mathrm{kDa}$ protein was isolated from plasma membranes of rat liver [69] and adipocytes [60.70], and from rat jejunal microvilious membranes 171 . These plasma membrane fatty acid-binding proteins are immunologically related, since all react with an antibody raised against the protein from liver $[60,70,71]$. They differ from the cytosolic FABPs with respect to molecular mass, isoelectric point and structural and immunochemical properties 609.71$]$. The antibody against the

A

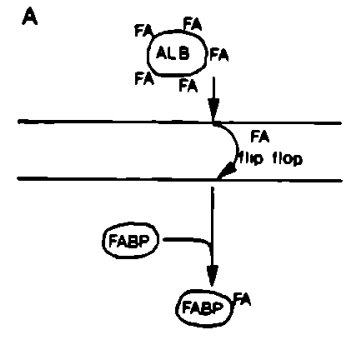
plasma membrane fatty acid-binding protein from liver can inhibit fatty acid uptake in hepatocytes $[62,63]$, adipocytes [60], cardiac myocytes [65], and jejunal mucosa cells [66] and fatty acid binding to plasma membranes of liver [69) and jejunum (71).

B

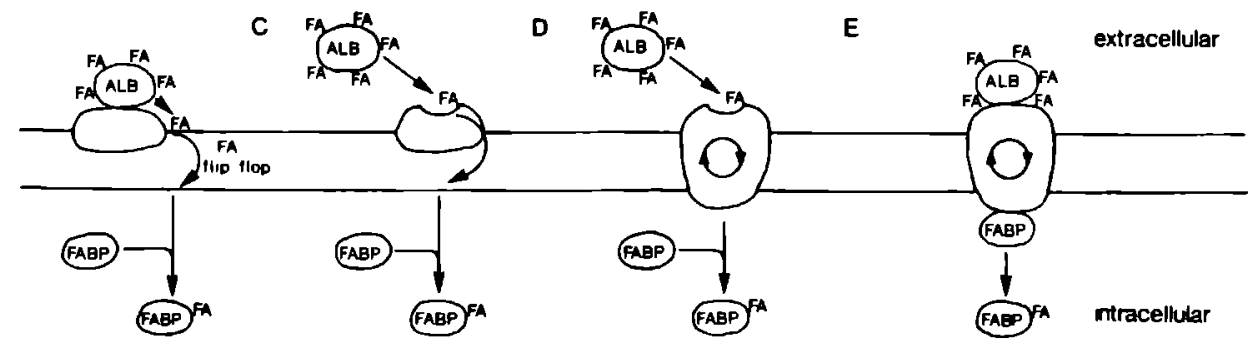

F19. 2.2. Models for the cellular uptake of fatty acids.

A Passive diffusion of fatty acids through the plasma membrane.

B Membrane-associated albumin receptor, that facilitates the dissociation of the albumin-fatty acid complex. Uptake by passive diffusion.

C Extrinsic membrane fatty acid-binding protein. Uptake by facilitated diffusion.

D Intrinsic membrane fatty acid translocator. Additional alternatives:

1. extracellular albumin-binding site.

2. intracellular FABP-binding site.

E Intrinsic membrane fatty acid translocator, with extracellular albumin-binding site, and intracellular FABP receptor function. 
An antibody against the protein from heart inhibits oleic acid binding to heart plasma membranes and its influx in cardiomyocytes [ 64 . The evidence presented for the existence of closely related, if not identical, plasma membrane fatty acid-binding proteins in various tissues sustains the idea that fatty acid uptake does not occur by diffusion only, but that it also is a facilitated process. The differences between hepatocytes and adipocytes and cardiomyocytes in the sensitivity of fatty acid uptake to membrane potential, sodium, and energy deprivation may relate to variations in other components, or to the microenvironment of the transport system.

The possible roles for the plasma membrane fatty acidbinding protein are depicted in panels C-E of Fig. 2.2. It could influence the albumin-fatty acid binding, and/or function as an acceptor for extracellular fatty acids. After (flip-flop) passage of the membrane the fatty acids are bound by cytosolic FABP (Fig. $2.2-c)$. Alternatively, the fatty acid may be transferred to the inner surface of the membrane by the membrane fatty acid-binding protein itself (or by another membrane-linked protein) by a conformational change (Fig. 2.2-D). In the last model (Fig. 2.2-E), the membrane fatty acid-binding protein functions both as albumin receptor and as fatty acid translocator.

No information is available until now on the primary and secondary structures of the plasma membrane fatty acid-binding proteins. Their high isoelectric point of 9.0 suggests an electrostatic interaction with a fatty acid anion. The extractability of the plasma membrane fatty acid-binding protein from membranes by sonication at a high salt concentration $[70]$, and the inhibition of fatty acid uptake by antibodies against this protein, suggest that it is a peripheral, rather than an integral membrane protein. Apparently, it is a common fatty acid acceptor in various tissues. Spontaneous transbilayer movement of the fatty acids may occur, or an additional, possibly tissue-specific, transfer process may subsequently take place after binding of the fatty acid. Such a complex system may be comparable to that from Escherichia coli [72].

\subsection{INTRACELLULAR TRANSPORT OF FATTY ACIDS.}

Cellular fatty acid uptake differs largely among various tissues. These differences are related to the type of fatty acid metabolism of these tissues. The intracellular systems utilize 
fatty acids for oxidation, synthesis of triacylglycerols, phospholipids, cholesterol, sphingolipids, and eicosanoids, with special preferences for certain fatty acids. In various tissues also de-novo fatty acid synthesis takes place. Therefore, intracellular transport and trafficking of fatty acids are important processes. Fatty acids can be transferred through the intracellular water phase as monomers, but the cytosolic fatty acidbinding proteins (FABPs) may have an important function in the targeting of these molecules. They may also play a modulatory role in cellular metabolism. Structural and functional aspects of these proteins will be surveyed in the next paragraphs.

FABPs form a class of proteins with a molecular mass of 14-15 kDa, that are abundantly present in the cytosol of tissues that are involved in the uptake or utilization of fatty acids. Their name was derived from their high affinity for long-chain fatty acids. The FABPs are members of a large group of lowmolecular mass, soluble proteins, that are involved in the binding of various hydrophobic substances. These proteins were first discovered when Levi and coworkers fractionated the cytosol (105,000 $\mathrm{x} \mathrm{g}$ supernatant) of liver in their search for proteins that account for the binding of bromosulfophthalein and bilirubin [3]. They found two major fractions involved in binding of these ligands, that were designated $Y$ and $Z$. In the $Y$ class, $M r 30-50$

Table 2.1.

The occurrence of fatty acid-binding proteins.

\begin{tabular}{|c|c|c|c|c|c|c|c|c|}
\hline Tissue & Rat & Man & Pig & Cattle & Mouse & Rabbit & $\begin{array}{c}\text { Guines } \\
\text { pig }\end{array}$ & Chicken \\
\hline Liver & + & + & + & + & + & + & + & + \\
\hline Heart & + & + & + & + & & + & + & + \\
\hline Intest ine & + & + & & + & + & & & + \\
\hline Stomech & + & & & & & & & \\
\hline Kidney & + & + & + & & & & & \\
\hline Adrenal & + & & & & & & & \\
\hline Brein & + & + & & & & & & \\
\hline lung & + & + & & & & & & \\
\hline Adipose tissue & + & + & + & + & & & & + \\
\hline skeletal muscle & + & + & + & + & & + & & + \\
\hline Mammary gland & + & & + & & & & & \\
\hline Placento & + & + & & & & + & & \\
\hline Testes & + & & & & & & & \\
\hline Ovary & + & & & & & & & \\
\hline Aorts & + & & & & & & & \\
\hline serum & - & - & & - & & & & - \\
\hline Erythrocyte & - & - & & & & & & + \\
\hline
\end{tabular}

Only the tissues investigated for the presence of FABP are given. 
kDa, organic anions are mainly bound by a group of glutathione $s$-transferases. The $\mathrm{z}$ class contains a number of proteins with molecular masses between 10 and $20 \mathrm{kDa}$, that each bind a different class of hydrophobic ligands. Among these are the sterolcarrier proteins, phospholipid-transfer proteins, retinoid-binding proteins and FABPs. The study of Levi et al. [73] initiated an extensive research of the proteins involved in binding of organic anions.

FABPs were first recognized in the early 1970's [73-73], when cytosolic proteins were incubated with $\left[{ }^{14} \mathrm{C}\right]$ oleic acid and then chromatographed over a gel filtration column. The radioactive label was recovered in two fractions, one with a Mr of approximately $68 \mathrm{kDa}$, containing albumin, and a second fraction of about 14-15 kDa (often described as $12 \mathrm{kDa}$ in the early reports). This fraction was called fatty acid-binding protein (FABP). Soon this FABP-fraction was demonstrated in a large number of tissues of various species (Table 2.1). It does not appear to be present in bloodserum or erythrocytes. Recently a protein with a molecular mass of 9955 was isolated from bovine liver [77,78], that binds medium-chain acyl-COA esters. In the last few years several review papers have been published on FABPs in general $[27,28,79,80]$, or focusing on hepatic and intestinal [25,81], or cardiac FABPs [26] and the role of FABP in muscular fatty acid metabolism [B2].

\subsection{QUANTITATION AND ISOLATION OF FABPS.}

For the quantitative determination of cytosolic FABP content a variety of methods has been deployed. These methods, summarized in Table 2.2, will be discussed in more detail in chapter 5.

Table 2.2.

Assay methods for quantitation of fatty acid-binding proteins.

Coelution on gel filtration chromatography
Electrophoretic comigration
Equilibrium dialysis
Affinity chromatography on ol eoyl-aminohexylamino-Sepharose
Radiochemical binding assay (charcoal, Lipidex 1000)
Binding of fluorescent fatty acid ansilogues
Iransfer of labelled fatty acids from liposomes
Immunochemical assay with specific antibodies


FABPs have been isolated from cytosols of a number of tissues of several species. Most isolation procedures are a combination of gel filtration and ion-exchange chromatography le.g. 8386]. Sometimes other techniques, such as affinity chromatography [87, preparative isoelectric focusing $[76,88-94]$, heat treatment $[95$ 98] or ammoniumsulphate precipitation $[95-97,99,100]$ are incorporated. Differences in protocols for the isolation of FABPs from distinct sources especially concern the buffers used in the ion-exchange steps. They reflect the structural differences of the FABP types isolated from various tissues.

\subsection{STRUCTURAL FEATURES OF FABPS.}

Amino acid composition and primary structure.

A comparison of amino acid composition, amino acid sequence, and nucleotide sequence of cloned CDNA or mRNA, of FABPs from different tissues clearly reveals the existence of distinct FABP types. The data reported for the amino acid composition of heart and liver FABPs of cattle, man, pig and rat are summarized in

Table 2.3.

General amino acid composition of heart and liver FABPs from cattle, man, pig and rat, and intestinal FABPs from man and rat.

\begin{tabular}{|c|c|c|c|}
\hline \multicolumn{4}{|c|}{ Amino acid composition (residues per mol FABP) } \\
\hline Amino acid & Liver & Heart & Intestine \\
\hline As $x$ & $11-13$ & $14-17$ & 19.21 \\
\hline Thr & $10-12$ & $17-19(p 1 g 7)$ & 10 \\
\hline Ser & $6-7$ & 6.9 & 1.5 \\
\hline Glx & $16-20$ & $12 \cdot 17$ & $15 \cdot 18$ \\
\hline Pro & $1-4$ & $1-2 \quad(p \mid g 6)$ & 0 \\
\hline Gly & 19.93 & $9 \cdot 12$ & $10-14$ \\
\hline Alo & $2-6$ & $5-7 \quad(p \mid g 11)$ & 6.7 \\
\hline Cys & $1-3$ & 0 (see text) & 0 \\
\hline Val & 9.12 & $8 \cdot 15$ & $9-11$ \\
\hline Met & $1-7$ & $2-3$ & 1.3 \\
\hline Ile & $6 \cdot 12$ & $3-7$ & 7 \\
\hline Leu & $3-10$ & $9-14$ & 10 \\
\hline Tyr & $1-3$ & $2 \cdot 3$ & $3 \cdot 4$ \\
\hline Phe & $6-9$ & $5-6$ & $8-9$ \\
\hline Trp & 0 & $1-4$ & $1-2$ \\
\hline His & $1-2$ & $2-4$ & $1-2$ \\
\hline Lys & $13-17$ & $10-18$ & $14 \cdot 16$ \\
\hline Arg & $2-3$ & $3-5$ & 6.7 \\
\hline
\end{tabular}

Data are derived from Refs. $83,84,86,87,90,95-97,101,103,105-110,138,259$. 
Table 2.3, together with values for intestinal FABPs of man and rat. Except for some discrepancies $195.98,101]$ all studies agree on the presence of cysteine only in hepatic FABPs, while tryptophan is present in all FABPs, except the liver type. Intestinal FABPs contain no proline, and their serine content is lower than that of the other types. Threonine and leucine content of heart FABP are higher. The arginine and the asparagine/aspartic acid contents are higher in heart than in liver FABPs, but even markedly more elevated in the intestinal type. The number of isoleucine and glutamine/glutamic acid residues are higher in liver FABPs. Recently the amino acid composition of a kidney specific FABP type from rat was described [102]. This FABP contains both cysteine and tryptophan residues.

At least two isoforms can be distinguished in liver FABPs of man, pig and rat that behave differently on DEAE-cellulose anion-exchange chromatography $[25,76,83,90,93]$. No significant differences could be detected in the amino acid composition of the isoforms $(76,83,90,93)$, but they were shown to contain different endogenously bound fatty acids $[25,90]$. Bovine heart and liver FABPs

Table 2.4.

Structure of faBps from various tissues.

\begin{tabular}{|c|c|c|c|c|c|c|c|c|}
\hline$\overline{\text { origin }}$ & $\begin{array}{c}\mathrm{Mr} \\
(\mathrm{O} a) \\
\end{array}$ & $\begin{array}{l}\text { Amino } \\
\text { acids } \\
\text { (nr) }\end{array}$ & IEP & N-terminus & $\begin{array}{l}\text { Cys } \\
\text { gres }\end{array}$ & dues/n & nolecul & Ref \\
\hline \multicolumn{9}{|l|}{ RAT } \\
\hline liver & $\begin{array}{l}14,272 \\
14,184\end{array}$ & $\begin{array}{l}927 \\
127\end{array}$ & $\begin{array}{l}\text { n.d. } \\
5.5\end{array}$ & $\begin{array}{l}\text { bl ocked } \\
\text { blocked }\end{array}$ & $\begin{array}{l}1 \\
1\end{array}$ & $\begin{array}{l}0 \\
0\end{array}$ & $\begin{array}{l}2 \\
2\end{array}$ & $\begin{array}{r}99 \\
103\end{array}$ \\
\hline intestine & 15,062 & 132 & n.d. & blocked & 0 & 1 & 0 & 101 \\
\hline heart & $\begin{array}{l}14,776 \\
16,992\end{array}$ & $\begin{array}{l}133 \\
134\end{array}$ & $\begin{array}{l}\text { n.d. } \\
5.0\end{array}$ & $\begin{array}{l}\text { n.d. } \\
\text { blocked }\end{array}$ & $\begin{array}{l}0 \\
0\end{array}$ & $\begin{array}{l}1 \\
2\end{array}$ & 1 & $\begin{array}{l}123 \\
110\end{array}$ \\
\hline $\begin{array}{l}\text { kidney } \\
\text { m.quadriceps }\end{array}$ & $\begin{array}{l}15,500 \\
16,000\end{array}$ & $\begin{array}{l}\text { n.d. } \\
\text { n.d. }\end{array}$ & $\begin{array}{l}5.3 \\
5.2\end{array}$ & $\begin{array}{l}\text { n.d. } \\
\text { n.d. }\end{array}$ & $\begin{array}{l}2 \\
0\end{array}$ & 1 & i.d. & 102 \\
\hline \multicolumn{9}{|l|}{ MAN } \\
\hline $\begin{array}{l}\text { liver } \\
\text { heart }\end{array}$ & $\begin{array}{l}14,178 \\
15,500 \\
15,500 \\
14,768\end{array}$ & $\begin{array}{l}127 \\
\text { n.d. } \\
\text { n.d. } \\
132\end{array}$ & $\begin{array}{l}5.8 \\
5.3 \\
5.2 \\
5.2\end{array}$ & $\begin{array}{l}\text { bl ocked } \\
\text { blocked } \\
\text { n.d. } \\
\text { blocked }\end{array}$ & $\begin{array}{l}1 \\
2 \\
0 \\
0\end{array}$ & $\begin{array}{l}0 \\
2 \\
1 \\
2\end{array}$ & $\begin{array}{l}1 \\
2 \\
3 \\
1\end{array}$ & $\begin{array}{r}105 \\
97 \\
84 \\
109\end{array}$ \\
\hline $\begin{array}{l}\text { intestine } \\
\text { m.psoas }\end{array}$ & $\begin{array}{l}15,100 \\
15,000\end{array}$ & $\begin{array}{l}132 \\
\text { n.d. }\end{array}$ & $\begin{array}{l}\text { n.d. } \\
5.2\end{array}$ & $\begin{array}{l}\text { n.d. } \\
\text { n.d. }\end{array}$ & $\begin{array}{l}0 \\
0\end{array}$ & $\begin{array}{c}1 \\
\text { n.d. }\end{array}$ & $\begin{array}{l}0 \\
1\end{array}$ & $\begin{array}{l}107 \\
200\end{array}$ \\
\hline \multicolumn{9}{|l|}{ CATtLE } \\
\hline $\begin{array}{l}\text { liver } \\
\text { heart }\end{array}$ & $\begin{array}{l}11,800 \\
15,300 \\
14,673\end{array}$ & $\begin{array}{l}\text { n.d. } \\
\text { n.d. } \\
132\end{array}$ & $\begin{array}{l}7.0 \\
4.9 \\
4.9\end{array}$ & $\begin{array}{l}\text { n.d. } \\
\text { blocked } \\
\text { blocked }\end{array}$ & $\begin{array}{l}2 \\
3 \\
1\end{array}$ & $\begin{array}{l}0 \\
2 \\
2\end{array}$ & $\begin{array}{l}1 \\
1 \\
2\end{array}$ & $\begin{array}{r}95 \\
96 \\
108\end{array}$ \\
\hline \multicolumn{9}{|l|}{ PIG } \\
\hline $\begin{array}{l}\text { liver } \\
\text { heart }\end{array}$ & $\begin{array}{l}14,500 \\
15,000 \\
\end{array}$ & $\begin{array}{l}\text { n.d. } \\
\text { n.d. }\end{array}$ & $\begin{array}{l}5.8 \\
4.9 \\
\end{array}$ & $\begin{array}{l}\text { n.d. } \\
\text { n.d. }\end{array}$ & $\begin{array}{l}1 \\
0 \\
\end{array}$ & $\begin{array}{l}0 \\
5 \\
\end{array}$ & $\begin{array}{l}1 \\
6\end{array}$ & $\begin{array}{l}83 \\
84\end{array}$ \\
\hline
\end{tabular}

- J.H. Veerkamp et al., unpublished results; n.d., not determined. 
could be separated into two isoforms with distinct isoelectric points by CM-cellulose cation-exchange chromatography [96] and isoelectric focusing [95], respectively. Only the bovine liver FABP isoforms differ in amino acid composition [95].

A number of characteristics of FABPs from different tissues is given in Table 2.4. The amino-terminal amino acid is acetylated $[101,103]$. This was thought to be an indication of their cytoplasmic destination [103], but apparently, acetylation is related to the residues adjacent to the amino-terminal amino acid [104].

Molecular masses of liver FABPs show values of just over $14 \mathrm{kDa}$, in contrast to $15 \mathrm{kDa}$ for all other types. Isoelectric points of the hepatic FABPs are generally higher than those of the other FABP types.

The amino acid sequence of the FABPs appears to be highly conserved throughout the evolution [105]. Corresponding FABP types from different species show a remarkably high degree of sequence homology (Table 2.5). The human and rat liver FABPs have an $82 \%$ sequence identity [106]. A similar $82 \%$ sequence identity was found for human and rat intestinal FABPs [107]. Bovine, human and rat heart FABPs also show a very high degree of homology [108,109]. Rat intestinal FABP has only 31 and $26 \%$ homology with heart and liver FABP, respectively $[101,110]$. The amino acid sequences of heart FABPs also have a large degree of homology with the murine adipocyte $P_{2}\left(P_{422}\right)$ protein [111), the human [112] and bovine [113] myelin $P_{2}$ proteins, with bovine mammary-derived growth inhibitor (MDGI) [114], and with the cellular retinoid-binding proteins [115,116].

No sequence homology of rat liver and intestinal FABPs [117] could be established with serum albumin [110], nonspecific lipidtransfer protein (sterol-carrier protein $n_{2}$ ) [119], phosphatidylcholine-transfer protein [120], and the apolipoproteins apo A-I and apo A-IV [106,107]. Statistical analyses of mRNA and protein

Table 2.5.

Amino ocid sequence homology of FABPs and other lipld-binding proteins.

\begin{tabular}{|c|c|c|c|}
\hline & $x$ & & $\bar{x}$ \\
\hline $\begin{array}{l}\text { Rat heart FABP } \\
\text { Human heart FABP } \\
\text { Bovine heart FABP } \\
\text { Murine odipocyte } P_{2} \quad(p 422) \\
\text { Human myel in P } \\
\text { Rat intestinal }{ }^{2} \text { FABP } \\
\text { Bovine MoGl }\end{array}$ & $\begin{array}{r}100 \\
90 \\
89 \\
67 \\
61 \\
31 \\
84\end{array}$ & $\begin{array}{l}\text { Rat liver FABP } \\
\text { Humen liver FABP } \\
\text { Rat intest Inal FABP } \\
\text { Rat heart FABP } \\
\text { Human myel in } P_{2} \\
\text { Murine adipoeyte } P_{2} \text { (p422) }\end{array}$ & $\begin{array}{r}100 \\
82 \\
26 \\
38 \\
27 \\
23\end{array}$ \\
\hline
\end{tabular}


sequence data [108] showed that distinct FABP types must have diverged some 650 million years ago, long before today's species diverged from their common ancestor. Divergence of FABPs and other, closely related, proteins as murine adipocyte $P_{2}$ (p422) and the myelin $P_{2}$ protein must have taken place several hundred million years earlier, before the invertebrate-vertebrate divergence [105].

Secondary structures.

Circular dichroism measurements and computer-aided predictions of secondary structures according to chou and Fasman [121] reveal a relatively high content of $\alpha$-helical structures in all FABPs (Table 2.6). Furthermore, a high percentage of $\beta$-structures is predicted. The $\alpha$-helices and $\beta$-structures form an alternating pattern of hydrophobic and hydrophilic domains $[90,109]$, that probably yield a protein with a hydrophilic surface for solubilization in the aqueous cytoplasm, and a distinct hydrophobic domain for ligand binding. The predicted secondary structure of human liver FABP [109] suggests that this protein may orient at a lipidwater interface, a property that may play an important role in the binding of fatty acids from membranes [105].

Table 2.6.

Structural details of fABPs from various tissues

\begin{tabular}{|c|c|c|c|c|c|c|}
\hline \multirow[t]{2}{*}{ origin } & \multirow[t]{2}{*}{ a-helix } & \multicolumn{2}{|c|}{$\beta$-structures } & \multirow{2}{*}{$\begin{array}{c}\text { Random } \\
\mathrm{coll}\end{array}$} & \multirow[t]{2}{*}{ Method } & \multirow[t]{2}{*}{ Ref. } \\
\hline & & $\beta$-sheet & $\beta$-turn & & & \\
\hline \multicolumn{7}{|l|}{ HEART } \\
\hline rat & 22 & & & 33 & CD & 86 \\
\hline \multirow[t]{2}{*}{ man } & 32 & & & 24 & CF & 109 \\
\hline & 25 & & & 30 & CD & 109 \\
\hline \multirow[t]{2}{*}{ cattle } & 15 & 51 & B & 26 & $C D$ & 96 \\
\hline & 19 & 49 & 27 & 5 & CF & 108 \\
\hline pig & 19 & 48 & $B$ & 25 & $C D$ & 192 \\
\hline \multicolumn{7}{|l|}{ LIVER } \\
\hline \multirow{3}{*}{ rat } & 14 & \multicolumn{2}{|c|}{39} & 47 & CD & 261 \\
\hline & 29 & 30 & 22 & 19 & CF & 90 \\
\hline & 38 & 27 & B & 27 & $\mathrm{CF}$ & 103 \\
\hline $\operatorname{man}$ & 30 & \multicolumn{2}{|c|}{37} & 33 & CF & 105 \\
\hline cattle & 12 & 45 & 15 & 27 & $C D$ & 139 \\
\hline \multicolumn{7}{|l|}{ INTESTINE } \\
\hline rat & 33 & 14 & 20 & 33 & CF & 101 \\
\hline
\end{tabular}

Values are given in $x$, and were obtained with the Chow-Fasman method (CF) (Ref 121) or circular dichroism measurement (CD). 
Investigation of the amino acid sequence of rat and human liver FABPs presented evidence for the presence of tandemly arranged repeats, that contain a relatively high degree of $\alpha-$ helix structure $[90,106]$. The existence of two regions of high homology, that contain tandem repeats, has also been shown in rat intestinal [117], and rat [110] and human [109] cardiac FABPs. No significant relationships could be demonstrated among these sequences of the different FABP types. These repeats appear to be the most highly conserved amino acid sequences of the entire protein, together with the amino-terminal part of the molecule [109]. Despite the high degree of amino acid sequence homology between human and rat heart FABPs, the internally repeating sequences of human heart FABP did not match with the repeats of its rat counterpart [109]. The occurrence of two small, highly homologous oligopeptides, each consisting of tandemly repeated sequences, in the two halves of rat and human liver FABP molecules led to the assumption that two separate intragenic duplications occurred in the evolution of these proteins $190,106,117]$. However, this hypothesis appears unlikely on basis of a structural analysis of rat liver FABP, that showed that the segments containing the highly homologous polypeptides are not located symmetrically in each half of the FABP molecule [122].

cDNA sequences and FABP genes.

Complementary DNA sequences have been established for rat liver and intestinal FABPs on basis of intestinal mRNAs [101,103,107], for murine adipocyte $P_{2}(p 422)$ protein [111, and human liver FABP [105.122]. Recently the structures of CDNA of rat [123,124] and bovine (108) heart FABPs were also described. All cDNAs contain $3 '$ and $5 '$ non-coding regions, of which the first show more homology between the same FABP types of different species than the latter [108,122]. The coding sequences of cDNA of rat liver and intestinal FABPs have been inserted in an appropriate expression vector (125, 126], and could be efficiently expressed in E.coli. The liver FABP from E.coli [125] however, does not have a blocked amino-terminus, in contrast to that in liver cytosol [90,103]. A frameshift mutation, introduced in vitro in the coding region of 1 iver FABP CDNA, resulted in the production of a less stable FABP, with a lower fatty acid-binding affinity [125].

The nucleotide sequences of the genes encoding rat liver FABP [122] and human intestinal FABP (107) have been completely established. These genes contain 3790 and 3382 nucleotides, respectively, and consist of 4 exons and 3 introns. The rat intestinal 
FABP gene was partially defined [107]. Also the genes for murine adipocyte $\mathrm{P}_{2}$ (p422) protein [127] and cellular retinol-binding protein II [120] were characterized. The genes encoding these proteins have a similar organization of 4 exons and 3 introns. Comparably positioned introns may vary considerably in size, but the introns in each of the genes are identically positioned relative to their exons $[107,128]$.

The polypeptide sequences encoded by each exon of rat liver FABP were compared with rat intestinal $F A B P$, rat cellular retinol-binding protein (CRBP), bovine cellular retinoic acid-binding protein, human myelin $\mathrm{P} 2$ protein, and murine adipocyte $P_{2}$ protein (p422) [122]. The first exon of liver FABP was significantly related to that of all the other members of this multigene protein family. Only the rat intestinal FABP sequence showed similarity with the sequence encoded by the third exon of liver FABP [122]. The amino-terminal sequence of these proteins (exon I) may define a structural and functional domain that is involved with the common property of these proteins, namely the binding of hydrophobic ligands $[106,122]$. Exons III and IV may be related to the differences in ligand specificities of the members of the protein family and/or to differences in the enzymes or cellular membranes with which they interact.

Tertiary structure.

A highly comparable secondary structure model has been proposed for all proteins of the above described multigene fami1y, together with specific variations for each separate protein [129]. Generally, the secondary structure predictions show a high level of $\beta$-structures, that can assemble into a $\beta$-barrel tertiary structure. A thorough investigation of the tertiary structure by $x$-ray diffraction at 2.5 A resolution has been reported for the intestinal FABP type from rat [130], using the crystallized protein derived from E.coli [131]. The protein is build up of $10 \beta$-strands that are arranged in anti-parallel direction. These $\beta$-strands form a "shell-like" structure or $\beta$-barrel, with two $\alpha$-helices on top in a parallel arrangement. The outer surface of the protein predominantly contains hydrophilic side-chains, whereas most non-polar residues are located at the inner side of the "shell", thus creating a hydrophobic cavity where one fatty acid molecule can be bound.

The internal repeat sequences are located in areas of the FABPs with predicted $\beta$-structures and decreasing hydrophobicity [109], yielding a protein with alternating hydrophobic and hydro- 
philic regions. Offner et al. [109] predicted a secondary structure for human heart FABP consisting of 6 regions of $\beta$-structure, separated by reverse turns or $\alpha$-helices. Although slightly different from the $10 \beta$-strands of intestinal FABP [131], this secondary structure for heart FABP can allow the protein to be folded into a $\beta$-barrel tertiary structure. Based on the high degree of sequence homology and the predicted comparable secondary structure [129], it is likely that other members of the multigene family of FABPs have a comparable tertiary structure.

A corresponding conformation of a $\beta$-barrel composed of eight anti-parallel $\beta$-strands has been reported for another group of proteins that carry hydrophobic ligands, as serum retinol-binding protein [132], bilin-binding proteins [133,134], and $\beta$-lactoglobulin [135]. These proteins show only 25-30\% sequence homology and have neither an evolutionary nor a structural relationship to the FABP family [120]. Appropriate modification of the primary structure of the residues that build up the central cavity of the proteins may lead to their different ligand specificities [136].

\subsection{THE LIGAND-BINDING SITE OF FABP.}

Most information concerning the ligand-binding site of FABPs has been derived from comparative studies of amino acid sequences and secondary structure predictions. The remarkably high degree of sequence homology of the amino-terminal segments of FABPs and the closely related cellular retinoid binding proteins, adipocyte $P_{2}$ (p422) and myelin $P_{2}$ proteins, indicates an involvement of this part of the protein in the binding of hydrophobic ligands $[106,109,110,117,122]$. Other sequences within the proteins may be involved in the specificity of the ligand-binding, either separate or in concert with the amino-terminal domain [106]. Domains with amphipathic $\alpha$-helical structure have been suggested to be involved in the binding of FABPs to hydrophobic ligands, since this was observed for albumin [137] and the apolipoproteins apoA-I and apo A-IV [106,138]. However, sequences homologous with the latter proteins and such amphipathic structures were not found in FABPs $[106,110,117$.

The hydropathy of FABPs is of great importance for their interaction with ligands. Relative hydropathy plots are clearly different for liver, intestinal, and heart FABPs [110], but hydropathy has been highly conserved during evolution. Out of the 23 amino acids that are non-identical in human and rat liver FABP, 
74 maintain the same relative hydropathy [106].

Binding of long-chain fatty acids to FABP is non-covalent [90], and involves both hydrophobic and ionic interactions $[139,140]$. The fatty acid-binding site of liver and heart FABPs is different, as can be deduced from their interaction with fluorescent fatty acid analogues $[83,140,141]$. The ionic interactions may be ascribed to arginine in liver, intestinal and heart FABPs. Modification of arginine residues of human [83] and bovine [139] liver FABP, and of pig heart FABP [B] strongly reduced binding of longchain fatty acids. The remaining binding activity was entirely due to hydrophobic interactions [139]. Detailed x-ray diffraction analysis of rat intestinal FABP confirmed the interaction of an arginine residue at position 127 of the protein with the ionized carboxyl-moiety of the fatty acid [130]. The bound fatty acid is located in the interior of the protein, and has a bent conformation with several gauche bonds. The arginine involved is the only basic amino acid that extends into the hydrophobic core of the FABP-molecule. More support for the involvement of this amino acid in the ligand binding came from comparison of the amino acid sequence of other FABPs and closely related proteins. All, except CRBP, have an arginine residue at the same position [139]. The absence of this arginine in a mutant FABP produced in E.coli [125], results in a reduction of fatty acid-binding, comparable to chemical modifications of this amino acid $[83,139]$. Arginine residues are also involved in ionic interactions with the polar headgroup in the binding of phospholipids by the phosphatidylcholinetransfer protein [142].

${ }^{13} \mathrm{C}-\mathrm{NMR}$ spectroscopy studies of the structure-function relationships of rat liver and intestinal FABPs revealed some major discrepancies between the interactions of these two FABP types with [carboxy $1-{ }^{13} \mathrm{C}$ ] fatty acids $[143,144]$. Whereas both proteins bind oleic acid to a maximum of $1 \mathrm{~mol} / \mathrm{mol}$, palmitic acid may be bound up to 2-3 mol/mol by liver FABP. The intestinal type only binds one mol of palmitic acid per mol protein. The maximal palmitic acid binding by the liver type is dependent on the (temperature-dependent) physical state of the unbound fatty acids, and the $\mathrm{pH}$. Furthermore, differences were found in the type of interaction of the fatty acids with these two FABP types. As with the high affinity binding of fatty acids to albumin [145], fatty acid binding to intestinal FABP involves ionic interactions. The ${ }^{13} \mathrm{C}-$ NMR data [144] support the involvement of Arg-127 in this interaction, as was proposed from $x$-ray diffraction analysis [130]. Although they appear to be fully ionized at neutral $\mathrm{pH}$, the anionic carboxyl groups of the fatty acid are not involved in 
electrostatic ion-pair interactions with cationic residues of hepatic FABP. Binding affinities (for the first mol fatty acid) were comparable for both FABPs $[126,144]$. ${ }^{1} \mathrm{H}-\mathrm{NMR}$ studies of 1 igand interaction with bovine liver FABP gave strong indications for the occurrence of conformational changes upon fatty acid binding [139]. Involvement of histidine and lysine residues was excluded by ${ }^{1} \mathrm{H}-\mathrm{NMR}$ and acetylation studies on bovine liver FABP [139] and ${ }^{13} \mathrm{C}-\mathrm{NMR}$ studies of rat intestinal and liver FABPs [144].

The presence of cysteine only in hepatic FABP (and, as was recently reported, in the kidney type (102]), and the ligand specificity of this protein that clearly differs from that of the other types, could be an indication of an involvement of this amino acid in the interaction of the protein with (some of) its ligands. Fatty acid binding to human, bovine and rat liver FABPs was, however, not affected by modification of the sulfhydryl group $[83,139,146]$. Considering the striking conservation of cysteine in human and rat liver FABPs [117 (at position 69) this amino acid may be involved in the binding of other hydrophobic ligands or in some other function specific for hepatic FABPs. For the nonspecific lipid transfer protein a role for cysteine has been suggested in transient interactions of this protein with intracellular membranes $[147$.

\subsection{TISSUE DISTRIBUTION AND CONTENT OF FABPS.}

When FABPs from different tissues of the rat were isolated and characterized, it soon became clear that, although closely related, they are different proteins. They have distinct physicochemical characteristics and ligand specificity. Until now at least four distinct FABP types have been identified: hepatic, cardiac, intestinal and renal, and preliminary evidence is available for the existence of a distinct muscular FABP [82,148]. The names are derived from the tissue of their first detection, and do not imply a confinement solely to these tissues. Murine adipocytes contain a specific lipid-binding protein (murine adipocyte $\mathrm{P}_{2}$ or $\mathrm{p} 422$ ), that binds both oleic acid and retinoic acid [149].

Tissue distribution of cardiac and hepatic FABPs of rat, man and pig has been investigated with specific antibodies in immunodiffusion experiments $[146,150,151]$, ELISA procedures $[148,152,153]$, and by western blotting $[123,148,153]$. The heart and liver FABP types are clearly distinguishable with specific antibodies $(86,96,148,150,153,154]$. Intestinal FABP is immunochemically distinct from liver FABP 
[151]. Immunoreactivity with antibodies to rat liver FABP is restricted to liver, small intestinal mucosa and adipose tissue $[87,89,151,153,155,156]$, while anti-heart FABP antibodies react with a variety of rat tissues $[102,123,151-153,156]$. Cardiac FABP is found in heart as well as in several skeletal muscles, and reactivity was also found with kidney, aorta, brain, testis, ovary, lung and adipose tissue. The tissue distribution of cardiac and hepatic FABPs is similar in man and pig [148]. In slow-twitch muscles the content of heart FABP is significantly higher than in the fasttwitch type $[123,152,153,157$. Low-molecular-mass proteins reactive with antibodies against intestinal FABP are present in intestine and stomach [151]. Concomitant expression of two distinct FABP type has until now been described for two tissues. Intestinal mucosa contains the liver and intestinal FABP types [146], and in rat kidney recently heart FABP and a kidney-specific FABP type have been identified [102]. The kidney FABP type is predominantly present in the cortex, whereas heart FABP is found in both cortex and medulla.

Indications for the presence of more FABP types than the heart, liver, intestinal and kidney types can be derived from the variable kd values of dealbuminized cytosolic proteins of various rat tissues [158], and especially from the differences between the fatty acid-binding capacity and the content of heart and liver types in these tissues [152] (Fig. 2.3). Many investigators determined the FABP content of various tissues with antibodies against liver FABP $[76,146,159,160]$. The comparison of the FABP content of various rat tissues, determined with anti-liver FABP, with the cytosolic oleic acid-binding capacity clearly demonstrates the inability to determine FABP in many tissues with anti-liver FABP antibodies. Similarly, antiserum directed against heart FABP does not detect FABP in liver whereas the FABP content of e.g. kidney adrenal and brain is grossly underestimated (Fig. 2.3).

The relationship of liver FABP to its homologues from brain and lung cytosol still remains unclear. Rat brain cytosol was reported not to $[94]$, or only slightly [153] react with anti-liver FABP. Bass et al. (161) could not detect any reactivity with cytosol, whereas only one of the two FABPs they isolated from rat brain reacted with anti-liver FABP. With lung immunereactivities were reported with antibodies to liver FABP [162], or to the cardiac type $[151,153]$. FABP from adipose tissue is immunochemically similar to liver FABP (89), but cytosolic proteins from adipose tissue react also with antibodies to heart FABP [150,152]. Rat mammary gland contains a FABP, that shows an immunochemical identity to heart FABP [163]. FABPs form 4-6\% of cytosolic proteins in rat 


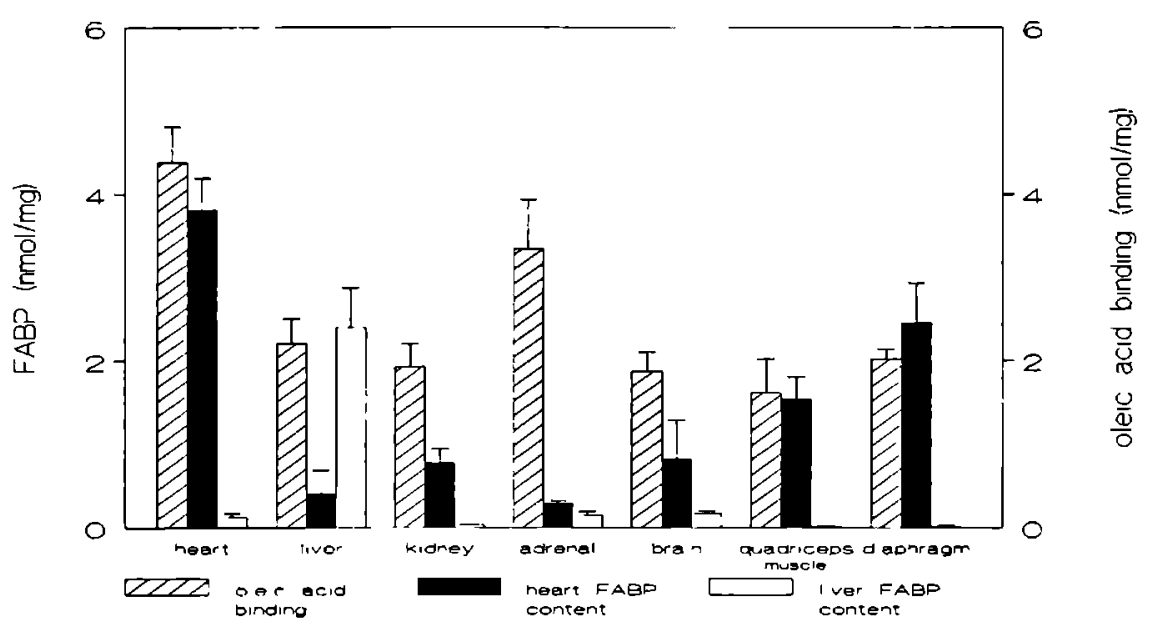

Fig. 2.3. Comparison of the fatty acid-binding capacity and the immunoreactivities with ant $i$-rat heart and liver FABP antibodies of cytosols from various rat $t$ issues.

heart and 2-4\% in rat liver, kidney, adrenal, skeletal muscles, mammary gland, brain and intestine [87,150-153,163-165]. Human liver contains approximately the same content of FABP as the corresponding rat tissues, but rat heart contains more FABP than human heart $[148]$.

The tissue distribution of heart and liver FABPs based on immunochemical observations agree well with that of MRNA of both types in these tissues. Rat heart FABP mRNA is present in relatively high amounts in slow-twitch muscle (e.g. soleus), in intermediate levels in fast-twitch skeletal muscle, and testes, in low levels in kidney, brain, aorta and adrenal $[123,124,166]$ but not in liver, intestine, spleen and lung [124]. In male rats, liver FABP mRNA was demonstrated in high concentrations only in liver and intestine ( 0.7 and $2.1 \%$ of total mRNA, respectively) [167]. Intestinal FABP mRNA is limited to small ( $1 \%$ of total mRNA) and large intestine in rat, man and monkey $[107,150,167]$. No more than a trace of these mRNAs was present in the other investigated tissues.

\subsection{CELLULAR AND SUBCELLULAR DISTRIBUTION OF FABP.}

In livers of man, rat and mice, FABP is only detectable in hepatocytes $[159,168-170]$. No other cell type present in liver reacts 
with antibodies to hepatic FABP. In the hepatic acinus of the male rat, there is a declining portal-to-central gradient of liver FABP, whereas in the female it shows a more uniform pattern [1711. In fetal human liver FABP is detectable already after 7 weeks of gestation in a uniform distribution throughout the fetal liver. Its distribution changes into a primarily periportal localization in adult human liver $[170,172]$. The intestinal and hepatic FABP types both decrease in concentration from the proximal to the distal part of the intestine in suckling and adult rats and both FABP types are located predominantly in the top of the villi $[146,168,173,174]$. This decline is not found in weanling animals [173].

By immunocytochemical staining $[169,173,175]$, and immunochemical quantitation of subcellular fractions [152,153], FABPs are only detectable in the cytosol of heart, liver, and intestine. In fed rats, reactivity with anti-liver FABP is mainly located around glycogen areas, where smooth endoplasmatic reticulum and mitochondria are located $[169,175]$. After 2 days fasting this pattern changed into a diffuse distribution throughout the hepatocyte [175]. No evidence was found for the association of FABP with mitochondria $[152,153,169]$, smooth endoplasmic reticulum [169,173] or lysosomes [169]. A small fraction of intestinal FABP (16\%) was found in association with intracellular membranes [146]. For rat heart a gradient-like distribution of FABP (with $15 \%$ present in mitochondria) was suggested, based on immuno-electron microscopical observations [165]. Using immunogold labelling and immunodiffusion, binding of FABP to bovine liver and heart mitochondria, nuclei, and microsomes was shown [176-178]. Bovine liver FABP was demonstrated only in association with the outer mitochondrial membrane $[179]$, but cardiac FABP was also found in the matrix of the myocardial mitochondria [178]. Using a highly sensitive double-antibody immunoassay, the FABP concentrations of subcellular fractions of bovine myocard were determined. FABP accounted for 0.02 and $0.003 \%$ of total protein of mitochondrial matrix and nuclei, respectively, whereas cytosolic FABP accounted for $0.32 \%$ of cytosolic [178].

The subcellular distribution of FABP differs clearly from those of non-specific lipid transport protein (sterol-carrier protein ${ }_{2}$ ) and phosphatidylcholine transfer protein [180-183]. Only 60-70\% of these proteins is located in cytosol of liver. In the adrenal gland the cytosolic portion of sterol-carrier protein is only 198 [183]. 
Up to $85 \%$ of the fatty acids endogenously bound to rat liver FABP are unsaturated, with a high percentage (50-75\%) of polyunsaturated species $[25,87,143,184,185]$. For bovine heart FABP similar data were reported [186]. The different isoforms of rat liver FABP have distinct profiles of endogencusly bound fatty acids [25,90]. The molar ratio of endogenously bound fatty acids varied between 0.4 and $1.3 \mathrm{~mol} / \mathrm{mol}$ FABP $[25,90,164,184]$.

The affinity for long-chain fatty acids estimated from the coelution of a mixture of (labelled) fatty acid and cytosolic protein from a gel filtration column was in the $\mu$ molar range 173 75.187]. However, because of the non-equilibrium conditions of the coelution method, accurate determination of $\mathrm{Kd}$ values necessitates another approach. Assays employing an equilibrium between bound and free fatty acids allow scatchard plot analysis of binding data. Equilibrium dialysis, fluorescence and radiochemical binding assays have been used to determine the dissociation constants of FABPs for a variety of ligands (Appendix I). Kd values for long-chain fatty acids are in the range of $0.1-1 \mu \mathrm{M}$ for all FABP types. The $\mathrm{Kd}$ values for their COA and carnitine esters are in the same order of magnitude $[25,76,84,188]$.

Both heart and liver FABPs show a preference for the longer, unsaturated fatty acid species $[76,73,83,84,87,95,189]$. Human and rat liver FABP and human heart FABP have a preference for long-chain saturated fatty acids of 16-19 carbon atoms, but mono- and polyunsaturated fatty acids up to 22 carbon atoms are quite well bound $183,84,189]$. Bromo-substitution did not affect binding, in contrast to a 2-hydroxyl group [83]. The fluorescent fatty acids 11-(dansylamino) undecanoic acid, 16-anthroyloxy-palmitic acid and 1-pyrene-dodecanoic acid, all show kd values comparable to those of oleic acid [83]. The Kd values are somewhat higher with the former 2 acids for the FABPs from heart than from liver [83]. For oleic acid the reverse is the case.

Binding is generally considered to occur non-covalently, at an equimolar ratio $[25,84,85,164,189,190]$, but some controversy has arisen, concerning the stoichiometry of fatty acid binding to FABP. Haunerland et al. [95] first reported binding of 2 mol oleate per mol FABP from bovine liver. The binding of both fatty acid molecules would occur at a single binding site, whereby the molecules are in parallel orientation (140]. The marked difference in $\mathrm{Kd}$ values (Appendix I) indicate that binding of the first ligand alters the affinity of the binding site for the second molecule [139]. Offner et al. [86,109] observed binding of oleic and 
palmitic acid to rat heart and liver FABP and human heart FABP at a $2 \mathrm{~mol} / \mathrm{mol}$ ratio, using liposomes as fatty acid donors. Kidney FABP showed only one binding site, under similar conditions [102]. In our laboratory this assay produced values of maximally 0.7 mol oleic acid/mol human heart FABP [84]. Transfer assays of oleic acid from mitochondria to liver or heart FABPs, and Lipidex binding assays, showed a comparable binding stoichiometry, that did not exceed 1 mol fatty acid per mol FABP [83].

In NMR studies on $\left[{ }^{13} \mathrm{C}\right]$ oleic acid binding to rat liver and intestinal FABPs, cistola et al. could not demonstrate a stoichiometry exceeding $1 \mathrm{~mol} / \mathrm{mol}[143,144]$. Palmitic acid, however, was bound up to 2-3 $\mathrm{mol} / \mathrm{mol}$ by liver FABP, but maximally in an equimolar ratio by the intestinal type. The measurements of the higher binding ratios were allowed by the preservation of the equilibrium condition with the employed technique, since it did not require separation of bound and free fatty acids. The materials applied for separation of bound and free ligand in other assays may compete with FABP for ligand binding, thus leading to an underestimation of the binding capacity of FABP [143]. An increase of the amount of Lipidex does, however, not affect the binding of fatty acid to FABP 11911. Apparently the stoichiometry of fatty acid binding to FABP is greatly dependent on the assay conditions applied. Especially the solubility and the associative behaviour of the fatty acid may be important. The binding ratio of palmitic acid to hepatic FABP was shown to depend on the physical state of the unbound fatty acid, thus on temperature, and on the $\mathrm{pH}$ of the assay mixture [144].

Rat liver and intestinal FABP genes have been inserted and brought to expression in E.coli [125,126]. The bacterially derived FABPs were used to study ligand binding and secondary and tertiary structures. The liver FABP type could bind up to 2 mol long-chain fatty acid per mol with a $\mathrm{Kd}$ value of 1.7-3.2 $\mu \mathrm{M}$, and a higher affinity for unsaturated fatty acids [126]. Site directed mutagenesis of the carboxyl-terminal part of rat liver FABP markedly reduced fatty acid binding [125]. Binding properties of E.coli-derived intestinal FABP were similar to those of the native intestinal FABP. It bound one mol fatty acid per mol protein, but the apparent Kd values were also clearly increased [126]. Intestinal FABP has an approximately equal affinity for oleic, palmitic and arachidonic acid (Kd 2.9-3.7 $\mu \mathrm{M}$ ). Analysis of its tertiary structure showed that intestinal FABP noncovalently binds one mol of fatty acid per mol protein [130], which was confirmed by ${ }^{13} \mathrm{C}$-NMR studies [144].

Pig heart FABP was reported to self-associate into several 
forms of higher molecular weight [192]. This concentrationdependent self-aggregation was suggested to be an important regulatory step in the control of energy production through the $\beta$-oxidative pathway in heart [165]. The self-aggregated FABP forms of heart may play different roles in cardiac energy metabolism. In this model, only two forms act in the translocation of acylcarnitine to mitochondria [193]. Self-aggregation has not been reported for any other FABP type. Other investigators found no evidence for a concentration-dependent self-association of heart FABP from cattle [96], rat [86] or man [109].

The ligand specificity of liver FABP is clearly distinct from that of the other FABP types. Liver FABPs appear to function as a general carrier of hydrophobic ligands, whereas the other FABP types apparently function more specifically as carriers for long-chain fatty acids and their COA and carnitine esters. Human heart FABP only binds fatty acids, and long-chain acyl-carnitine and - COA esters [84]. Liver FABP has been reported to bind (in vitro) retinyl-palmitate $[154]$, heme $[25,156,189,194]$, prostaglandins [190], hematin, 1-anilino-8-naphthalene sulfonate (ANS), bilirubin, and bromosulfophthalein [195], with affinities comparable to those for long-chain fatty acids (Appendix I). Binding of lysophosphatidylcholine [196], steroids [76] and bile acids [195] to liver FABP has also been demonstrated, but with somewhat lower affinity. No binding of retinoids [83], clofibric acid [83,194], prostaglandins, long-chain alcohols [83,189], methyl-palmitate, COA, malonyl-COA [189] or cholesterol [189,194] could be detected to rat and human liver FABP in studies of competitive displacement of 11-(dansylamino) undecanoic acid or ANS. Palmitoyl-carnitine and palmitoyl-glycerol are only bound with very low affinity [83]. Liver FABP showed a higher affinity for monohydroxy-bile acids than for trihydroxy-bile acids in competition to ANS [195]. Various inhibitors of carnitine-palmitoyl transferase have a high affinity for FABP [83].

To date binding of ligands other than fatty acids has only been reported for hepatic FABP, not for any of the other FABP types. Binding characteristics are similar for the isolated isoforms of liver FABP [25,03]. Recently, it was described that the murine adipocyte $P_{2}(p 422)$ protein is able to bind both oleic and retinoic acid from liposomes [149], but its Kd value for oleic acid was much lower $(3 \mu \mathrm{M})$. 
Although the involvement of FABPs in intracellular fatty acid transport and utilization is generally accepted, the massive amount of research into these proteins has only provided much circumstantial evidence for their physiological role(s). No conclusive evidence is available.

Two major functions have been assigned to the FABPs. First, the facilitation of transport, which may include release of fatty acids and/or movement through the aqueous phase, and secondly, modulation of enzyme and/or metabolic activities by storage of substrates, sequestration of substrates and/or effectors and protection against inhibitors. The function may be related to the ligand bound to the protein: fatty acid, acyl-CoA, acylcarnitine or other hydrophobic ligands.

The major role assigned to FABPs is facilitation of intracellular transport or specific trafficking of fatty acids and acyl-derivatives, thereby providing a possibility of targeting of these compounds towards oxidation or esterification. Tipping and Ketterer [197] concluded on basis of theoretical considerations, that FABP could enhance the rate of intracellular transport of its Iigand by an order of magnitude. Cooper et al. [53] presented evidence that the metabolism of palmitic acid in liver is diffusion-limited, and that almost all fatty acids in the cytosol are bound to FABP. From the concomitant increase of $z-$ protein (FABP) cuntent and palmitic acid uptake by livers isolated from clofibrate treated rats, Renaud et al. [198] concluded that this protein is involved in fatty acid uptake. Experiments with inhibitors of fatty acid binding to FABP, as flavaspidic acid or $\alpha$-bromopalmitic acid, with jejunal preparations, hepatocytes and perfused liver did not give equivocal results $[184,190 \cdot 201]$.

The ability of FABPs to release fatty acids from membranes was demonstrated by many investigators [83,188,202-204]. Liver FABP is, however, less effective than albumin in preventing fatty acid accumulation in membranes [1431. Evidence for in vitro fatty acid transfer between membranes by FABP could be obtained for membrane systems separated by a polycarbonate filter [202,203], and for two separated monolayers [202]. FABPs are able to deliver long-chain fatty acids to the mitochondrial $\beta$-oxidation system for oxidation $[26,88,165,202]$, or to microsomes for acy $1-C O A$ synthesis $[83,203]$. At a $1: 1$ ratio of fatty acid to protein, FABP-bound palmitate proved to be a better substrate for the mitochondria than albumin-bound fatty acid [26]. 
Maximal rates of palmitoylcarnitine oxidation in rat heart mitochondria varied according to a FABP concentration-dependent function [193]. A model for a FABP-dependent flux of acylcarnitine between the cytoplasm and the inner mitochondrial membrane was postulated on basis of electronspin resonance studies of 16doxylstearoylcarnitine distribution and oxidation [193]. The occurrence of two specific self-aggregated FABP species as acylcarnitine translocators would contribute to the regulation of $\beta$-oxidation and energy production in the heart [193].

Evidence for the physiologically important function of FABPs in modulation of metabolism has been derived from their influence on the in vitro activity of a number of enzymes. Rat liver FABP is able to preclude or reverse the inhibition by fatty acids or their acyl-COA esters of mitochondrial ATP/ADP translocase [205), microsomal 4-methyl sterol oxidase $[98,206)$ and acyl-COA:cholesterol acyltransferase [206] and of cytosolic acetyl-CoA carboxylase [207], and both the mitochondrial [194] and microsomal acyl-COA synthases $[143,162,188,199,208]$. When liposomes were used as fatty acid donor, instead of salt or detergent suspensions, liver FABP markedly decreased the activity of microsomal acyl-COA synthase [209]. WuRideout et al. [208] described an inhibitory effect of liver FABP on mitochondrial long-chain acyl-COA synthase. Heart FABP does not stimulate microsomal acyl-CoA synthase activity [188]. Hepatic and intestinal FABPs stimulate the activity of several microsomal enzymes involved in the synthesis of triacylglycerols and phospholipids, such as acyl-COA: glycerol-3 phosphate acyltransferase [179,184,210], diacylglycerol acyltransferase [211,212] and phosphatidate phosphohydrolase [213]. Lung FABP stimulates 2-4-fold the activity of pulmonary microsomal glycerophosphate acyltransferase [214]. Human liver FABP stimulates glucose-6-phosphate dehydrogenase [215]. The effects of FABPs on the activities of a number of enzymes may depend on the system in which the fatty acids or acyl-CoA esters are presented. They may either reflect a specific influence of these proteins on the release of fatty acids from membranes, or a site-directed transfer of fatty acids or acyl-COA esters to the active site of the enzyme. An aspecific solubilizing effect may be involved in their influence on several enzymes, but the (partial) impossibility observed in some cases $[184,199,211,214]$, to duplicate the observed effects with albumin reflects a more direct involvement of FABP. Furthermore, Mccormack and Brecher showed that fatty acids must first desorb from liposomal membranes, before FABP can have an effect on acyl-COA formation by acyl-COA synthase [203]. FABPs apparently penetrate a phospholipid bilayer only to a minor extent [202]. Bordewick et 
al. (179) presented evidence for a direct interaction of (bovine) liver FABP with microsomal membranes in the stimulation of acyltransferases.

The relative cytosolic abundance of FABPs le.g. 87,148,150-153,161,163165) suggests a role for these proteins in temporary intracellular storage of fatty acids. Binding of fatty acids and their CoA- and carnitine-esters by FABPs enables the maintenance of a low concentration of the unbound form of these substances within the cell over a large concentration range, which is important because of the damaging effects of high concentrations of these compounds on membranes [216], and the marked influence of acyl-CoA esters on many enzyme activities.

A protective role may be of special importance during ischemia in heart, when high concentrations of free fatty acids arise 1217 . Recent observations on ischemia in perfused rat hearts showed, however, a marked release of FABP from the heart together with only minor amounts of fatty acids [218]. This seems to plead against a protective role of FABP in heart, but fatty acids may be stripped from FABP during membrane passage.

The intracellular storage pool of FABP-bound fatty acids can readily deliver substrate for energy production or biosynthetic processes. Binding to FABP may regulate the intracellular concentrations of fatty acids and acyl-COA and acyl-carnitine esters, and thus influence the overall rate of intracellular lipid metabolism. Inversely, the amount of fatty acid stored intracellularly by binding to FABP may be determined by the rates of fatty acid uptake and utilization.

some recent studies have indicated a role for FABPs or related proteins in (indirect) regulation of growth and differentiation. The level of liver FABP is positively associated with the growth activity of rat hepatocytes [219]. Ligands of this protein may be involved in normal mitosis and carcinogen-induced cell proliferation of hepatocytes [219]. A polypeptide growth inhibitor purified from bovine mammary gland (MDGI), which shows extensive homology with rat heart FABP, inhibits proliferation of Ehrlich ascites and mammary carcinoma cells [114]. Cellular retinol- and retinoic acid-binding proteins may mediate transport of these ligands to their nuclear receptor 12201 , and in this way influence their action on epithelial differentiation and tumorigenesis 221 . The adipocyte differentiation is accompanied by the transcriptional activation of the gene of the adipocyte lipidbinding $P_{2}$ (p422) protein [222]. 
2.11. INFLUENCE OF PHYSIOLOGICAL CONDITIONS AND DRUG TREATMENT ON FABPS.

Most support for the physiological role(s) of FABPs has been gathered from studies of the relation of the FABP content or the fatty acid-binding activity of cytosolic proteins with physiological conditions and drug treatments that involve changes in lipid metabolism (Appendix II). The different tissues show a distinct response of the FABP concentration to physiological changes. The concentration of liver FABP can markedly change, whereas that of heart FABP is relatively stable. Although less information is available, intestinal FABP appears to be closer to the hepatic type in its response to variations. Both the FABP contents of heart and liver, but not of intestine, are higher in females $[87,150,153,158,171,223,224]$. The sex influence in liver corresponds to the effects of steroid hormones [223].

Starvation [153,158,225-227], (hypolipidemic) drugs and peroxisome proliferators $[150,153,158,227-230]$ only have a marked effect on the FABP content of liver. Clofibrate also has an increasing effect on the fatty acid-binding capacity of kidney cytosol [159] and on the hepatic FABP type in rat intestine $[150]$. The capacity of the $\beta-$ oxidation system in several rat tissues [231] is strongly correlated with the cytosolic fatty acid-binding capacity in control and clofibrate-treated animals [232]. Brain forms an exception in this respect. Increase of the fat content or addition of fat to the diet clearly affects the FABP content of liver $[160,233,234]$ and heart [165]. A high carbohydrate diet also increases the liver FABP content [233]. In intestine, a high-fat diet produces a relatively larger induction of the intestinal FABP type [223]. Chronic alcohol consumption by rats induced a dramatic increase of hepatic FABP content [235], but this was not always the case [236]. Choline-deficient diet increased the FABP concentration of rat liver threefold [237. The diurnal rhythm had only a minor influence on the levels of liver and heart FABP $[150,153,158,227,229]$.

During prenatal and postnatal development the FABP content of heart and liver increase $[87,152,153,223,238-240]$, as do the $\beta$-oxidative capacities of these tissues [231]. Interestingly, the cytosolic fatty acid-binding capacity of both tissues is already at the adult level in newborn animals [158]. Based on bromosulfophthalein binding, the liver FABP content is already at the adult level at the late fetal stage in guinea pigs [241] and monkeys [242]. FABP-immunoreactive hepatocytes were found in the human liver as early as the seventh week of gestation [170], and remained present in a frequency of approximately $80 \%$ throughout the gestational 
period (243). This percentage is lower in adult liver. In the human intestine, immunoreactive FABP was demonstrated at the $23 \mathrm{rd}$ week of gestation. Changes of the $\alpha$-fetoprotein content could not explain the differences between fatty acid-binding capacity and FABP content [153]. The two FABPs in kidney show a distinctive developmental pattern [102]. Whereas the heart type is detectable at comparable levels in neonatal and adult kidney, the concentration of the kidney FABP type markedly increases during postnatal development [102].

The FABP concentration varies markedly among various types of skeletal muscle $[123,152,153,157]$. The FABP content is higher in slow-twitch than in fast-twitch muscles. Chronic electrostimulation of rat tibialis anterior (a fast-twitch muscle), that had previously been shown to cause a rise in oxidative metabolism [244], induced a rise of the FABP content to a level comparable to that of slow-twitch muscle and close to that of heart [245]. Myoglobin and mitochondrial enzyme activities showed much smaller increments [245].

\subsection{STABILITY AND TURNOVER.}

Most investigations concerning stability and turnover rates of FABPs have been carried out with the hepatic and intestinal types. FABPs are very stable proteins, with a high resistance to enzymic digestion $[83,90,110,146]$, and radiation $[131]$. The binding of fatty acids to liver [99] and heart FABP [110] appears to even increase this resistance. The liver FABP produced in E.coli had a comparable stability, but a mutant liver FABP, produced by site-directed mutagenesis of the FABP gene introduced in E.coli, had a clearance rate that was 10-fold higher than that of the wild-type FABP [125]. The mutant protein had a modified carboxyterminal sequence, resulting in an altered secondary structure with a decreased hydrophobicity and a markedly reduced binding of oleic acid.

During isolation of bovine FABPs Spener and coworkers apply temperatures up to $50^{\circ} \mathrm{C}$ and a $\mathrm{pH}$ of 4.0 , without significantly affecting the activity of the proteins $[95,96]$. Ion-exchange chromatography and delipidation at an early stage of purification, however, lead to loss of binding activity [96].

Bass et al. [227] determined the rates of degradation of FABP and total cytosolic protein after pulse-labelling with $\mathrm{NaH}^{14} \mathrm{CO}_{3}$, and calculated half-lives of 3.1 and 2.9 days for FABP and total 
protein. Apparently the degradation rate of liver FABP is comparable to that of an average cytosolic protein. Based on the observed half-life, FABP concentrations change only relatively slowly, compared to the rate of fluctuations of fatty acid metabolism. This is in agreement with the slight diurnal rhythm of the protein $[150,153,158,227,2291$. The isoforms of rat liver FABP have a similar degradation rate in vivo [227, although their endogenous ligands differ $[25,90]$.

The half-life of $\left[{ }^{35} \mathrm{~S}\right]$ methionine-labelled FABP in cultured neonatal rat cardiomyocytes was 2.5 days [239]. The ability of hepatocytes to modulate the concentration of a protein which appeared to be identical to liver FABP [219] within the relatively short time period spanned by mitosis [246] is not compatible with a half-life of 2-3 days. The half-life of $2 \mathrm{~h}$ reported for the sterol-carrier protein and hepatic FABP [247] markedly contrasts the findings reported by Bass et al. [227]. However, despite their substantial similarity, FABP and sterol-carrier protein are now considered to be different proteins $\{248,249]$.

The higher levels of liver FABP in female rats, as well as the increased content of this protein in liver of male animals at clofibrate treatment are not related to differences in the turnover rate of the protein. They appear to be correlated with an increase of the specific FABP mRNA content of the liver [150].

The liver and intestinal FABP types exhibit different regulatory responses in intestinal mucosa [150]. Although the mRNA concentration of the liver FABP type is approximately $50 \%$ higher in the intestine of female rats than of males, there is no sexrelated difference in the steady-state level of this protein, due to a 1.35-fold higher turnover rate in female jejunum [150]. No sex-related differences are observed for the intestinal FABP type or its mRNA.

A differential regulatory response is also present in the effect of clofibrate treatment on both types of FABP in the intestinal mucosa of male rats. Whereas the liver type is induced up to 2-fold by clofibrate, the intestinal FABP type is only $25 \%$ higher. Clofibrate treatment doubled the concentration of liver FABP MRNA in the intestine, but had no effect on the intestinal FABP MRNA [150]. The influence of sex-difference and of clofibrate indicate that the concentrations of both proteins are modulated via changes in their rates of synthesis $[25,150]$.

Postnatal development of mRNA levels for the different FABP types appears to be quite different in various rat tissues. In small intestinal epithelium both mRNAs for liver and intestinal types of FABP are first detectable between the 19th and the 21 st 
day of gestation [167]. They undergo a coordinated three to fourfold increase during the first postnatal day. Thereafter the levels of intestinal FABP mRNA remain constant, while liver FABP mRNA increases further in intestine. Both mRNAs increase in this tissue during growth from 120 to 400 gram bodyweight. Liver FABP mRNA is expressed in a declining gradient from duodenum to colon. Furthermore, hepatic mRNA expression in the intestinal wall shows a second gradient, from the crypts to the villus tips [168].

Liver FABP mRNA concentration increases about 2 -fold in liver within the first $24 \mathrm{~h}$ after birth, but it does not change further until 35 days [167]. During growth from 120 to $400 \mathrm{~g}$, the FABP IRNA concentration doubles again. Sheridan and wilton found a linear increase of FABP specific mRNA in rat liver during postnatal development [250]. The FABP mRNA concentration in human liver undergoes much smaller changes during the fetal and neonatal period [251]. Hepatic FABP mRNA expression decreases gradually from the periphery to the central veins of the liver lobes, and is restricted to hepatocytes $[168]$.

Distinct patterns of developmental change in heart FABP mRNA concentration are observed in heart, placenta, brain and testes of the rat [124]. This specific mRNA sequence was already detectable in myocardium at day 19 of gestation. Its level rises rapidly during the first $48 \mathrm{~h}$ after birth, to reach the maximal, adult, value at approximately 14 days. Brain and testes also show a postnatal increase of cardiac FABP mRNA, but later than heart. Maximal values are reached at 24 and 70 days, respectively, in these tissues. Changes in the heart FABP mRNA concentration in kidney form a contrasting pattern to that observed in heart and brain [124]. The renal concentration of heart FABP mRNA is maximal during the fetal period, then falls rapidly during the first two days after birth, peaks again around day 8 , and finally declines to a very low adult level. The significance of this aberrant developmental pattern is still unclear. Possibly, a quantitative switch between the two FABP types expressed in the kidney [102] may relate to this phenomenon. In rat placenta the heart FABP mRNA concentration rapidly increases during the late gestational period [124].

\subsection{FABP AND PATHOLOgY.}

Structural mutants or FABP deficiencies due to genetic aberrations, have not been observed in man or animals up to now. 
Some pathological or experimental conditions show changes in the content or appearance of FABPs (Table 2.7). In diabetes a decline of liver FABP content was observed, together with the appearance of a FABP form with a molecular mass of $400 \mathrm{kDa}$ [225]. The appearance of a high-molecular form was also observed under diabetic conditions in human and rabbit placenta [252]. Hypertension, induced by DOCA-NaCl treatment or infusion of angiotensin-II resulted in the disappearance of the kidney FABP type from kidney cortex, whereas the heart FABP type remained unchanged in cortex and medulla [102]. The same models of experimental hypertension induced a marked decrease of the heart FABP type and its mRNA in rat aorta, but not in heart, skeletal muscle or kidney 1157 . surprisingly, spontaneously hypertensive rats showed an increase of FABP in the medulla, but not in the cortex [253].

FABP content and intracellular fatty acid metabolism may be closely related. In Morris hepatoma a nutritional regulation of fatty acid synthesis was absent, together with a decrease of the FABP content to $20 \%$ of that in liver [254]. The FABP level appears to be associated with normal mitosis and carcinogen-induced proliferation of hepatocytes [219]. This suggests that liver FABP may not only carry ligands that promote hepatocyte division, but also

Table 2.7.

FABP and pothology.

\begin{tabular}{|c|c|c|}
\hline Reported changes & & efs. \\
\hline \multicolumn{3}{|l|}{ Diabetes } \\
\hline $\begin{array}{l}\text { rot liver } \\
\text { rabbit placente } \\
\text { human placenta }\end{array}$ & $\begin{array}{l}\text { decreased FABP content, appearance of high-molecular form } \\
\text { appearance of different form } \\
\text { appearance of different form }\end{array}$ & $\begin{array}{l}225 \\
252 \\
252\end{array}$ \\
\hline \multicolumn{3}{|l|}{$\begin{array}{l}\text { Hypertension } \\
\text { spont aneous }\end{array}$} \\
\hline rat kidney & increased FABP content in medulla, not in cortex & 253 \\
\hline $\begin{array}{c}\text { Induced by DOCA-NaCl } \\
\text { or anglotensin II } \\
\text { rat kidney } \\
\text { rat borte }\end{array}$ & $\begin{array}{l}\text { disappearance kidney FABP from cortex, no effect on heart FABP type } \\
\text { marked reduction of heart FABP type }\end{array}$ & $\begin{array}{l}102 \\
166\end{array}$ \\
\hline $\begin{array}{c}\text { Morris hepetome } \\
\text { rat }\end{array}$ & Low FABP content & 254 \\
\hline $\begin{array}{c}\text { Hepetitis, cirrhosis, } \\
\text { Gilbert's syndrome, } \\
\text { Dubin-Johnson syndrome } \\
\text { humen liver } \\
\text { serum }\end{array}$ & $\begin{array}{l}\text { decreased FABP content } \\
\text { elevated FABP levels }\end{array}$ & 159 \\
\hline $\begin{array}{c}\text { Obesity (Zucker rat) } \\
\text { rat liver }\end{array}$ & inereased FABP content & 262 \\
\hline $\begin{array}{l}\text { Isehemia/Ca-paradox } \\
\text { perfused rat heart }\end{array}$ & release of FABP & 18,255 \\
\hline
\end{tabular}


certain chemically activated carcinogens in their passage from cytoplasm to chromatin [219]. The covalent binding of metabolites of carcinogens to this protein was already detected before its fatty acid-binding capacity was known [76]. Liver FABP content is markedly decreased in patients with various liver diseases, whereas their serum FABP concentration is higher than in normal subjects [159]. A release of heart FABP in the perfusate was found in experimental ischemia and Ca-paradox in perfused rat hearts $[217,255]$.

\subsection{CHROMOSOMAL LOCALIZATION OF FABP GENES.}

Localization of the genes encoding for FABPs, and other hydrophobic ligand-binding proteins, may provide new insights into their physiological roles and regulation. Useful information may be derived from the comparison of inbred strains with known mutations or deletions, in situ hybridization to metaphase chromosomes and somatic cell hybrid clones. Table 2.8 summarizes the available data concerning chromosomal localization of the genes encoding heart, liver and intestinal FABP, cellular retinolbinding proteins, adipocyte $P_{2}$ (p422) protein, and albumin in man and mouse. No data are available for rat. The mouse genes for liver, intestinal [107] and heart [124] FABPs are located on different chromosomes, as are the human intestinal and liver FABP genes $[107,256]$. Human heart FABP-encoding DNA sequences have not yet been assigned to a specific chromosome, but interestingly a cDNA probe to its mouse counterpart hybridized with sequences on at least three chromosomes [124]. These may represent pseudogenes,

Table 2.8

Chromosomal localization of genes encoding FABP and other proteins with high affinity for hydrophobic ligands.

\begin{tabular}{lll}
\hline Protein & \multicolumn{2}{c}{ Chromosome (region) } \\
\cline { 2 - 3 } Man & Mouse \\
Liver FABP & $2(p 12-q 12)$ & 6 \\
Intestinal FABP & $4(q 2 B-q 31)$ & 3 \\
Heart FABP & 3 & 4,8 and 10 or 15 \\
Albumin & $4(q 11-q 22)$ & 5 \\
CRBP & 3 & 9 \\
CRBP-II (intestine) & 3 & 9 \\
Adipocyte $P_{2}$ (ph22) & $?$ & 3 \\
\hline
\end{tabular}


or actively transcribed genes that encode other, closely related, proteins that are not yet identified [124]. These proteins may be other FABP types, closely related to heart FABP, such as the FABP from skeletal muscle that is also detected by antibodies to heart FABP [123, 152, 153].

Although a number of hydrophobic ligand-binding proteins are closely related, and probably originate from a common ancestor gene [105], the genes encoding for these proteins are located dispersed throughout the genome in both mouse and man. only the CRBP and CRBP-II genes are closely linked on the same chromosome. The genes for human intestinal FABP [256] and albumin [257] are both located on the long arm of chromosome 4. In the mouse albumin is encoded by a gene on chromosome 5, that is closely linked to the gene for alpha-fetoprotein, a protein that is also involved in fatty acid transport [258].

\subsection{CONCLUSIONS.}

The existence of various types of FABPs, and the relative abundance of these proteins in many tissues are indications of an important function for these proteins in cellular metabolism. The distinct tissue distribution and ligand specificities, and the differential response of the various FABP types to metabolic changes induced by various conditions show an adaptation of each type of this protein to a specific environment. These properties of the FABPs may relate to tissue-specific differences in targeting of hydrophobic ligands (fatty acid, acyl-CoA, acylcarnitine, or other) to specific subcellular systems, interaction with and protection of cellular membranes or enzyme systems, or modulation of lipid metabolism. Furthermore, FABPs may be indirectly involved in regulation of growth, differentiation and transmembrane signalling. 


\subsection{MATERIALS.}

The list below sums up all specific reagents and materials that were used in this study, including the suppliers.

[ $\left.1-{ }^{14} \mathrm{C}\right]$ arachidonic acid, $\left[1-{ }^{14} \mathrm{C}\right]$ myristic acid, $\left[1-{ }^{14} \mathrm{C}\right]$ oleic acid, $\left[1-{ }^{14} \mathrm{C}\right]$ palmitic acid, $\left[1-{ }^{14} \mathrm{C}\right]$ palmitoyl-coenzyme $\mathrm{A}$, and $\left[1-{ }^{14} \mathrm{C}\right]$ stearic acid: Amersham International plc., Amersham, UK. [ $\left.1-{ }^{14} \mathrm{C}\right]$ Palmitoyl-carnitine: New England Nuclear Research Products Dreieichenhain, FRG.

(specific activities of the radioactive compounds were 2.15-2.22 GBq/mol, approximately 120-135 dpm/pmol).

Lipidex 1000: Canberra Packard, Downers Grove, IL, USA. Protein A-Sepharose CL-4B, Sepharose CL-4B, Sephacryl S-200, Pharmalyte ampholines: Pharmacia Biotechnology International, Uppsala, Sweden.

DEAE-cellulose (DE-32): Whatman International Ltd., Maidstone, Kent, UK.

IgG fractions of sheep-anti rat serum albumin, goat-anti rat serum albumin, and rabbit-anti swine serum albumin : Cappel Laboratories, West Chester, PA, USA.

Horseradish peroxidase-conjugated sheep-anti rabbit IgG, peroxidase conjugated swine-anti rabbit IgG, rabbit-anti human serum albumin (IgG fraction): Dakopatts a/s, Glostrup, Denmark. Horseradish peroxidase conjugated goat-anti rabbit IgG: Nordic Immunology, Tilburg, The Netherlands.

Nitrocellulose sheets (BA-85, pore size $0.45 \mu \mathrm{m})$ : Schleicher and Schuell, Dassel, FRG.

Flat-bottom polystyrene Microtiter ELISA plates: Greiner, Nurtingen, FRG. 
o-phenylene-diamine, Tween-20, bovine serum albumin: sigma Chemical Co., st.Louis, MO, USA.

4-chloro-1-naphthol: Aldrich Chemie Benelux NV, Brussels, Belgium.

Triton X-100: Serva, Heidelberg, FRG.

Tresyl-chloride (2,2,2-trifluoroethanesulfonyl chloride): Fluka AG, Buchs, Switzerland.

Ammonyx-LO: Millmaster onyx International, Fairfield, NJ, USA.

clofibrate (Atromid S): ICI, Rotterdam, The Netherlands.

Cholesterol, bilirubin, fatty acids: Merck, Darmstadt, FRG.

All-trans retinol and retinoic acid: Eastman Kodak Co., Rochester, NY, USA.

Prostaglandins $E_{1}, A_{1}, F_{1 a}$ and 15-Methyl-prostaglandin $F_{2 a}$ : The Upjohn Company, Don Mills, Ontario, Canada.

Egg phosphatidylcholine: Lipid Products, South Nuffield, Surrey, UK.

Unless otherwise stated, all other chemicals were of the highest available purity grade, purchased from Merck, Darmstadt, FRG, Boehringer, Mannheim, FRG or Sigma Chemical Co., st.Louis, Mo, USA.

\subsection{ORIGIN OF TISSUES.}

Rat tissues.

Rat tissues (heart, liver, skeletal muscles, intestine, kidney, adrenals, brain) were obtained from random-bred male albino wistar rats, weighing $200 \pm 20 \mathrm{~g}$, unless otherwise stated. water and food (a pelleted diet containing $22 \%$ protein, $4.8 \%$ fat and 67 carbohydrates, RMH-TM, from Hope Farms BV, woerden, The Netherlands) were provided at libitum. The animals were maintained on a cycle of alternating 12 hour light and darkness periods. Animals were killed by cervical dislocation around the midpoint of the light period.

\section{Pig tissues.}

Most tissues (heart, liver, muscle, kidney) were collected at the slaughterhouse, placenta immediately after delivery at the farm. They were used immediately, or in some cases stored at $-70^{\circ} \mathrm{C}$ until use. 
Human tissues.

Human tissue samples (heart, liver, muscle, kidney, intestine, brain, and retina) were obtained either from biopsies taken from patients undergoing surgery, or from autopsies within $20 \mathrm{~h}$ after death. Placenta was obtained shortly after delivery. The materials were used immediately, or stored at $-70^{\circ} \mathrm{C}$ until use.

\subsection{PREPARATION OF HOMOGENATES AND CYTOSOLS, AND SUBCELLULAR FRACTIONATION.}

Rat hearts and livers were perfused in situ with cold homogenization buffer (10 mM K-phosphate/ $154 \mathrm{mM} \mathrm{KCl,} \mathrm{pH} \mathrm{7.4),} \mathrm{and}$ excised. After removal of fat, all tissues were immediately cooled in ice-cold homogenization buffer, and rinsed with the same buffer. The materials were then minced and whole homogenates, $40 \%$ (v/v) for liver, 25\% for heart, kidney and brain and $10 \%$ for all other tissues, were prepared in ice-cold homogenization buffer, either by hand-homogenisation in a Potter-Elvehjem homogenizer, or, for large samples, in a Waring Blendor followed by a Polytron homogenizer. The homogenates were centrifuged $10 \mathrm{~min}$ at $600 \mathrm{xg}$. The resulting supernatant was then centrifuged for $90 \mathrm{~min}$ at $105,000 \times \mathrm{g}$ to yield a cytosolic protein preparation. Floating fat was aspirated and finally the clear supernatants were stored at $-20^{\circ} \mathrm{C}$.

\section{Subcellular fractionation.}

Livers and hearts from male albino wistar rats $(200 \pm 20 \mathrm{~g})$ were cooled to $0^{\circ} \mathrm{C}$ in SET buffer $(250 \mathrm{mM}$ sucrose/ $2 \mathrm{mM}$ EDTA/ 10 mM Tris-HCl, pH 7.4) immediately after excision. All subsequent steps were performed at $0^{\circ} \mathrm{C}$. To isolate mitochondria, tissues were homogenized in $20 \mathrm{vol}$. SET buffer and centrifuged at $600 \mathrm{x}$ $g$ for $10 \mathrm{~min}$. Pellets were resuspended in 0.5 vol. SET buffer and spun down again (10 $\mathrm{min}, 600 \times \mathrm{g})$. The $600 \times \mathrm{g}$ supernatants were combined and centrifuged for $10 \mathrm{~min}$ at $10,000 \mathrm{xg}$. The $10,000 \mathrm{x}$ $g$ supernatant was used for preparation of microsomal and cytosolic fractions $(90 \mathrm{~min} 105,000 \times \mathrm{g}$ pellet and supernatant). The mitochondrial fraction (10,000 x g pellet) was resuspended in 0.5 vol. SET buffer and divided into 3 parts. One portion was kept as intact mitochondria, one part was extracted with $0.05 \% \mathrm{Na}-$ deoxycholate ( $\mathrm{pH} 7.0$ ) and subsequently centrifuged for $10 \mathrm{~min}$ at $20,000 \times \mathrm{g}$. The third part was extracted with a solution of $125 \mathrm{mM} \mathrm{KCl} / 1 \mathrm{mM}$ EDTA/ $10 \mathrm{mM} \mathrm{K}$-phosphate (pH 6.0) and centrifuged 
for $10 \mathrm{~min}$ at $20,000 \times \mathrm{g}$. The obtained pellet was then extracted with Na-deoxycholate as described above. The obtained fractions and mitochondrial extracts were used for immunological quantitation of FABPs.

\subsection{BIOCHEMICAL METHODS.}

Dealbuminization of cytosolic proteins.

Prior to determination of the fatty acid-binding capacity, residual albumin was removed from cytosolic protein samples by affinity chromatography. Sepharose $C L-4 B$ was activated with tresyl-chloride according to the method of Nilsson and Mosbach [263]. The IgG fraction of antiserum to albumin of man, rat or pig was coupled to the activated gel at pH 7.5, essentially as described for trypsin [263]. Coupling yield was approximately 14-15 $\mathrm{mg} I \mathrm{gG} / \mathrm{ml}$ Sepharose. Columns of $10 \mathrm{ml}$ Sepharose-anti-albumin were routinely used to remove residual albumin from cytosolic protein preparations of all tissues (2-4 $\mathrm{mg}$ protein). The dealbuminized protein samples were concentrated by ultrafiltration, using a Diaflo YM-2 membrane.

Dealbuminization was verified by quantitation of the albumin content prior to and after the procedure by an enzyme-linked immunosorbent assay (ELISA), that was performed essentially as described by Hudson and Hay [264].

Preparation of Lipidex 1000.

The methanol in which Lipidex 1000 is supplied was removed by extensive washing with water on a Buchnel funnel, followed by $10 \mathrm{vol}$. $10 \mathrm{mM} \operatorname{Tris}-\mathrm{HCl}(\mathrm{pH} \mathrm{8.0)}$. The material was stored in a $1: 1$ suspension in the same buffer in glass vials at $4^{\circ} \mathrm{C}$.

Delipidation.

Endogenous fatty acids were removed from protein samples by delipidation on a Lipidex 1000 column $(0.8 \times 6 \mathrm{~cm})$ at $37^{\circ} \mathrm{C}$, as described by Glatz et al. [164], to obtain accurate values of fatty acid-binding activity.

Preparation of fatty acid-buffer solutions.

Aqueous solutions of fatty acids were obtained by mixing 40 nmol fatty acid from an ethanolic stock solution (450 $\mu \mathrm{M}$ ) with $6.4 \mathrm{ml} 10 \mathrm{mM}$ Tris $-\mathrm{HCl}(\mathrm{pH} 8.5)$. The aqueous solutions were used immediately afterwards. 
Fatty acid-binding assay.

Protein samples were delipidated with Lipidex 1000 at $37^{\circ} \mathrm{C}$, and cytosolic protein samples were first dealbuminized on an anti-albumin-sepharose $4 \mathrm{~B}$ column, as described above. $\left[1-{ }^{14} \mathrm{C}\right]-$ labelled fatty acid $(0.1-3.0 \mu \mathrm{M} ; 130 \mathrm{dpm} / \mathrm{pmol})$, delipidated protein and buffer ( $10 \mathrm{mM}$ Tris-HCl, $\mathrm{pH} 8.0$ ) were mixed in $1.5 \mathrm{ml}$ polyethylene vials in a final volume of $0.4 \mathrm{ml}$. After incubation for $10 \mathrm{~min}$ at $37^{\circ} \mathrm{C}$ the mixtures were cooled on ice and $0.1 \mathrm{ml}$ ice-cold Lipidex 1000 suspension in $10 \mathrm{mM}$ Tris-HCl (pH 8.0) (1:1, $\mathrm{v} / \mathrm{v}$ ) was added to separate protein-bound and free fatty acids [164]. The amount of protein-bound fatty acid was calculated from the radioactivity in supernatant samples, obtained after a $30 \mathrm{~min}$ incubation at $0^{\circ} \mathrm{C}$. Fatty acid-binding parameters were obtained from Scatchard plot analysis of the binding data [265].

\subsection{IMMUNOCHEMICAL TECHNIQUES.}

Preparation of antisera.

New Zealand white rabbits were injected intracutaneously on the back at multiple sites with an emulsion of $1 \mathrm{ml} 10 \mathrm{mM}$ Tris$\mathrm{HCl}(\mathrm{pH}$ 8.0) containing $100 \mu \mathrm{g}$ FABP and $1 \mathrm{ml}$ Freunds complete adjuvant. At 3 -week intervals rabbits were boostered with the same amount of antigen, mixed with Freunds incomplete adjuvant. Blood samples for antibody titer determinations were collected every 3 weeks. Final exsanguination was performed by cardiac punction. Sera were isolated and stored at $-20^{\circ} \mathrm{C}$. IgG-fractions of the antisera were prepared with protein-A Sepharose as described by Goudswaard et al. [266].

Determination of antibody titers.

Aliquots of $50 \mu \mathrm{l}$ pure FABPs in $50 \mathrm{mM}$ sodium-carbonate ( $\mathrm{pH}$ $9.6)$ were coated onto the wells of a microtiter plate overnight at $20^{\circ} \mathrm{C}$. The wells were washed 5 times with PBS-Tween (5.4 mM Naphosphate/ 1.3 mM K-phosphate/ $150 \mathrm{mM} \mathrm{NaCl}$ (pH 7.4), 0.058 Tween20) and once with distilled water. Successive 2-fold dilutions of the antiserum (100 $\mu \mathrm{l}$ in PBS-Tween) were added and the plates were incubated for $1 \mathrm{~h}$ at $20^{\circ} \mathrm{C}$. The wells were washed as described above and $100 \mu \mathrm{l}$ of $1000 \mathrm{x}$ diluted peroxidase conjugated swine-anti rabbit IgG in PBS-Tween was added. After $1 \mathrm{~h}$ incubation $\left(\right.$ at $20^{\circ} \mathrm{C}$ ) the wells were washed again. The bound peroxidase was assessed with $100 \mu \mathrm{l}$ of a freshly prepared solution of 2.2 $\mathrm{mM}$ o-phenylene diamine/ $0.0128 \mathrm{H}_{2} \mathrm{O}_{2}$ in $100 \mathrm{mM}$ citrate/ $200 \mathrm{mM} \mathrm{K}-$ 
phosphate (pH 5.0). After incubation in the dark for $30 \mathrm{~min}$ at $20^{\circ} \mathrm{C}$ the reaction was stopped by addition of $50 \mu \mathrm{l} 12.58 \mathrm{H}_{2} \mathrm{SO}_{4}$. The product of the peroxidase reaction was determined at $492 \mathrm{~nm}$ with a Titertek Multiscan.

Antibody titers were defined as the reciprocal values of the serum dilution required to obtain 50 maximal reaction, determined from a semi-log plot of absorbance versus serum dilution. Maximum was obtained from wells incubated with 10-25x diluted antiserum, minimum from wells without serum.

ELISA for the quantitative measurement of FABPs.

standard curves (in triplicate) of 0-7 ng FABP and aliquots containing 1.25 or $0.625 \mu \mathrm{g}$ cytosolic protein/ml in $50 \mathrm{mM}$ sodiumcarbonate ( $\mathrm{pH} 9.6$ ) were coated on 96-well ELISA plates, overnight at $20^{\circ} \mathrm{C}(80 \mu \mathrm{l} /$ well). Samples were coated 8 -fold in both concentrations. IgG-fractions of the antisera were appropriately diluted in PBS-Tween to produce linear standard curves. The rest of the procedure was carried out as described above for titer determinations. The amount of immune-reactive protein in the samples was determined from standard curves, calculated by Iinear regression analysis.

3.6. ELECTROPHORESIS, ISOELECTRIC FOCUSING, AND WESTERN BLOTTING.

Polyacrylamide slabgel electrophoresis.

Polyacrylamide slab gel electrophoresis at pH 8.8 (4-20\% acrylamide gradient in $0.1 \% \mathrm{SDS}$ ) was performed according to the method of Laemmi [267, using a GE-2/4 Gel LS Electrophoresis Apparatus (Pharmacia Biotechnology International, Uppsala, Sweden). Slots were loaded with 1-50 $\mathrm{\mu g}$ of protein. Gels were fixed with methanol/ acetic acid/ water $(5: 1: 4 ;$ by vol.) and silver-stained according to the method of Morrisey [268].

Ultrathin-layer isoelectric focusing.

Native ultrathin-layer isoelectric focusing was performed on 58 polyacrylamide gels (100 x $200 \mathrm{~mm}, 0.3 \mathrm{~mm}$ thick). Gels, containing 2 \& Pharmalyte ampholines ( $\mathrm{pH} 3-10$ or 4-6.5), were prepared on silanized glass plates. Phosphoric acid ( 1 M) was used as anode solution and $I \mathrm{M} \mathrm{NaOH}$ as cathode solution. Protein samples $(1-10 \mu \mathrm{g})$ were subjected to focusing at $2500 \mathrm{~V}$ in a Desaga Mediphor Electrophoresis Apparatus. Gels were fixed overnight in trichloroacetic acid/ water (12:88; by vol.), con- 
taining 58 sulphosalicylic acid, and then washed twice for $20 \mathrm{~min}$ with ethanol/ acetic acid/ water (20:8:72; by vol.) and stained with $1.25 \%$ coomassie brilliant blue $\mathrm{R}-250$ in the same solution for $1 \mathrm{~h}$ at $70^{\circ} \mathrm{C}$. Gels were destained with ethanol/ acetic acid/ water (20:8:72; by vol.) for $1 \mathrm{~h}$ at $70^{\circ} \mathrm{C}$ and subsequently at room temperature until the background was clear. A calibration protein mixture (Pharmacia) was included for determination of pI values.

Western blotting.

Buffers for immunoblotting:

Transfer buffer: $25 \mathrm{mM}$ Tris/ $192 \mathrm{mM}$ glycine (pH 8.8)/ $20 \%(\mathrm{~V} / \mathrm{v})$ methanol.

Blocking solution: $10 \mathrm{mM}$ Tris-HCl/ $350 \mathrm{mM} \mathrm{NaCl}(\mathrm{pH} \mathrm{7.6)/}$

$3 \%(\mathrm{w} / \mathrm{v})$ bovine serum albumin.

Incubation buffer: $10 \mathrm{mM}$ Tris-HCl/ $150 \mathrm{mM} \mathrm{NaCl}(\mathrm{pH} \mathrm{7.6)/}$

$0.3 \%$ bovine serum albumin $(w / v) / 1 \%$ Triton $\mathrm{X}-100(\mathrm{v} / \mathrm{v}) / 0.5 \%$ Na-deoxycholate (w/v)/

$0.1 \%$ sodium dodecyl sulfate $(w / v)$.

PBS (phosphate buffered saline):

$5.4 \mathrm{mM}$ Na-phosphate/ $1.3 \mathrm{mM} \mathrm{K}$-phosphate/ $150 \mathrm{mM} \mathrm{NaCl}$ (pH 7.4).

PBS-Triton: $\quad 5.4 \mathrm{mM} \mathrm{Na-phosphate/} 1.3 \mathrm{mM} \mathrm{K}$-phosphate/ $150 \mathrm{mM} \mathrm{NaCl}(\mathrm{pH} \mathrm{7.4)}, 0.5 \%$ Triton $\mathrm{X}-100(\mathrm{v} / \mathrm{v})$

Substrate solution: 4-chloro-1-naphthol $(0.5 \mathrm{mg} / \mathrm{ml}) / 0.012 \% \mathrm{H}_{2} \mathrm{O}_{2}$

Blotting of proteins from SDS-polyacrylamide slabgels to nitrocellulose paper and immunodetection of antigens was carried out essentially as described by Towbin et al. [269]. Proteins were transferred electrophoretically to nitrocellulose in transfer buffer, using a $12 \mathrm{~V}$ car-battery charger as power supply. Blotting was performed overnight at approximately $80 \mathrm{~mA}$ at $20^{\circ} \mathrm{C}$. Immediately after blotting the nitrocellulose sheets were dried. For immunostaining the blots were first saturated by incubation for $1 \mathrm{~h}$ in blocking solution. Blots were then incubated for $2 \mathrm{~h}$ with antiserum diluted in incubation buffer. After washing twice with incubation buffer and once with PBS-Triton the nitrocellulose filters were incubated with peroxidase-conjugated goat-anti rabbit IgG $[250 \mathrm{x}$ diluted in PBS-Triton, containing $0.5 \%(\mathrm{w} / \mathrm{v})$ bovine serum albumin] for $1 \mathrm{~h}$. The blots were subsequently washed twice with incubation buffer and once with PBS. Antigens were detected by incubation of the bound peroxidase with substrate solution. 
Radioactivity measurements.

Radioactive samples were counted in a Tricarb 4000 series liquid scintillation counter (Packard Instruments), using Aqualuma plus liquid scintillation cocktail (Lumac/3M, Schaesberg, The Netherlands).

Protein determinations.

For protein quantification the method of Lowry et al. [270] was used, if necessary after precipitation of the protein with trichloroacetic acid $[271]$. Bovine serum albumin was used as standard. In case of pure FABPs, protein concentration was calculated from quantitative amino acid analysis, since the Lowry procedure gave an overestimation, dependent on the type of FABP.

Statistical comparison of data.

statistical significance of differences were calculated by student's unpaired t-test. Values are given as mean \pm SD. 


\subsection{INTRODUCTION.}

The first evidence for the presence of FABP in rat heart was based on coelution of protein samples with radiolabelled fatty acids on a gel filtration column $[74,3]$. The protein was first isolated from rat and pig heart by Fournier and co-workers $[88,192]$. Rat heart FABP later has been isolated and characterized by several authors $[85,86,154]$. Unterberg et al. (97) recently published a paper on human heart FABP. These isolations were all based on the coelution method, except the purification of rat heart and liver FABP by Glatz et al. (BS), where a radiochemical binding assay was used to monitor the purification. This assay applies Lipidex 1000 at $0^{\circ} \mathrm{C}$ to separate free and protein-bound fatty acids after equilibration at $37^{\circ} \mathrm{C}$ [164]. Affinity of the gel filtration matrix and of other proteins present in the sample (e.g. albumin) for fatty acids may lead to competition for the available ligand in the coelution procedure. This problem is prevented when the binding assay is used to locate fatty acidbinding activity in samples after each purification step.

In rat heart, FABP may comprise up to $4 \mathrm{nmol} / \mathrm{mg}$ of cytosolic protein $[151,158,164]$. Fournier et al. [88] and Glatz et al. [26] demonstrated the ability of heart FABP to deliver fatty acids to the mitochondrial B-oxidation system, supporting the view that FABP plays an important role in intracellular translocation of fatty acids. In heart, FABP may also act as an intracellular storage pool of fatty acids and protect the cell against the detrimental effects of long-chain fatty acids and acyl-COA esters, as occur during ischemia and hypoxia. The precise function of FABP in

\footnotetext{
- This chapter was adapted from Paulussen et al., 1988 [84].
} 
lipid metabolism however, remains to be established. A systematic investigation of the protein-ligand interaction and of the preferential ligand population may provide clues in this respect for the various types of FABP.

Quantitative binding data of fatty acids to heart FABPs are only available for rat heart FABP, with oleic and palmitic acid and their COA esters $[85,86]$. With bovine and human heart FABP, only some qualitative results were given for the binding of fatty acids $[96,97,177)$, and some data with respect to fluorescent fatty acids $[17,272]$. The binding of other ligands, except for lysophosphatidylcholine to heart FABP [196], has never been studied to our knowledge.

The homology of heart FABPs can be studied by immunochemical analyses. An antiserum against bovine heart FABP showed crossreactivity with human heart FABP, and with cytosols of pig and rat heart [97]. Preparation of FABPs from various tissues and from various species, and more antisera may provide more insight in this respect.

In this chapter the purification and physico-chemical characterization of FABPs from heart of man, pig and rat are described. Their affinity for fatty acids, CoA-esters and other hydrophobic ligands was studied. With purified FABPs specific antisera were raised, which were used to determine immunological cross-reactivity. The effect of the IgG fraction of anti-human heart FABP serum on fatty acid binding was investigated.

\subsection{METHODS.}

Purification of fatty acid-binding protein.

All purification steps were performed at $4^{\circ} \mathrm{C}$. An amount of 500-600 $\mathrm{mg}$ cytosolic protein was concentrated to $8 \mathrm{ml}$ by ultrafiltration on a Diaflo YM-2 membrane (Amicon Corp., Lexington, USA). After precipitation of denaturated protein by centrifugation at $10,000 \times \mathrm{g}$ for $10 \mathrm{~min}$, the material was applied to a Sephacryl s-200 gel filtration column $(2.6 \times 110 \mathrm{~cm})$ equilibrated in $30 \mathrm{mM}$ Tris-HCl (pH 8.0). During the chromatography procedures protein was located by measurement of the absorbance at $280 \mathrm{~nm}$, and $5 \mathrm{ml}$ fractions were collected at a $40 \mathrm{ml} / \mathrm{h}$ flow rate. Samples of the fractions were assayed for fatty acid-binding activity. The activity-containing fractions in the 10-20 $\mathrm{kDa}$ range were combined and dialysed overnight against $5 \mathrm{mM}$ Tris-HCl (pH 8.4). 
The dialysed protein solution was then loaded onto a DE-32 cellulose anion-exchange column $(2.5 \times 8 \mathrm{~cm})$ equilibrated in the same buffer. Bound protein was eluted stepwise (flow $36 \mathrm{ml} / \mathrm{h}$ ) with 15,30 and $50 \mathrm{mM} \mathrm{Tris}-\mathrm{HCl}(\mathrm{pH} 8.0)$, followed by a gradient of 0-300 $\mathrm{mM} \mathrm{KCl}$ in the latter buffer, and fractions of $9 \mathrm{ml}$ were obtained. Finally, the columns were washed free of remaining proteins with $1 \mathrm{M} \mathrm{KCl}$.

Fatty acid-binding activity measurements.

Determination of fatty acid-binding activity was performed as described in section 3.4. Column fractions were routinely tested at a concentration of $1 \mu \mathrm{M}$ fatty acid. Specific binding activities at the subsequent stages of the purification procedure were measured with a range of 0.1-10 $\mu \mathrm{M}$ fatty acid, after delipidation (and dealbuminization in case of cytosolic proteins).

Competition assays in the presence of heme, retinol or retinoic acid contained $0.06 \%$ Ammonyx-LO. This detergent was also included in the control incubations of these experiments. Concentrations of $\left[{ }^{14} \mathrm{C}\right]$ oleic acid and of competitive ligands used in these experiments are given in Tables 4.4 and 4.5 .

Binding of fatty acids from liposomes.

Binding of fatty acids using liposomes as donors was determined as described by Brecher et al. [273]. Different amounts of multilamellar liposomes, containing egg phosphatidylcholine, cholesterol and $\left[{ }^{14} \mathrm{C}\right]$ oleic acid $(20: 7: 1)$ were incubated in $10 \mathrm{mM}$ Tris- $\mathrm{HCl} / 100 \mathrm{mM} \mathrm{NaCl}(\mathrm{pH} 7.4)$ for $60 \mathrm{~min}$ at $25^{\circ} \mathrm{C}$ with FABP or bovine serum albumin in a total volume of $150 \mu \mathrm{l}$. Liposomes were precipitated by centrifugation ( $3 \mathrm{~min}, 15,000 \mathrm{xg}$ ) and the amount of protein-bound fatty acids was determined from the radioactivity in the supernatant (specific activity of the $\left[{ }^{14} \mathrm{C}\right.$ ) oleic acid was $3300 \mathrm{dpm} / \mathrm{nmol})$. Using $\left[{ }^{14} \mathrm{C}\right]$ oleic acid and $\left[{ }^{3} \mathrm{H}\right] \mathrm{cho}$ esterol double-labelled liposomes, precipitation was shown to be almost complete (over 96\%).

Electrophoretic techniques.

Slabgel electrophoresis.

Polyacrylamide slabgel electrophoresis was performed at $\mathrm{pH}$ 8.8 on a 4-20\% acrylamide gradient in $0.1 \%$ SDS. Gels were fixed with methanol/acetic acid/water (5:1:4; by vol.) and silverstained according to the method of Morrisey (268). 
Isoelectric focusing.

Native ultrathin-layer isoelectric focusing was performed on $5 \%$ polyacrylamide gels $(0.3 \mathrm{~mm}$ thick), containing $2 \%$ Pharmalyte ampholines ( $\mathrm{pH} 3-10$ or 4-6.5). Phosphoric acid (1 M) was used as anode solution and $1 \mathrm{M} \mathrm{NaOH}$ as cathode solution. After focusing of the protein samples $(1-10 \mu \mathrm{g})$ at $2500 \mathrm{~V}$, the gels were fixed overnight and stained with Coomassie brilliant blue R250. pI values were determined from a calibration protein mixture (Pharmacia) that was included. For more details see section 3.6.

Amino acid analysis.

Samples of FABPs were hydrolysed with $6 \mathrm{M} \mathrm{HCl}$ (containing $0.05 \%$ phenol) for $24 \mathrm{~h}$ at $105^{\circ} \mathrm{C}$ and analyzed on a Rank Hilger Chromaspek analyzer in Na-citrate buffer, using norleucine as internal standard. Tryptophan and tyrosine were determined spectrophotometrically as described by Edelhoch [274].

Immunochemical procedures.

Preparation of antisera.

New zealand white rabbits were injected subcutaneously at multiple sites on the back with $100 \mu \mathrm{g}$ FABP in $1 \mathrm{ml}$ buffer $\mathrm{D}$, mixed with $1 \mathrm{ml}$ complete Freund's adjuvant. The rabbits were given subcutaneous booster injections $(100 \mu \mathrm{g}$ in $1 \mathrm{ml}$, mixed with $1 \mathrm{ml}$ incomplete Freund's adjuvant) at 3 week-intervals until sufficiently high titers were obtained. Titers were determined in an enzyme-linked immunosorbent assay (ELISA), that was performed essentially as described by Hudson and Hay [264]. A detailed description of the procedure is given in section 3.5. The IgG fraction of the antiserum was isolated with Protein A-Sepharose CL-4B, as described by Goudswaard et al. [266].

Inhibition of fatty acid binding by anti-FABP IgG.

Inhibition of fatty acid binding to human heart FABP was studied as described for non-specific lipid transfer protein [150], with some modifications. Delipidated FABP $(1.5 \mu \mathrm{g})$ was incubated in $300 \mathrm{HI} 10 \mathrm{mM}$ Tris-HCl (pH 8.0) in the presence of $2.5 \mathrm{mg}$ lysozyme and different IgG concentrations (from either pre-immune or anti-human heart FABP serum) for $30 \mathrm{~min}$ at $37^{\circ} \mathrm{C}$. Lysozyme was used as inert protein instead of albumin [182], because of the fatty acid-binding properties of the latter. After I $\mathrm{h}$ at $0^{\circ} \mathrm{C},\left[{ }^{14} \mathrm{C}\right]$ oleic acid binding was determined as described in section 3.4 . 


\section{Purification of heart FABPs.}

FABP was purified from the cytosol of heart of man, pig and rat by gel filtration and subsequent anion-exchange chromatography. Fig. 4.1 shows the binding of $\left[1-{ }^{14} \mathrm{c}\right]$ oleic acid to proteins of $105,000 \times \mathrm{g}$ supernatant of human heart muscle after gel filtration on sephacryl s-200. The first peak showing fatty acid-binding activity corresponds to a molecular mass of more then $60 \mathrm{kDa}$ and contains serum albumin. The second fatty acid binding peak, with a molecular mass of 10-20 kDa, represents FABP. Only this protein peak is reactive with a specific antiserum to human heart FABP. Gel filtration of pig and rat heart $105,000 \times \mathrm{g}$ supernatant on Sephacryl s-200 gave comparable results. Application of the same method as described for rat heart FABP [85], using DEAE-Sephacel anion-exchange chromatography and a second gel filtration step on sephadex G-50 yielded FABP preparations that always contained myoglobin and some other minor proteins. Variation of the $\mathrm{pH}$ of the buffer did not lead to better results. Pure FABPs were obtained with anion-exchange chromatography on DEAE-cellulose, starting at pH 8.4 with a low ionic strength buffer and eluting at $\mathrm{pH} 8.0$ by an increase of the ionic strength (Fig. 4.2). The fractions of the Sephacryl S-200

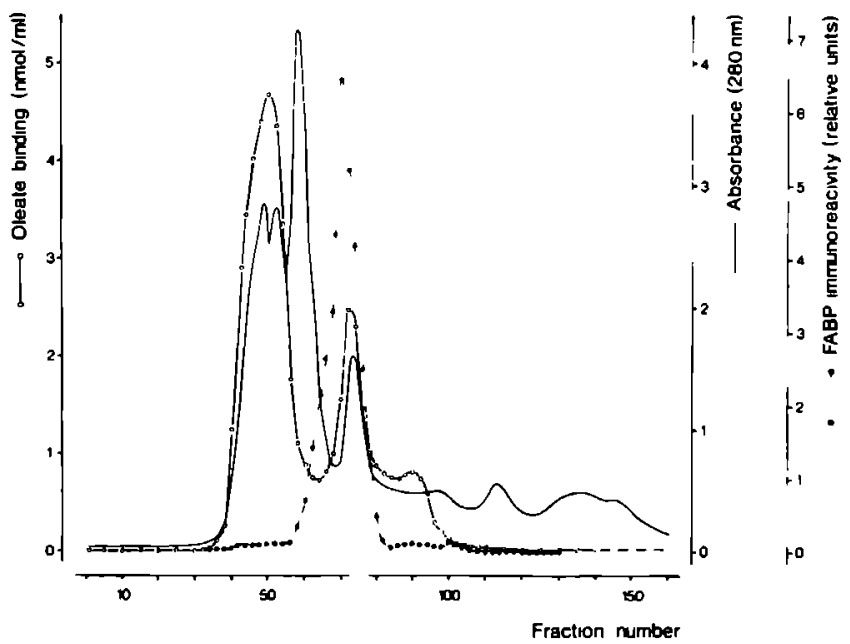

Fig. 4.1. Gel filtration of $8 \mathrm{ml}$ concentrated human heart 105,000 $\times \mathrm{g}$ supernatant, containing $582 \mathrm{mg}$ protein, on Sephecryl s-200 $(2.6 \times 100 \mathrm{~cm})$. The colum was eluted with $30 \mathrm{mH}$ Tris-HCl (pH 8.0) at $4^{\circ} \mathrm{C}$. The flow rate was $40 \mathrm{ml} / \mathrm{h}$ and $5 \mathrm{ml}$ fractions were collected. Fractions were assayed for protein $(-), c^{14} \mathrm{c}$ oleic acid binding (100 $\mathrm{\mu l}$ samples) $(0-0)$ and immunological reactivity with ant $i$-human heart faBp serum (1 $\mu \mathrm{g}$ protein) (0-0). 
column containing FABP were dialysed against $5 \mathrm{mM}$ Tris-HCl (pH 8.4) and applied to the DEAE-cellulose anion-exchange column. Adsorbed proteins were eluted stepwise with increasing Tris concentration at $\mathrm{pH}$ 8.0. Myoglobin was present in the fraction eluted with $15 \mathrm{mM} \mathrm{Tr}$ is- $\mathrm{HCl}$ ( $\mathrm{pH} 8.0$ ), due to its higher pI. Human heart FABP eluted as a single peak with $30 \mathrm{mM}$. The same procedure
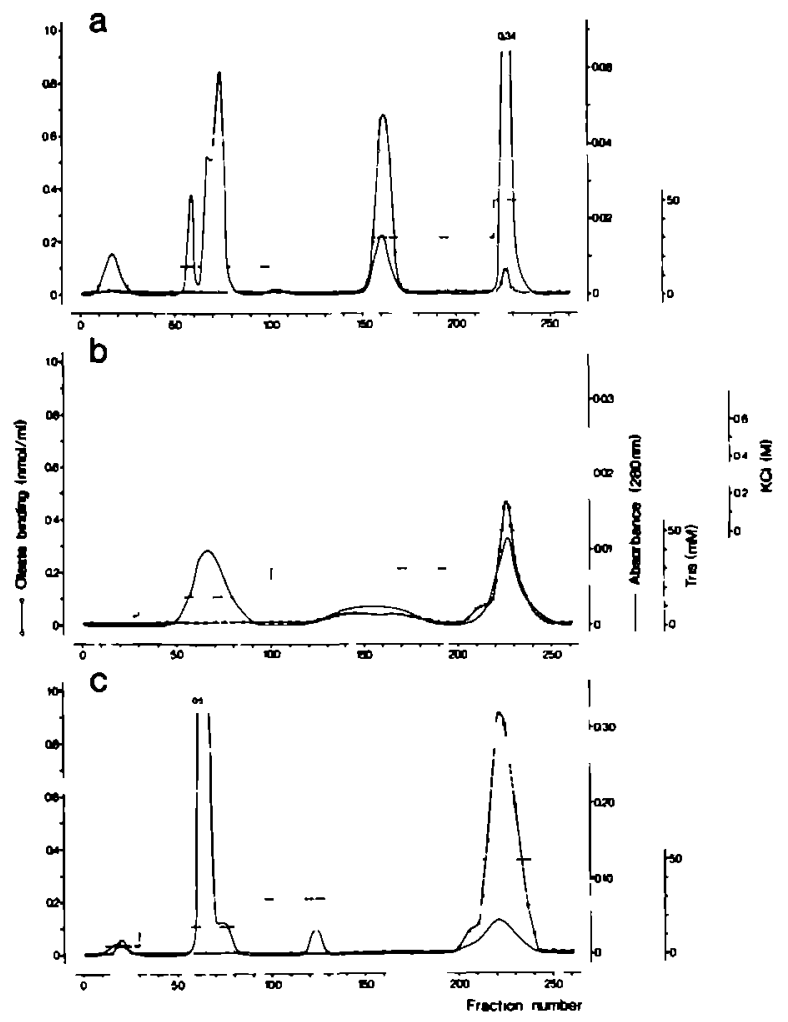

Fig. 4.2. Anion-exchange chronatography of the combined FABP-containing fractions of the Sephacryl S-200 colum on DEAE-cellul ose (DE-32). The FABP-containing frections were dialysed overnight against $5 \mathrm{mH}$ Trig-HCl (PH 8.4) and laoded onto a DE-32 column (2.5 $\times 8 \mathrm{~cm}$ ) equilibrated in the sane buffer. Fractions of $9 \mathrm{ml}$ were collected ot $136 \mathrm{ml} / \mathrm{h}$ flow rate. Panel a: human heart; panel b: pis heart and ponel c: rat heart. Band protein wae eluted etepulse with 15, 30 and 50 Mt Tris-HCL (PH 8.0) (- - -). Pig heart FABP was eluted with a linear KCl gradient (....) in 50 mit Irls-HCl (pH, B.0). Protein was monitored at $280 \mathrm{~mm}(\longrightarrow)$ and $300 \mu \mathrm{l}$ samples were assayed for $\left[{ }^{14} \mathrm{C}\right]$ oleic ocid binding $(0-0)$. 
Table 4.1.

Purification of FABP from heart.

\begin{tabular}{|c|c|c|c|c|c|}
\hline & Purification step & $\begin{array}{l}\text { Protein } \\
\text { (mg) }\end{array}$ & $\begin{array}{l}\text { Specific bigding } \\
\text { octivity } \\
\text { (nnol/mag) }\end{array}$ & $\begin{array}{l}\text { Yield } \\
(x)\end{array}$ & $\begin{array}{r}\text { Purification } \\
\text { (-fold) }\end{array}$ \\
\hline Man & $\begin{array}{l}105,000 \times \text { g supernatant } \\
\text { Sephacryl s-200 } \\
\text { DEAE-cellul ose }\end{array}$ & $\begin{array}{l}582 \\
4.8 \\
3.1^{d}\end{array}$ & $\begin{array}{r}1.7 \\
5.0 \\
30.7\end{array}$ & $\begin{array}{r}100 \\
22.6 \\
9.6\end{array}$ & $\begin{array}{r}1.0 \\
2.9 \\
18.1\end{array}$ \\
\hline Pig & $\begin{array}{l}105,000 \times \text { g supernatant } \\
\text { Sephacryl s- } 200 \\
\text { DEAE-cellulose }\end{array}$ & $\begin{array}{l}460 \\
54.6 \mathrm{~d} \\
4.6 \mathrm{~d}\end{array}$ & $\begin{array}{l}1.1^{c} \\
3.7 \\
12.1\end{array}$ & $\begin{array}{l}100 \\
39.9 \\
11.0\end{array}$ & $\begin{array}{r}1.0 \\
3.4 \\
11.0\end{array}$ \\
\hline Rat & $\begin{array}{l}105,000 \times \text { g supernatent } \\
\text { Sephacryl s-200 } \\
\text { DEAE-cell lul ose }\end{array}$ & $\begin{array}{r}536 \\
64.4 \\
3.4^{d}\end{array}$ & $\begin{array}{r}1.8^{c} \\
3.7 \\
27.3 \\
\end{array}$ & $\begin{array}{l}100 \\
24.7 \\
9.6\end{array}$ & $\begin{array}{r}1.0 \\
2.1 \\
15.2 \\
\end{array}$ \\
\hline
\end{tabular}

Determined by the method of Lowry et ol. [270].

b Measured with 1 mM $\left[9-{ }^{2} \mathrm{C}\right.$ oleic acid at $37^{\circ} \mathrm{C}$, with delipidated protein samples.

Determined after dealbuminization.

Determined from quantitative amino acid anslysis.

was applied for the purification of FABPs from pig and rat heart. Rat heart FABP eluted with $50 \mathrm{mM}$ Tris and pig heart FABP was released from the column at nearly $200 \mathrm{mM} \mathrm{KCl}$ in the latter buffer. Representative results of the purification procedures are summarized in Table 4.1. The yield of the FABPs was about $10 \%$.

Characterization of heart FABPs.

Protein samples from different stages of the purification procedures were subjected to polyacrylamide gel electrophoresis in SDS. The purified FABPs obtained after DEAE-cellulose anionexchange chromatography contain single protein bands with an estimated molecular mass of 15,000 Da for rat and pig heart FABP and 15,500 Da for human heart FABP (Fig. 4.3).

Isoelectric focusing of these proteins on ultrathin-layer polyacrylamide gels revealed one band with an isoelectric point of 5.2, 4.9 and 5.0 for human, pig and rat heart FABP, respectively. These isoelectric points agree with the behaviour of the proteins on the DEAE-cellulose anion-exchanger. The discrepancy with the previously reported values of 7.0 [85] and 5.5-5.8 (B6) for rat heart FABP may be due to the presence of urea during those isoelectric focusing studies. Delipidation had no effect on the observed isoelectric points, as was also observed for bovine heart FABP [96]. 


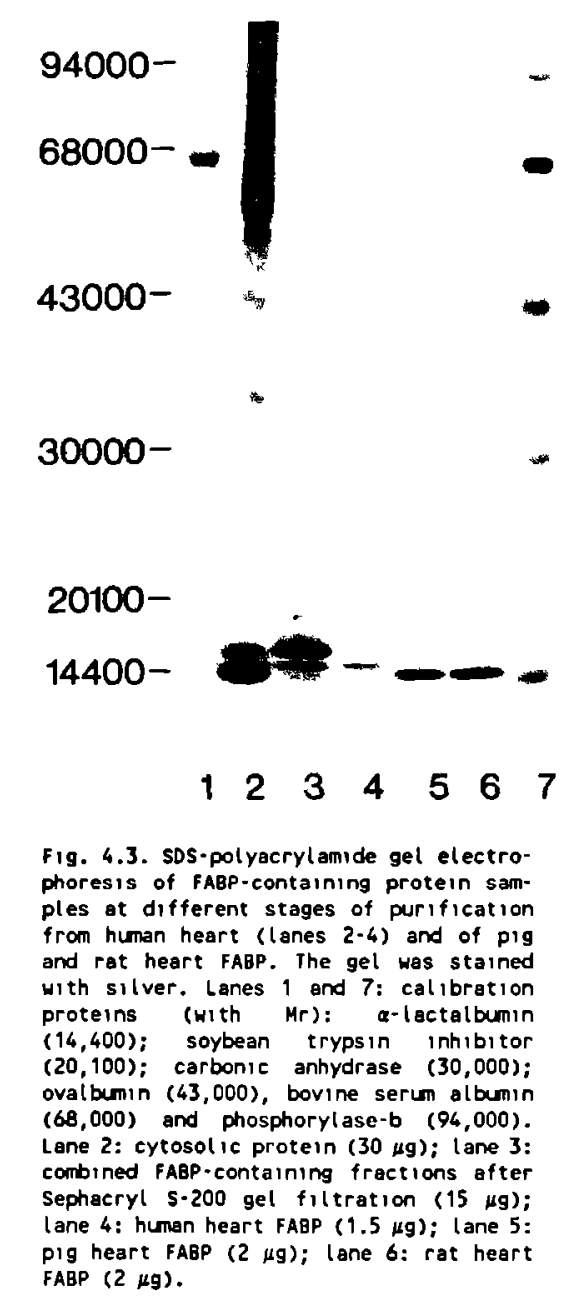

The purity of the FABP preparations could also be concluded from the specific reaction with FABP that was observed on blots of cytosolic protein preparations immunostained with antisera raised against these FABPs.

The amino acid composition of the FABPs was derived from acid-hydrolysed samples. Tryptophan and tyrosine were determined spectrophotometrically. Tyrosine values obtained in this way corresponded with the values found by amino acid analysis. The overall amino acid composition of the heart FABPs of the three species shows many similarities, as the presence of tryptophan and the absence of cysteine (Table 4.2). Pig heart FABP however contains relatively more proline, alanine, glutamic acid (+ glutamine) and tryptophan, and less threonine and lysine than the human and rat proteins. The amino acid composition of rat heart FABP closely correlates with earlier reports 185 , 86,110], that of human heart FABP differs from previous data [97] by a higher glutamine (and glutamic acid) content, a lower number of lysines and the absence of cysteine. Data on the amino acid composition of pig heart FABP have not been published earlier. Bovine heart FABP mostly resembles human and rat heart FABP in its amino acid composition, but was shown to contain cysteine [96].

As was reported before $[85,86]$, the method of Lowry et al. (270) is not accurate for determination of the protein mass of the purified FABPs. Quantitative amino acid analysis showed that concentrations determined by the Lowry method were 1.2-1.4 times too high. 
Binding characteristics of heart FABPs.

Table 4.2.

Binding parameters for different long-chain fatty acids and fatty acyl-esters were obtained from scatchard plot analysis of binding isotherms at $37^{\circ} \mathrm{C}$. Fixed amounts of purified, delipidated FABP were incubated with fatty acid concentrations of $0.1-3 \mu \mathrm{M}$. Binding characteristics were comparable for all heart FABPs investigated (Table 4.3). The highest binding capacities were observed for oleic and palmitic acid. Myristic acid, arachidonic acid, palmitoylcoenzyme $A$ and palmitoyl-carAmino acid composition of heart fatty acidbinding proteins.

\begin{tabular}{lrrr}
\hline $\begin{array}{l}\text { Amino } \\
\text { acid }\end{array}$ & \multicolumn{1}{c}{ Man } & Pig & Rat \\
\hline Asx & $108 \pm 4$ & $105 \pm 7$ & $119 \pm 2$ \\
Thr & $127 \pm 10$ & $54 \pm 2$ & $134 \pm 9$ \\
Ser & $54 \pm 5$ & $60 \pm 3$ & $66 \pm 6$ \\
Glx & $102 \pm 5$ & $130 \pm 3$ & $102 \pm 6$ \\
Pro & $18 \pm 4$ & $45 \pm 1$ & $11 \pm 1$ \\
Gly & $84 \pm 1$ & $81 \pm 10$ & $93 \pm 9$ \\
Alo & $57 \pm 3$ & $85 \pm 6$ & $56 \pm 3$ \\
Cys & $0 \pm$ & 0 & 0 \\
Val & $63 \pm 4$ & $62 \pm 6$ & $79 \pm 5$ \\
Met & $17 \pm 4$ & $12 \pm 5$ & $10 \pm 2$ \\
Ile & $33 \pm 6$ & $27 \pm 5$ & $36 \pm 4$ \\
Leu & $104 \pm 3$ & $95 \pm 7$ & $74 \pm 4$ \\
Tyr & $16 \pm 1$ & $24 \pm 3$ & $15 \pm 3$ \\
Phe & $46 \pm 4$ & $44 \pm 7$ & $44 \pm 4$ \\
Trp & $9 \pm 1$ & $34 \pm 1$ & $12 \pm 1$ \\
His & $25 \pm 3$ & $28 \pm 3$ & $28 \pm 5$ \\
Lys & $107 \pm 8$ & $76 \pm 3$ & $95 \pm 7$ \\
Arg & $32 \pm 2$ & $38 \pm 2$ & $27 \pm 7$ \\
\hline
\end{tabular}

a Values are means \pm S.D. of three preparations and given in residues $/ 1000$ amino acid residues.

nitine were bound to a lesser extent. Binding affinities for palmitoyl-coenzyme $A$ and -carnitine were comparable to that for palmitic acid. No marked influence of $\mathrm{pH}$ was observed on binding of oleic or palmitic acid in the range of $\mathrm{pH} 6.5-9.0$.

Affinity of human heart FABP for different fatty acids and fatty acid derivatives was also assessed by measuring inhibition of the binding of $\left[{ }^{14} \mathrm{C}\right]$ oleic acid. Total ligand concentration was kept at $1 \mu \mathrm{M}$ (Table 4.4). In a control experiment no ligand was added to determine the effect of a decrease of the oleic acid concentration. Human heart FABP exhibits the highest affinity for fatty acids of 18 carbon atoms and longer, preferring the unsaturated types. Palmitic and stearic acid take intermediate positions, whereas fatty acids of shorter chain-length and CoA and carnitine esters of palmitic acid do not compete well with oleic acid.

The effect of other hydrophobic ligands on $\left[{ }^{14} \mathrm{C}\right]$ oleic acid binding was determined in a second series of competition studies (Table 4.5). Increasing concentrations of unlabelled ligands were added. Heme, bilirubin and prostaglandin $E_{1}$, that were reported to bind to liver FABP $[25,98,190,194,195]$, could not effectively inhibit oleic acid binding by heart FABP, neither could three other prostaglandins, cholesterol, retinol or retinoic acid. 
Table 4.3.

Binding parameters for long-chain fotty acids and acyl-esters.

\begin{tabular}{|c|c|c|c|c|c|c|}
\hline \multirow[b]{2}{*}{ Fatty acid } & \multicolumn{2}{|c|}{ Man } & \multicolumn{2}{|c|}{ Pig } & \multicolumn{2}{|c|}{ Rat } \\
\hline & $\begin{array}{c}\text { Bmex } \\
(\mathrm{mmol} / \mathrm{mg})\end{array}$ & $\begin{array}{c}\text { Apporent Kd } \\
(\mu M)\end{array}$ & $\begin{array}{l}\text { Bmax } \\
(\mathrm{nmol} / \mathrm{mg})\end{array}$ & $\begin{array}{c}\text { Apparent Kd } \\
(\mu H)\end{array}$ & $\begin{array}{l}\theta \max \\
(\operatorname{mmol} / / m g)\end{array}$ & $\begin{array}{c}\text { Apparent Kd } \\
(\mu g)\end{array}$ \\
\hline Myristic ocid & $5.62 \pm 1.18$ & $0.88 \pm 0.41$ & $12.98 \pm 0.41$ & $1.81: 0.16$ & $13.22 \pm 6.11$ & $0.95 \div 0.22$ \\
\hline Palmitic acid & $26.71 \times 3.40$ & $0.60 \pm 0.26$ & $23.40 \pm 3.00$ & $1.26 \pm 0.40$ & $22.15 \pm 5.95$ & $0.78 \div 0.16$ \\
\hline Oleic acid & $30.00 \times 2.44$ & $0.20 \pm 0.05$ & $22.68 \div 2.16$ & $0.43 \pm 0.09$ & $29.03 \pm 4.34$ & $0.38 \div 0.11$ \\
\hline Arachidonic acid & $18.04 \div 2.13$ & $0.17 \pm 0.04$ & $14.38 \pm 3.41$ & $0.24 \pm 0.03$ & $18.05 \pm 3.39$ & $0.16 \div 0.04$ \\
\hline Palmi toyl-coenzyme A & $19.43 \pm 2.37$ & $0.50 \pm 0.13$ & \multicolumn{2}{|c|}{ N.D. } & $20.49 \pm 5.28$ & $0.51 \pm 0.04$ \\
\hline Palmitoyl-carnitine & $12.98 \pm 0.98$ & $0.42 \pm 0.34$ & \multicolumn{2}{|c|}{ N.D. } & $11.22 \pm 3.13$ & $0.59 \div 0.24$ \\
\hline
\end{tabular}

W.D. = not determined.

Data are derived from Scatchard plot analysis of binding isotherms at $37^{\circ} \mathrm{C}$. Per assay 1.5-2.5 $\mu \mathrm{g}$ del ipidated protein (based on quantitative amino acid analysis) was used. Values are means \pm so of 3-5 experiments. 
Table 4.4.

Effect of fatty Bcids and derivatives on $\left[^{14} \mathrm{C}\right.$ olele acid binding to human heart FABP.

\begin{tabular}{llccc}
\hline${ }^{14}$ cjoleic acid & $(\mu M)$ & 0.8 & 0.5 & 0.2 \\
Competitor & $(\mu M)$ & 0.2 & 0.5 & 0.8 \\
\hline Hone & & $93 \pm 4$ & $78 \pm 9$ & $57 \pm 6$ \\
& & & & \\
Oleic acid (control) & $(c 18: 1)$ & $72 \pm 11$ & $42 \pm 6$ & $17 \pm 4$ \\
Lauric acid & $(c 12: 0)$ & $84 \pm 7$ & $73 \pm 6$ & $40 \pm 7$ \\
Myristic acid & $(c 14: 0)$ & $93 \pm 14$ & $79 \pm 15$ & $41 \pm 10$ \\
Palmitic acid & $(c 16: 0)$ & $88 \pm 12$ & $68 \pm 7$ & $29 \pm 7$ \\
stearic acid & $(c 18: 0)$ & $89 \pm 6$ & $64 \pm 9$ & $30 \pm 9$ \\
Linoleic acid & $(C 18: 2)$ & $78 \pm 7$ & $48 \pm 7$ & $23 \pm 5$ \\
Arachidonic acid & $(c 20: 4)$ & $84 \pm 10$ & $47 \pm 3$ & $26 \pm 14$ \\
Erucic acid & $(c 22: 1)$ & $89 \pm 9$ & $54 \pm 16$ & $24 \pm 8$ \\
Palmitoyl-coA & & $86 \pm 12$ & $71 \pm 6$ & $49 \pm 9$ \\
Palmitoyl-carnitine & & $70 \pm 8$ & $58 \pm 14$ & $52 \pm 7$ \\
\hline
\end{tabular}

Incubation vials contained $5 \mu \mathrm{g} / \mathrm{ml}$ delipidated FABP and total fatty acid concentration of $1 \mu \mathrm{M}$. Values are given as percentage of the binding at $1 \mu \mathrm{M}\left[^{14} \mathrm{cjoleic}\right.$ acid and represent means \pm SD of at least 3 exper iments.

Addition of $\mathrm{Mg}^{2+}$ had no effect on the binding to human heart FABP of either oleic and palmitic acid or competition of prostaglandins with oleic acid, in contrast to observations with rat liver FABP [190]. Flavaspidic acid, an inhibitor of fatty acid binding to hepatic FABP [199], also decreased oleic acid binding to heart FABP, but to a lesser extent.

Binding of fatty acid by FABP from multilamellar liposomes.

When incubated with $\left[{ }^{14} \mathrm{C}\right]$ oleic acid-containing liposomes, human heart FABP takes up fatty acids from the membranes. The maximal fatty acid binding was slightly dependent on protein concentration, but did not exceed $0.7 \mathrm{~mol} / \mathrm{mol}$ FABP (Fig. 4.4), indicating the presence of only one fatty acid-binding site per FABP molecule. Calculation of binding parameters from the data obtained with fatty acid concentrations up to $5 \mu \mathrm{M}$ using Scatchard plot analysis gave $K d$ values similar to those obtained with the Lipidex binding assay $(0.5-1.0 \mu \mathrm{M})$. Incubation of bovine serum albumin with these liposomes resulted in a $5 \mathrm{~mol} / \mathrm{mol}$ binding ratio (insert Fig. 4.4). 


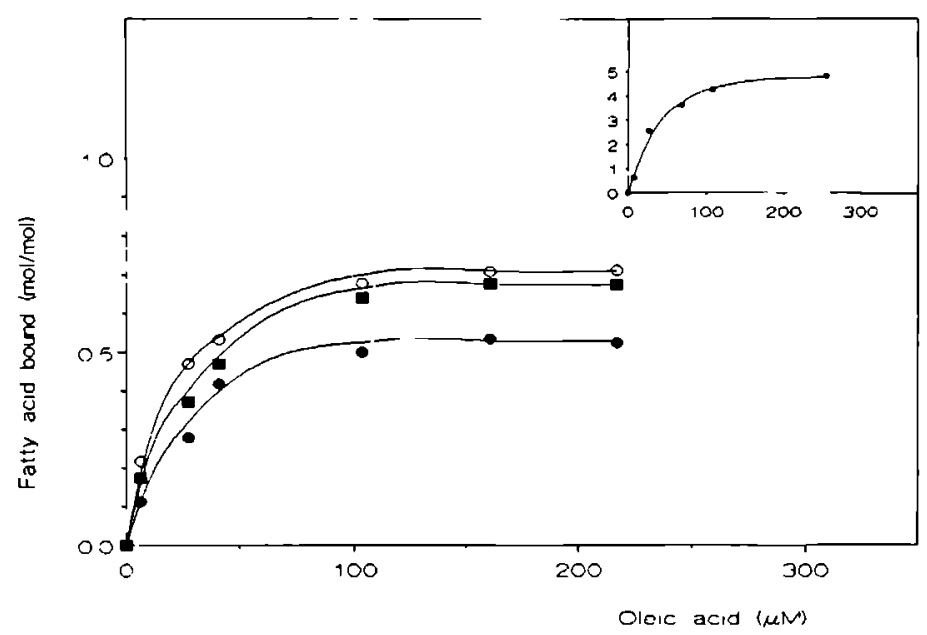

Fig. 4.4. Binding of $\left[{ }^{14} \mathrm{C}\right]$ oleic acid by human heart FABP from liposomes. Different concentrations of protein were incubated with increasing amounts of $\left[{ }^{14} \mathrm{C}\right]$ oleic acid containing phosphatidylchol ine liposomes for $1 \mathrm{~h}$ at $25^{\circ} \mathrm{C}$. Liposomes were spun down and binding of oleic acid to FABP was determined from the amount of radioactivity present in the supernatant. FABP concentrations: $(0-0) 5.6 \mu \mathrm{M} ;(10-11.3 \mu \mathrm{M} ;(0-0) 22.5$

$\mu M$. Insert: binding of oleic acid by 5 MM bovine serum albumin.

Immunological relationship of FABPs.

The heart FABPs of the three species were examined for cross-reactivity with specific anti-FABP sera. On immunoblots of cytosolic proteins the antisera only reacted with FABP. The immunological cross-reactivity was determined in ELISA as the serum dilution at which half maximal binding occurred and expressed as a percentage of the reaction of an antigen with its specific antiserum. Antiserum to human heart FABP reacted with human and pig heart FABP; the antiserum directed against pig heart FABP showed a similar cross-reactivity (Table 4.6). Both antisera gave a weak cross-reaction with rat heart FABP. Anti-rat heart FABP serum only reacted strongly with rat heart FABP. None of the antisera reacted with liver FABP of man, pig or rat, purified as described (85]. Antiserum to rat liver FABP did not react with heart FABP of the three species either.

Inhibition of oleic acid binding to FABP by specific antibodies.

Binding of $\left[{ }^{14} \mathrm{C}\right]$ oleic acid to human heart FABP could be inhibited by preincubation of the protein with the IgG fraction 
Table 4.5.

Effect of various possible ligands on $\left[1{ }^{-14} \mathrm{C}\right]$ olele acid binding to human heart fABP.

\begin{tabular}{|c|c|c|c|c|}
\hline \multirow{3}{*}{ Competitor } & & \multicolumn{3}{|c|}{ Concentration of competitor $(\mu \mathrm{M})$} \\
\hline & & \multirow[t]{2}{*}{1.0} & \multirow[t]{2}{*}{2.0} & \multirow[t]{2}{*}{4.0} \\
\hline & & & & \\
\hline oleic acid & & $75 \pm 7$ & $58 \pm 7$ & $40 \pm 4$ \\
\hline Heme & & $94 \div 2$ & $96 \pm 12$ & $91 \pm 6$ \\
\hline Bilirubin & & $85 \div 2$ & $88 \pm 7$ & $76 \pm 6$ \\
\hline Prostaglandin $E_{1}$ & & $97 \pm 6$ & $98 \pm 5$ & $98 \pm 2$ \\
\hline Prostaglandin $A_{1}$ & & $104 \pm 8$ & $95 \pm 5$ & $86 \pm 11$ \\
\hline Prostaglandin $F_{1 a}$ & & $8 B \pm 10$ & $94 \pm 6$ & $86 \pm 10$ \\
\hline 15-Methyl-prostaglandin $F_{2 a}$ & & $9 \pm 7$ & $93 \pm 4$ & $97 \pm 4$ \\
\hline Cholesterol & & $96 \pm 3$ & $103 \pm 1$ & $106 \pm 4$ \\
\hline Retinol & & $97 \pm 3$ & $96 \pm 4$ & $85 \pm 5$ \\
\hline \multirow[t]{3}{*}{ Retinole acid } & & $99 \div 2$ & $96 \pm 14$ & $86 \pm 4$ \\
\hline & \multicolumn{4}{|c|}{ Concentretion of competitor $(\mu \mathrm{M})$} \\
\hline & 0.2 & 0.5 & 1.0 & 5.0 \\
\hline B-Flavaspidic acid & $9 B \pm B$ & $n+10$ & $67 \div 19$ & $59 \div 6$ \\
\hline
\end{tabular}

Incubation vials contained $5 \mu \mathrm{g} / \mathrm{ml}$ delipidated FABP and $1 \mu \mathrm{M}\left[^{14} \mathrm{c}\right]$ olele acid. Increasing concentrations of unlabelled 1 igand were added. Values are expressed as percentage of the binding of $1 \mathrm{KM}\left[{ }^{14} \mathrm{C}\right]$ oleic scid and represent means \pm S.D. of at least 3 experiments.

of the antiserum to human heart FABP (Fig. 4.5). IgG isolated from the pre-immune serum of the same rabbit did not affect oleic acid binding.

\subsection{DISCUSSION.}

Pure and myoglobin-free FABPs could be isolated from the cytosol of heart of man, pig and rat by gel filtration on Sephacryl s-200, followed by anion-exchange chromatography on DEAEcellulose. The recovery of FABP of about $10 \%$ is comparable to that obtained with rat liver FABP [85]. The heart FABPs are of comparable size, human heart FABP having a somewhat higher molecular mass. The isoelectric points observed correspond with values reported before $[88,97,192]$ and are in the same range as that of bovine heart FABP [96]. All liver FABPs have a somewhat smaller molecular mass $[95,103,105]$, and a higher isoelectric point $[87,92,95]$. 
The amino acid composition of the heart FABPs shows marked differences from that of rat [85,86,103], bovine [95] and human liver FABP $[92,105]$. In contrast to liver, tryptophan is present in heart FABPs $[96,110]$ and cysteine is absent, except for bovine heart FABP [96]. In agreement with their lower $P I$ values the number of lysine residues is lower in heart FABPs compared to liver FABPs [85.87, $95,195]$. The observed differences agree well with the marked differences of the primary structure of rat heart and liver FABP [106, $110,117,123]$.

All 3 heart FABPs exhibited comparable binding characteristics. Binding affinity increased with longer acyl chains. Kd values observed with rat heart FABP for palmitic and oleic acid are comparable to those obtained with samples of heart cytosolic protein $[158,164]$. Palmitic acid binding capacity of rat heart FABP was somewhat lower than observed previously [85]. Based on the Lipidex binding assay, $0.3-0.5 \mathrm{~mol}$ oleic or palmitic acid is bound per mol protein. This relatively low stoichiometry may be caused by loss of binding activity of the protein during the purification, since no contamination with other proteins could be detected on SDS-polyacrylamide gel electrophoresis, using highly sensitive silver-staining nor on immunoblots or in isoelectric focusing gels. These and our previous data [26,85, 164] substantiate the binding of up to one mol fatty acid per mol FABP. This value is in contrast with the binding ratio of 2 $\mathrm{mol} / \mathrm{mol}$ observed by offner et al. [86] for both rat heart and liver FABP using liposomes as fatty acid donors. We could however, not obtain ratios exceeding 0.7 with the same liposome assay. The apparent $\mathrm{Kd}$ values for oleic and palmitic acid of rat liver FABP were much higher in the liposome system [273] than we

Table 4.6.

Imunological cross-reactivity of heart fatty acid-binding proteins.

\begin{tabular}{lccc}
\hline Ant iserum & ant 1 -human & ant $1 \cdot p 1 g$ & ant I-rat \\
FABP & & & \\
\hline from & 100 & $77 \pm 8$ & $9 \pm 1$ \\
Man & $72 \pm 4$ & 100 & $4 \pm 1$ \\
Pig & $16 \pm 4$ & $14 \pm 1$ & 100 \\
\hline Rat &
\end{tabular}

Serum dilutions at which half maximal binding was obtained in an ELISA were taken as measure for the immunological cross-reactivity of the three heart FABPs. Per well $0.25 \mu \mathrm{g}$ FABP was used. Values are means \pm S.D. of at least 3 experiments, and given as percentage of the binding of the specific ant iserum to the antigen. 


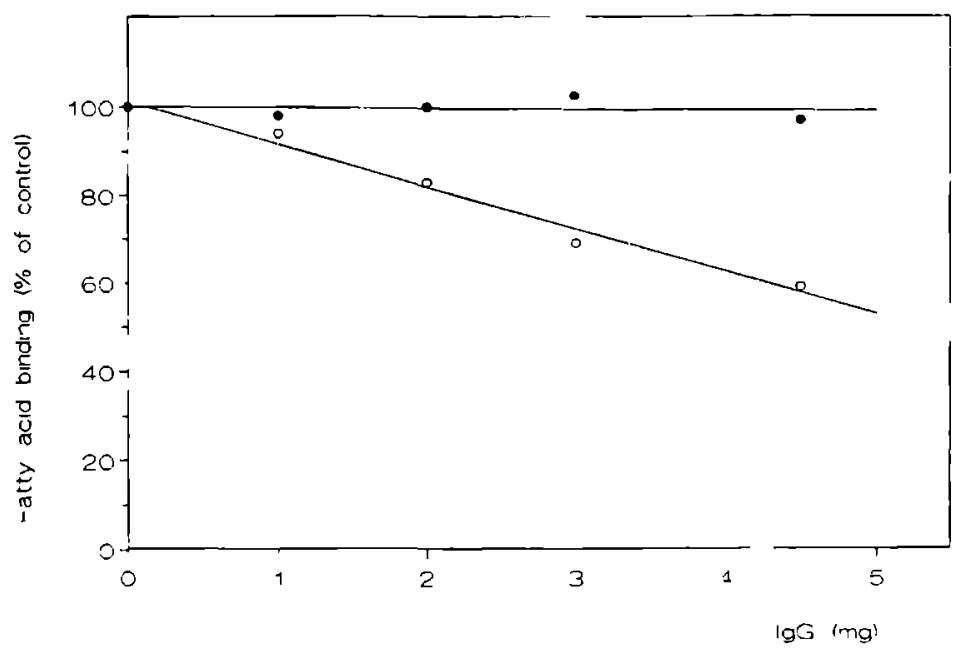

Fig. 4.5. Inhibition of fatty acid binding by the I gG fraction of antiserum against human heart FABP. Delipidated human heart FABP $(1.5 \mu g)$ was preincubated at $37^{\circ} \mathrm{C}$ with increasing amounts of IgG directed against human heart FABP (0-0) or from preimune serum (1-0) in the presence of $2.5 \mathrm{mg}$ (ysozvme (as inert protein). After keeping the mixtures on ice for $1 \mathrm{~h}$, fatty acid binding was assayed at $1 \mu \mathrm{M}\left[{ }^{14} \mathrm{C}\right]$ oleic acid. Binding is given as percentage of the control (which contained only (ysozyme and FABP).

and others found in the Lipidex binding assay $[25,85,164]$. With human heart FABP we observed comparable values with both assays. Recent NMR-studies showed a $1: 1$ stoichiometry in fatty acid binding to rat liver FABP in a vesicle system of $4 \mathrm{~mol}$ oleic acid and $20 \mathrm{~mol}$ phosphatidylcholine per mol FABP [143]. Oleic acid partitioning favoured membrane binding with increasing oleic acid content. Rudel et al. [17] established a $1: 1$ stoichiometry of 16-(9'anthroyloxy)palmitic acid to bovine heart FABP by fluorimetric titration in agreement with electrophoretic data [186]. Fournier et al. [192] reported a binding ratio of $0.2 \mathrm{~mol} / \mathrm{mol}$ for 12 -doxylstearic acid.

The preference for binding of long (unsaturated) fatty acids was confirmed by their competition with $\left[{ }^{16} \mathrm{C}\right]$ oleic acid binding to human heart FABP. Although many other hydrophobic ligands are bound by liver FABP $[25,98,190,194 \cdot 196]$, heme, bilirubin, prostaglandins, cholesterol and retinoids were unable to compete with oleic acid as a ligand for human heart FABP. The competition assay does not exclude a separate binding site for hydrophobic ligands other than that for fatty acids, as was observed for lysophosphatidylcholine binding to rat liver FABP [196]. The latter compound 
was however not bound by rat heart FABP [196]. The binding of 16(9'-anthroyloxy)palmitic acid by bovine heart FABP [272] and of dansyl-amino-undecanoic acid by rat heart FABP [238] was weak compared to the analogous liver proteins. These observations also indicate structural differences of the fatty acid-binding sites of heart and liver FABP.

The binding of acyl-COA esters by heart FABPs was also observed by other investigators 196,97$)$, but no data were given. Recently, Burrier et al. (18B] reported that rat liver but not rat heart FABP bound oleoyl-COA. Rat liver FABP binds CoA esters of palmitic and oleic acid with lower affinity than their corresponding fatty acids [25), in contrast to the comparable affinity of heart FABP for palmitic acid and palmitoyl-COA shown here. Palmitoyl-COA however, less effectively displaced oleic acid than palmitic acid from human heart FABP, similarly as from rat liver FABP [25]. With regard to the possible protective role of this protein in heart, e.g. during ischemia [275,276], the binding of long-chain acyl-COA and -carnitine esters to FABP may be of importance.

The high degree of immunological cross-reactivity between human and pig heart FABP and their antisera contrasts their low reactivity with antiserum to rat heart $F A B P$ and with rat heart FABP, respectively. The antiserum against bovine heart FABP reacted with cytosol and FABP from human and bovine heart and with rat and pig heart cytosol [97]. The absence of a reaction of anti-heart FABP sera with liver FABP was already observed separately for rat [86] and cattle [96].

In conclusion, FABPs from rat, human, bovine and pig heart appear to form a closely related group that is clearly different from liver FABP. All species-specific forms have a molecular mass of about $15 \mathrm{kDa}$ and an isoelectric point around $\mathrm{pH} 5$. Liver FABP appears to be a more general carrier for hydrophobic ligands, whereas heart FABP is more specifically involved in binding of fatty acids and acyl-derivatives. The fatty acid-binding capacity of rat heart cytosol is not markedly influenced by sex, starvation or clofibrate treatment in contrast to that of liver [158]. All these observations suggest different roles of liver and heart FABP types in cellular metabolism. Their specific tissue distribution $[82,151,153,277$ is another important indication in this respect. 


\subsection{SUMMARY.}

Fatty acid-binding proteins were isolated from cytosol of hearts of man, pig and rat by gel filtration and anion-exchange chromatography. The heart FABPs had a Mr of about 15 (pig, rat) and $15.5 \mathrm{kDa}(\mathrm{man})$; $\mathrm{pI}$ values were $5.2,4.9$ and 5.0 for human, pig and rat heart, respectively. In contrast to liver FABPs, tryptophan was present in the heart FABPs. Binding characteristics for long-chain fatty acids determined with the radiochemical binding assay were comparable for all 3 proteins. Heart FABPs also bind palmitoyl-COA and -carnitine with an affinity comparable to that for palmitic acid. Other ligands investigated heme, bilirubin, cholesterol, retinoids and prostaglandins could not compete with oleic acid for binding by human heart FABP. Binding parameters of FABP for oleic acid from multilamellar liposomes were comparable to those from the Lipidex binding assay. Immunological interspecies cross-reactivity with antisera against the heart FABPs was much higher between man and pig than between rat and man or pig. None of the antisera reacted with liver FABPs. The IgG fraction of anti-human heart FABP serum inhibited fatty acid binding to human heart FABP. 



\title{
FAT TY ACID-BINDING CAPACITY \\ OF CYTOSOLIC PROTEINS OF VARIOUS RAT TISSUES.
}

\author{
Effect of postnatal development, starvation, sex, \\ clofibrate feeding and light cycle.*
}

5.1. INTRODUCTION.

To quantitate the amount of fatty acid-binding protein present in tissue cytosols, and to investigate the influence of various parameters on the FABP concentration, a variety of procedures has been applied (Table 2.2). Quantitation of this protein from the amount of radioactivity present in the FABP-containing fractions after coelution of a protein sample with labelled fatty acids, which was used in many studies $[74,87,89,278]$, is hampered by the high affinity of ligands for most gel types [201.226], and by the existence of a non-equilibrium between protein and ligand. The same disadvantages apply to the electrophoretic quantitation of FABP in the presence of labelled ligand.

Immunochemical determination of FABP [87,146,160] depends on the availability of appropriate, highly specific, antibodies, and can only provide quantitative data without further information on functional properties. Already in 1974 Ockner and Manning [146] found indications that most hepatic FABP was not identical with the intestinal protein. Until now at least four distinct structurally different low-molecular-weight FABPs have been identified: hepatic, intestinal, cardiac and renal FABP $[85,87,101-103,150]$. These types may have a different reactivity, depending on the applied antibody. The concomitant expression of two distinct FABP types in one tissue has been described for jejunum, where the hepatic and intestinal types are present [150], and for kidney, that contains heart FABP together with a kidney-specific type of the protein [102]. The mRNAs of intestinal and liver FABPs are present in various adult rat tissues [167]. To ensure reliable data

"This chapter was adapted from Paulussen et al.. 1986 [158]. 
on tissue FABP content based on immunochemical quantitation, the applied antibodies have to be well characterized regarding their mono-specificity for FABP in cytosolic protein preparations, and their reactivity towards different FABP types.

Determination of FABP by gel filtration and subsequent affinity chromatography of cytosolic protein on oleoyl-aminohexylamino-Sepharose [228] applies denaturating conditions for the elution of the protein, and thus is not adequate for the study of fatty acid-binding characteristics and comparison of different ligands.

For quantitation of FABPs by total binding capacity and investigation of fatty acid-binding characteristics, assays are available that involve binding of radioactive or fluorescent fatty acids. The radioactive fatty acids may be presented to the protein either free in aqueous solution, or incorporated in multilamellar liposomes. After establishment of the binding equilibrium, a separation of free and protein-bound ligand can be achieved with dextran-coated charcoal [279] or Lipidex 1000 [191], or by centrifugation in the case of liposomes [273]. With fluorescent labels, binding is determined from the enhancement of fluorescence that occurs upon binding of the fatty acid analogue, requiring no separation of bound and free ligand $[83,280]$. This assay is most sensitive for liver FABPs, due to their high enhancement of fluorescence at binding of fluorescent fatty acids, but appears less suitable for heart FABP, where only a minor fluorescence enhancement occurs by binding to the protein [83]. Prior to the determination of its fatty acid-binding capacity, protein samples have to be delipidated to prevent competition of endogenously bound ligand, especially at low fatty acid concentrations [164]. Both for delipidation and as adsorbent for unbound fatty acids Lipidex 1000 is preferred, because it does not retain or denature protein, as takes place with charcoal [191]. Fatty acid-binding assays for FABP are, however, only useful for quantitative purposes in the absence of other proteins with fatty acid-binding activity, like e.g. albumin.

The functional assay that was developed in our laboratory, in which unbound and protein-bound fatty acids are separated with the use of Lipidex 1000 [191], allows an accurate determination of the fatty acid-binding capacity of cytosolic protein preparations. With this method the FABP content of rat heart and liver were shown to be in the same order of magnitude [164]. The palmitate-binding capacity showed a marked diurnal variation in both tissues [164]. Other investigators found only a slight diurnal variation of liver FABP measured by immunoassay [225]. 
This chapter describes the determination of the fatty acidbinding capacity of rat tissue cytosols as a measure for their FABP content. The influence of postnatal development, starvation, sex, clofibrate feeding and light cycle was studied. In some experiments both oleic and palmitic acid were used as ligands.

\subsection{METHODS.}

Preparation of cytosols.

Rat tissues were obtained from male albino wistar rats, weighing 180-220 gram, unless otherwise stated. Hearts and livers were perfused in situ with $10 \mathrm{mM}$ K-phosphate/ $154 \mathrm{mM} \mathrm{KCl}$ (pH 7.4). Tissues were excised and immediately cooled and rinsed in the same buffer. Cytosols were prepared as described in section 3.3. Clofibrate treated rats received an oral dose of $50 \mathrm{mg}$ clofibrate/day in $1 \mathrm{ml} 60 \%$ glycerol $(\mathrm{v} / \mathrm{v})$ for 8-10 days. Rats were maintained on a cycle of alternating $12 \mathrm{~h} \mathrm{light}$ and dark periods. The animals were killed by cervical dislocation around the midpoint of the light phase, unless indicated otherwise.

Dealbuminization, delipidation and fatty acid-binding assay.

Cytosolic protein samples (2-4 $\mathrm{mg})$ were cleared of residual albumin by immuno-affinity chromatography. The affinity column $(10 \mathrm{ml})$ was prepared by coupling of the IgG fraction of sheep anti-rat albumin to tresylchloride-activated sepharose CL-4B, prepared as described by Nilsson and Mosbach [263]. After concentration of the dealbuminized protein samples by ultrafiltration, using a Diaflo YM-2 membrane, and subsequent delipidation on a $0.8 \times 6 \mathrm{~cm}$ Lipidex 1000 column at $37^{\circ} \mathrm{C}$, the binding of $\left[{ }^{14} \mathrm{C}\right]-$ labelled fatty acid at $37^{\circ} \mathrm{C}$ was determined by the Lipidex procedure, as described in section 3.4. Amounts of 20-25 $\mu \mathrm{g}$ protein were applied per assay.

other procedures.

Sephacryl s-200 gel filtration was carried out as previously described in section 4.2. Protein was measured by the method of Lowry et al. [270], with bovine serum albumin as standard. Enzymelinked immunosorbent assay (ELISA) of albumin was essentially as described by Hudson and Hay [264]. The product of the peroxidase 
reaction was determined with a Titertek scanner at $492 \mathrm{~nm}$.

Fatty acid-binding parameters were derived from scatchard plot analysis [265] of the binding isotherms at $37^{\circ} \mathrm{C}$, using $6-10$ fatty acid concentrations. Maximal binding $\left(B_{\max }\right)$ is expressed in nmol fatty acid/mg cytosolic protein, apparent binding affinity (Kd) in $\mu \mathrm{M}$ fatty acid. Binding constants were compared by the student's unpaired $t$-test.

\subsection{RESULTS.}

All samples analyzed for fatty acid binding were passed through a sepharose-anti-albumin column to remove residual albumin and delipidated, to obtain accurate values of fatty acidbinding activity. The albumin concentration, calculated from an ELISA using specific anti-rat serum albumin antibodies, decreased from $0.1-0.3 \mathrm{nmol} / \mathrm{mg}$ cytosolic protein (depending on the efficiency of perfusion) to less than $0.02 \mathrm{nmol} / \mathrm{mg}$ protein after dealbuminization. Cytosolic protein preparations that have not been delipidated show a nonlinear relationship between the amount of protein and fatty acid bound, resulting in underestimation of the fatty acid binding, especially at lower fatty acid concentrations. With delipidated proteins the relation is linear, as was
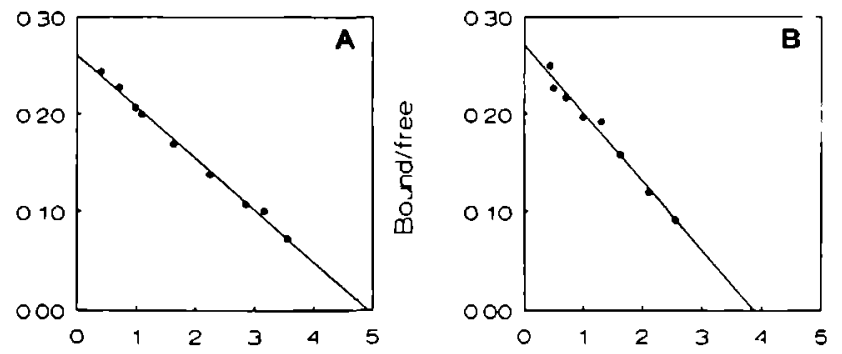

Bound (nmol/mg protein)

Fig. 5.1. Scatchard plot anatysis of the binding of oleic and palmitic acid by liver cytosol of a clofibrate-fed rat. Results of a representative experiment are shown. Dealbuminized, delipidated eytosolic protein semples $(25 \mu g)$ were incubated with 0.1 $3.0 \mu \mathrm{H}\left[1-{ }^{4} \mathrm{c}\right]$ labelled fatty acid. After equilibration, free and protein-bound fatty acids were separated by use of Lipidex 1000 at $0^{\circ} \mathrm{C}$. The concentration of free fatty acids was calculated from the initial concentration and the amount of protein-bound fatty acid.

Panel A: oleic acid binding; r=-0.998 ( $n=9) ; \mathrm{Kd}=0.92 \mu \mathrm{M} ; \mathrm{Bmax}=4.81 \mathrm{~mol} / \mathrm{mg}$ cytosolic protein.

Panel B: polmitic acid binding; $r=-0.995$ (n=8); $K d=0.71 \mu M ; ~ B m a x=3.86 \mathrm{~mol} / \mathrm{mg}$ eytosolic protein. 
also shown previously [164]. Binding parameters were determined with Scatchard plot analysis of fatty acid binding isotherms at $37^{\circ} \mathrm{C}$. After delipidation we always observed linear scatchard plots (correlation coefficient $(r)=-0.992 \pm 0.011$, mean $\pm S D, n=194$ ), indicating a reproducible, (nearly) complete delipidation. Fig. 5.1 shows representative scatchard plots for palmitic and oleic acid binding, in this case by liver cytosol of a clofibrate-fed rat.

Table 5.1 shows that the maximal fatty acid binding capacity is of the same order of magnitude in the cytosol of kidney, adrenal,

brain, quadriceps muscle and diaphragm as in heart and liver. Sephacryl s-200 gel filtration (not shown) demonstrated that the fatty acid-binding activity was (nearly) completely located in the protein fraction of $\mathrm{Mr} 10,000-15,000$, as was observed for liver and heart ${ }^{[85] . ~ T h e s e ~ p r o t e i n s ~ h a v e ~ a ~ h i g h ~ a f f i n i t y ~ f o r ~}$

Table 5.2

Postnatal development of cytosolic fatty acid-binding capacity.

\begin{tabular}{|c|c|c|c|c|c|c|}
\hline \multirow{3}{*}{$\begin{array}{l}\text { Age } \\
\text { (days) }\end{array}$} & \multicolumn{3}{|c|}{ Liver } & \multicolumn{3}{|c|}{ Heart } \\
\hline & \multicolumn{2}{|c|}{ oleic acid binding } & & \multicolumn{2}{|c|}{ oleic acid binding } & \\
\hline & $\begin{array}{c}\text { Bmax } \\
(\mathrm{mmol} / \mathrm{mg})\end{array}$ & $\begin{array}{c}\text { Apparent Kd } \\
(\mu M)\end{array}$ & & $\begin{array}{c}\text { Bmax } \\
\text { (minol/mg) }\end{array}$ & $\begin{array}{c}\text { Apparent Kd } \\
(\mu M)\end{array}$ & \\
\hline 0 & $2.32 \pm 0.34$ & $0.57 \pm 0.23$ & (4) & $3.42 \div 0.83$ & $0.52 \pm 0.16$ & (4) \\
\hline 10 & $2.84 \div 0.27$ & $0.33 \pm 0.12$ & (4) & $3.60 \pm 0.59$ & $0.33 \pm 0.08$ & (4) \\
\hline 21 & $2.44 \pm 0.58$ & $0.52 \pm 0.13$ & (4) & $3.67 \div 0.81$ & $0.27 \pm 0.06$ & (4) \\
\hline 40 & $2.57 \pm 0.49$ & $0.84 \pm 0.22$ & $(6)$ & $3.95: 0.58$ & $0.47 \pm 0.06$ & (5) \\
\hline 70 & $2.21+030$ & $0.37 \div 0.13$ & (7) & $4.38 \div 0.43$ & $0.63 \pm 0.20$ & (5) \\
\hline
\end{tabular}

Date of oleic acid binding were obtained as described in Table 5.1. Values represent means $t$ So of the numer of separate preparations given within parentheses. Male, fed rats were taken from different litters. With 0 - and 10-day-old rats, tissues of several animals fron the same litter were combined. No significant age-related differences were found in heart and liver. 
oleic and palmitic acid in all these tissues.

The effect of postnatal development on the cytosolic fatty acid-binding capacity of heart and liver was determined in rats of 0 (i.e. within $12 \mathrm{~h}$ of birth), 10, 21, 40 and 70 days of age (Table 5.2). In both tissues the fatty acid-binding activity is already present at birth, and does not change markedly during postnatal development.

The fatty acid-binding constants for oleic acid were measured after $66 \mathrm{~h}$ of starvation in 40- and 70-day-old animals (Table 5.3). Starvation increases maximal oleic acid-binding capacity of liver, but no changes are observed in heart. The oleic acidbinding capacity of both heart and liver cytosol is higher in female than in male rats (Table 5.4). No differences are observed with palmitic acid. The binding affinities for oleate and palmitate acid are comparable in male and female animals. In males the binding capacity for oleate in liver is higher than for palmitate, whereas heart shows a slightly higher binding capacity for palmitate. In female rats the binding capacity in liver does not differ for oleate and palmitate, but the binding capacity in heart is 2-fold higher with oleate.

The maximal binding capacities for both oleate and palmitate were also determined at the midpoint of the dark phase of the light cycle (Table 5.5). When compared to mid-light values, only the oleate-binding capacity of liver is higher. The palmitatebinding capacity of liver cytosolic protein is slightly, but significantly, lower. In heart both the binding capacity for oleate and palmitate are decreased at the midpoint of the dark phase.

The effects of feeding of the hypolipidemic drug clofibrate

Table 5.3 .

The effect of starvation on cytosolic fatty acid-binding capacity of heart and liver.

\begin{tabular}{|c|c|c|c|c|c|c|c|}
\hline \multirow{3}{*}{\multicolumn{2}{|c|}{$\begin{array}{l}\text { Age Condition } \\
\text { (days) }\end{array}$}} & \multicolumn{3}{|c|}{ Liver } & \multicolumn{3}{|c|}{ Heart } \\
\hline & & \multicolumn{2}{|c|}{ Oleic acid binding } & \multirow[b]{2}{*}{$(\mu M)$} & \multicolumn{3}{|c|}{ Oleic acid binding } \\
\hline & & Bmax & $\begin{array}{l}\text { Apparent } \mathrm{kd} \\
\mathrm{ag} \text { ) }\end{array}$ & & Bmax & $\begin{array}{l}\text { Apparent } \mathrm{Kd} \\
\text { ag) }\end{array}$ & $\mu(M)$ \\
\hline \multirow[t]{2}{*}{40} & fed & $2.57 \pm 0.49$ & $0.84 \pm 0.22$ & $(6)$ & $3.95 \pm 0.58$ & $0.67 \pm 0.06$ & (5) \\
\hline & starved & $4.36 \pm 0.76^{\circ}$ & $0.78 \pm 0.30$ & (6) & $3.00 \pm 0.39$ & $0.68 \pm 0.17$ & (4) \\
\hline \multirow[t]{2}{*}{70} & fed & $2.21 \pm 0.30$ & $0.37 \pm 0.13$ & (7) & $4.38 \pm 0.43$ & $0.63 \pm 0.20$ & (5) \\
\hline & starved & $3.25 \pm 0.64^{\circ}$ & $1.06 \pm 0.18$ & (4) & $4.39 \div 1.32$ & $0.82 \pm 0.16$ & (4) \\
\hline
\end{tabular}

Significance of Bmax values: different from fed $\mathrm{p}<0.01$. Data of olelc acid binding were obtained as described in Table 5.1. Starvation period was $66 \mathrm{~h}$. Values are means \pm SD of the number of separate preparations of male rat tissues given within parentheses. 
on the fatty acid-binding capacities of heart, liver, kidney, and quadriceps muscle are summarized in Table 5.6. Clofibrate feeding does not affect the oleate-binding capacity in quadriceps muscle. oleate-binding capacity of liver is, however, 2-fold increased, whereas a decrease in binding capacity is found for oleate in heart, and for palmitate in liver. In kidney, a 1.5-fold rise in maximal oleate binding is induced by clofibrate feeding.

The apparent $\mathrm{Kd}$ values for oleate and palmitate found with liver and heart cytosolic proteins are within the same range, and comparable to previous data obtained with palmitate [164]. There is no explicit difference in the $\mathrm{Kd}$ values for oleic and palmitic acid in the various series of experiments. The values are in the same order of magnitude as observed with purified FABP preparations from liver and heart $[25,85,248]$. The $k d$ values for oleate in adrenal, skeletal muscle and diaphragm (Table 5.1) are comparable to the $k d$ values in heart and liver. Brain and kidney cytosols display somewhat higher dissociation constants for oleate.

\subsection{DISCUSSION.}

Gel filtration and the binding assay established the presence of one or more FABPs in the molecular weight range of $10,000-15,000 \mathrm{Da}$ in all rat tissues investigated. With the applied binding assay the total activity of all FABPs in the cytosol was determined. Some FABPs may be associated with mem-

Toble 5.4.

Effect of sex and fatty acid on fatty acid-binding capacity of eytosols from heart and liver of fed rats.

\begin{tabular}{|c|c|c|c|c|c|c|}
\hline \multirow{3}{*}{ Sex } & & Liv & & & \multirow{2}{*}{\multicolumn{2}{|c|}{$\begin{array}{l}\text { Heart } \\
\text { Fatty acid binding }\end{array}$}} \\
\hline & \multirow[t]{2}{*}{ Fatty acid } & \multicolumn{2}{|c|}{ Fatty acid binding } & & & \\
\hline & & $\begin{array}{c}\text { Bmax } \\
\text { (nmol/mg) }\end{array}$ & $\begin{array}{c}\text { Apporent Kd } \\
\text { (페) }\end{array}$ & & $\begin{array}{c}\text { Bmax } \\
(\mathrm{mmol} / \mathrm{mg})\end{array}$ & $\begin{array}{c}\text { Apparent Kd } \\
\text { (uस })\end{array}$ \\
\hline \multirow[t]{2}{*}{ mole } & oleic acid & $2.21 \pm 0.30$ & $0.37=0.13$ & (7) & $4.38 \div 0.43$ & $0.63 \pm 0.20(5)$ \\
\hline & polmitic acid & $4.08 \div 0.38^{\circ}$ & $1.00 \div 0.24$ & (8) & $3.40 \div 0.39^{e}$ & $0.83 \pm 0.11$ (6) \\
\hline \multirow[t]{2}{*}{ fenale } & oleic acid & $3.44 \pm 0.71^{b}$ & $0.75 \pm 0.14$ & (4) & $5.94 \div 0.79^{d}$ & $0.82 \pm 0.21 \quad(5)$ \\
\hline & polmitic acid & $3.88+0.24$ & $0.54 \div 0.13$ & (4) & $298+0.57^{\circ}$ & $0.46 \pm 0.12 \quad(6)$ \\
\hline
\end{tabular}

Stetistical significance of Bmax values: $p<0.0001$ (liver, male; oleic vo polmitic acid); $b<0.01$ (liver, oleic acid: male vs female); $p<0.05$ (heart, male; oleic vs palmitic acid); $d^{0} 0.01$ (heart, oleic acid; male vs female); "P<0.001 (heort, fenale; oleic vs polmitic ocid).

Binding parameters were obtained as described in Table 5.1 . Values are means $t 50$ of the number of preparstions given within parentheses. 
branes or cell organelles 198,146$]$, although this is not observed with immunocytochemistry [169]. The binding capacity for oleate ranged from 1.6-4.4 nmol/mg cytosolic protein in the investigated rat tissues. This indicates a proportion of 2-68 of cytosolic proteins, calculated on basis of the molecular mass of FABP (14$15 \mathrm{kDa})$, which is higher than found for sterol carrier protein in these tissues in the light phase 22813 . The binding capacity values of liver and heart cytosol of male, fed rats for palmitate in the light phase agree with earlier data published by Glatz et al. [164]. The values for liver also correspond to the data found with immunochemical analysis 187 and affinity chromatography [228,282]. For brain an amount of $0.4 \%$ of cytosolic protein was reported $[96,161]$, which is much lower than the 2.68 determined in this study. The binding capacity of rat brain cytosol is high in comparison to the low fatty acid-oxidation capacity of that tissue [231]. The apparent kd values for oleate in brain and kidney suggest the presence of other fatty acid-binding proteins in these tissues than those found in heart and liver.

During postnatal development up to 70 days we did not observe changes in the oleate-binding capacity in heart and liver cytosol of male rats. Foliot et al. [239] reported a 2-fold increase in rat liver during postnatal development to adult values at 30 days, based on bromosulfophthalein binding, whereas ockner et al. [87,223] found a 1.4-fold higher level with 60-day-old than with 30-day-old animals, using immunochemical quantitation of FABP. Levels of liver FABP MRNA increased in the first day after birth, but remained constant during the next 34 days of life [167].

Table 5.5.

The influence of the light cyele on the fatty acid-binding activity in cytosol of rat heart and liver.

\begin{tabular}{|c|c|c|c|c|c|c|c|}
\hline \multirow{2}{*}{$\begin{array}{l}\text { Fatty } \\
\text { acid }\end{array}$} & \multirow{2}{*}{$\begin{array}{l}\text { Phase } \\
\text { when } \\
\text { killed }\end{array}$} & \multicolumn{2}{|c|}{$\begin{array}{l}\text { Liver } \\
\text { Fatty acid binding }\end{array}$} & & \multicolumn{2}{|c|}{$\begin{array}{l}\text { Heart } \\
\text { Fatty acid binding }\end{array}$} & \\
\hline & & $\begin{array}{c}\text { Bmax } \\
(\operatorname{mol} / \mathrm{mg})\end{array}$ & $\begin{array}{c}\text { Apperent Kd } \\
(\mu N)\end{array}$ & & $\begin{array}{c}\text { Bmax } \\
(\mathrm{mmol} / \mathrm{mg})\end{array}$ & $\begin{array}{c}\text { Apparent Kd } \\
(\mu M)\end{array}$ & \\
\hline \multirow[t]{2}{*}{ oleic acid } & light & $2.21 \pm 0.30$ & $0.37 \pm 0.13$ & (7) & $4.38 \pm 0.43$ & $0.63 \pm 0.20$ & (5) \\
\hline & dark & $3.12 \pm 0.45^{8}$ & $0.73 \pm 0.17$ & (9) & $2.59 \pm 0.40^{\circ}$ & $0.44 \pm 0.13$ & (9) \\
\hline \multirow[t]{2}{*}{ palmitic ocid } & light & $4.08 \pm 0.38$ & $1.00 \div 0.24$ & (8) & $3.40 \pm 0.39$ & $0.83 \pm 0.11$ & (5) \\
\hline & dark & $3.17 \pm 108^{b}$ & $085 \pm 036$ & (B) & $1.55 \pm 024^{\circ}$ & $0.53 \pm 0.19$ & (9) \\
\hline
\end{tabular}

Statistical significance, different from light phase: $p<0.001$ b $^{b}<0.05$. Fatty acid-binding parameters were abtained as described in Table 5.1. Values represent means $t$ SO of the number of separate experiments indicated within parentheses. Rats (males) were maintained on a cycle of alternating 12 h light and dork periods. Animals were killed around the midpoint of the light or dark phase of the light cycle. 
Total palmitate-oxidation capacity (per $g$ wet weight) of rat liver was maximal at 21 days, that in rat heart at an age of 70 days [231].

other investigators found 1.2-1.5-times higher levels of FABP in liver cytosol of female than of male animals with the comigration technique [278,282] and immunochemical quantification $[87,150]$. We observed a comparable difference in oleate-binding capacity of liver and heart cytosol of female rats. However, on comparison of palmitate binding data no sex-related differences were found. Bass et al. [150] observed that in intestine sex has no influence on the content of FABPs of either the liver or the intestinal type.

Fatty acid-binding capacity of heart cytosolic protein was not affected by $66 \mathrm{~h}$ starvation of 40- and 70-day-old rats. In liver cytosol oleate-binding capacity was increased 1.4- and 1.7fold, respectively. With the immunochemical [227 and comigration method [225] a moderate decrease (16 and 35\%, respectively) was observed in the concentration of FABP of liver cytosol after 48 $\mathrm{h}$ starvation. The fatty acid-oxidation capacity and the citrate synthase activity per $g$ liver increased by 43 and $52 \%$, respectively, after 66-h starvation of 40-day-old rats [283]. Since liver weight decreased by $37 \%$, the capacity of fatty acid oxidation remains

Table 5.6.

The effect of clofibrate feeding on the fatty acid-binding capacity of cytosols from various rat tissues.

\begin{tabular}{|c|c|c|c|c|c|}
\hline \multirow[t]{2}{*}{ Tissue } & \multirow{2}{*}{$\begin{array}{l}\text { Fatty } \\
\text { acid }\end{array}$} & \multirow[t]{2}{*}{ Condition } & \multicolumn{3}{|c|}{ Fatey acid binding } \\
\hline & & & $\begin{array}{c}\text { Bmax } \\
(\mathrm{mmol} / \mathrm{mg})\end{array}$ & $\begin{array}{c}\text { Apparent Kd } \\
(\mu M)\end{array}$ & \\
\hline \multirow[t]{4}{*}{ Liver } & olele acid & fed & $2.21 \pm 0.30$ & $0.37 \pm 0.13$ & (7) \\
\hline & & clofibrate-fed & $4.71 \pm 0.58^{8}$ & $0.86 \pm 0.16$ & (4) \\
\hline & palmitic acid & fed & $4.08 \pm 0.38$ & $1.00 \div 0.24$ & (8) \\
\hline & & clofibrate-fed & $3.33 \pm 0.43^{c}$ & $0.72 \neq 0.11$ & (4) \\
\hline \multirow[t]{2}{*}{ Heart } & oleic acid & fed & $4.38 \pm 0.43$ & $0.63 \pm 0.20$ & (5) \\
\hline & & clofibrate-fed & $3.29 \pm 0.31^{\circ}$ & $0.39 \pm 0.11$ & (6) \\
\hline \multirow[t]{2}{*}{ Kidney } & oleic acid & fed & $1.92 \pm 0.28$ & $1.31 \pm 0.48$ & (4) \\
\hline & & clofibrate-fed & $3.17 \pm 0.60^{b}$ & $1.78 \pm 0.41$ & (4) \\
\hline \multirow[t]{2}{*}{ Skeletal muscle } & oleic ocid & fed & $1.61 \pm 0.41$ & $0.76 \pm 0.31$ & (4) \\
\hline & & cl of ibrate-fed & $1.34 \div 0.07$ & $0.73 \pm 0.01$ & (4) \\
\hline
\end{tabular}

Statistical significance, Bmax values different from fed onimals: ${ }^{\circ}$ p<0.001; $b<0.01 ; c$ p $<0.05$. Data of fatty acid binding were obtained as described in Jable 5.1. Male rats received an oral dose of $50 \mathrm{mg}$ clofibrate in a $1 \mathrm{ml} 60 \mathrm{X}(v / v)$ glycerol solution, for 8-10 days. Values represent means \pm so of the nuber of separate preparations given within parentheses. 
nearly constant in whole liver. Although cytosolic protein may decrease more at starvation than liver weight [227, the relatively higher concentration of FABP may annul this decrease.

When the fatty acid-binding activity was determined at the mid-point of the dark phase of the light cycle, only the oleatebinding capacity of liver cytosol was moderately higher. No diurnal variation of liver FABP was observed with immunochemical analysis by Bass et al. [227, in contrast to the (2-10-fold) diurnal change of sterol carrier protein observed in various tissues [281]. The decrease of palmitate binding by liver and heart cytosolic protein at mid-dark are at variance with earlier observations (164). This discrepancy may be caused by an incomplete removal of residual albumin in that study. In this study we applied anti-albumin antibodies that were covalently linked to Sepharose, instead of non-covalently protein-A-bound, to ensure complete dealbuminization, and we also investigated more series of animals. The palmitate-oxidation capacity was increased at the mid-dark period in liver, and to a minor extent also in heart, but changes are related to fluctuations of other mitochondrial activities [164] as with starvation [283]. The concomitant and comparable changes in FABP and fatty acid-oxidation capacity of rat liver due to starvation or to the light-dark cycle are therefore related to changes in liver composition, and indicate a protection of this protein and of mitochondrial enzymes against starvation-induced proteolysis.

Administration of the hypolipidemic drug clofibrate increased the FABP content of liver approximately 2-fold $[25,150,224$, $227,228,284,285]$. We found a similar increase of the binding capacity for oleate, but a minor decrease for palmitate. Clofibrate treatment resulted in a 2 -fold increment of liver FABP in intestine, and a $25 \%$ increase in intestinal FABP [150]. No literature data are available on the effect of clofibrate feeding on the fatty acid-binding capacity of kidney, heart and muscle. The observed effects of clofibrate feeding on fatty acid binding in liver, kidney, heart and muscle (Table 5.6) and in intestine [150] indicate that the levels of the different types of FABP are regulated by separate mechanisms. The effects of clofibrate feeding correspond with those on the total palmitate-oxidation capacity [231]. Clofibrate treatment caused a 2.8, 2.1 and 1.2-fold rise in the palmitate-oxidation capacity in liver, heart and kidney, respectively, and had no effect on oxidation in skeletal muscle. A $45 \%$ increase of oleate binding by liver cytosol was obtained in rats fed diets containing $19 \%(w / w)$ fat (Veerkamp, Zevenbergen and paulussen, unpublished data). The fatty acid-oxidation capa- 
city in liver rose with about $30 \%$ in these rats. clofibrate, starvation and high-fat diets also induce an increase of palmitoyl-CoA hydrolase $[286,287]$. The increase of acyl-COA concentration observed under these conditions $[286,287 \mathrm{7}$ may relate to these phenomena.

The binding capacity differs for palmitate and oleate in male liver, and in female heart and liver. The effects of the diurnal cycle and of clofibrate feeding on the binding capacity of liver cytosol of male rats also differ for oleate and palmitate. This suggests that different proteins may be involved in the fatty acid binding, or that different regulatory or inductory mechanisms exist for different fatty acids. other factor(s) present in the cytosol may influence the binding of the fatty acids to FABPs, since with purified FABP preparations from liver no difference in oleate and palmitate binding was observed [25,85].

In conclusion, various conditions appear to influence the fatty acid-binding capacity in the cytosol of rat tissues. Interpretation of data is complicated by different results dependent on the applied fatty acid and sex. The fatty acid-binding capacity, as measure for the cytosolic FABP content shows no clear relationship with the capacity of fatty acid oxidation, taken in consideration the observations with brain and postnatal development. The nutritional state and the diurnal cycle influence the capacity of cytosolic fatty acid binding and fatty acid oxidation per $g$ liver to a comparable extent, but have no effect for whole liver. clofibrate treatment apparently induces both FABP and fatty acid oxidation in rat liver and kidney.

\subsection{SUMMARY.}

Fatty acid-binding capacity of dealbuminized, delipidated cytosolic proteins from rat tissues was studied with a radiochemical binding assay. Oleate-binding capacity ranges from 1.6$4.4 \mathrm{nmol} / \mathrm{mg}$ cytosolic protein in liver, heart, kidney, adrenal, brain, skeletal muscle and diaphragm. Differences in binding affinity indicate the presence of different fatty acid-binding proteins in these tissues. No change in fatty acid-binding capacity of heart and liver cytosol was observed during postnatal development up to 70 days. Starvation did not affect the fatty acid-binding capacity of heart, but increased the oleate-binding capacity in liver cytosol. Sex-related differences of binding by heart and liver cytosolic proteins were found with oleate, but not with palmitate. Fatty acid-binding capacity of heart and 
liver cytosol did not show a marked diurnal variation. clofibrate treatment had different effects on the oleate-binding capacity of cytosolic proteins: an increase in liver and kidney, no change in skeletal muscle and a decrease in heart. The results are discussed in relation to data on fatty acid oxidation. 


\section{IMMUNOCHEMICAL QUANTITATION \\ OF FATTY ACID-BINDING PROTEINS.}

I. Tissue and intracellular distribution, postnatal development, and influence of physiological conditions on rat heart and liver FABP.*

\subsection{INTRODUCTION.}

A number of structurally different types of FABPs exist in heart, liver, intestinal mucosa and skeletal muscle [25,27.79,82]. These different FABP forms are not confined to these four tissues, but show a rather complex tissue distribution, suggesting a structural relation between FABP type and intracellular fatty acid metabolism of different tissues.

Not only the FABP type, but also the FABP content of the cytosol differs among tissues. Several methods have been described for the quantitation of these proteins. The comigration of (radio) labelled ligands with FABP on a gel filtration column, which was first applied for the isolation of this protein, has also been used for its quantitation $[164,223,225,233)$. The major disadvantages of this procedure are competition of other fatty acidbinding proteins in the cytosol with FABP and affinity of the gel matrix itself for fatty acids, and thus the non-equilibrium conditions of the assay. In our laboratory, a radiochemical binding assay was developed [164] to determine the FABP content of cytosolic protein samples as the fatty acid-binding capacity (after removal of albumin by affinity chromatography on antialbumin antibodies conjugated to sepharose).

Binding of fatty acids labelled with a fluorescent probe was also used to quantify the amount of FABP in protein samples [280]. Kawashima et al. [228] applied affinity chromatography on oleoylaminohexylamino-Sepharose of the low molecular weight fraction obtained by gel filtration, but this method requires denaturating conditions to elute FABP, which makes quantitation of its amount

"This chapter was adapted from Paulussen et al., 1989 [153]. 
less accurate. Several authors reported data on FABP concentrations derived from immunodiffusion or immunoelectrophores is assays $[87,146,150,151,160,165]$. More accurate radioimmunoassays for quantitation of liver FABP were reported by others $[160,284]$. Many earlier investigations le.9. 159,160.284] did not, however, take into account the existence of a greater variety of FABP forms in their assay of FABP content of other tissues than is present in liver. More recently, crisman et al. [152] developed a quantitative enzymelinked immunosorbent assay (ELISA) for measurement of heart FABP. Wilkinson and wilton [229] labelled FABP with antiserum and ${ }^{125} \mathrm{I}-$ labelled protein-A on immunoblots to establish the amount of FABP in their samples.

This chapter deals with the development of an ELISA for the quantitation of rat liver and heart FABP forms in cytosolic protein preparations of various rat tissues with IgG fractions of specific antisera. The assay was used to determine the subcellular distribution of FABP in heart and liver and the influence of a number of physiological conditions and of postnatal development on the FABP content of heart and liver. To provide a better evaluation of the FABP contents of tissue samples, we compared the immunochemical data with our data on the fatty acid-binding capacity [158, chapter 5 ]. The $\alpha$-fetoprotein content of heart and liver cytosol was determined during postnatal development, to provide a possible explanation for differences observed between FABP content and fatty acid-binding capacity. Also, the FABP content of liver was compared among 7 strains of inbred rats, and assayed after administration of a number of agents that are known to affect lipid metabolism.

\subsection{METHODS.}

Preparation of cytosols.

Unless otherwise stated, cytosols were prepared from male, fed albino wistar rats (weighing $200 \pm 20 \mathrm{~g}$ ) as described in section 3.3. , and were stored at $-20^{\circ} \mathrm{C}$.

Comparison of inbred strains and effects of agents affecting lipid metabolism.

Liver cytosols used for the estimation of FABP content in a series of fully inbred strains of rats and after treatment with 
agents affecting lipid metabolism were obtained from the experiments described by Geelen et al. [288]. In the experiment involving agents that affect lipid metabolism, all animals, including controls, received a diet supplemented with $5 \%$ olive oil. Supplemented diets were fed during 21 days, starting with 8-week-old wistar rats. A molecular mass of 13,500 Da was used in calculations for sterol carrier protein-2 [289].

Subcellular fractionation.

Homogenates of livers and hearts from male albino wistar rats $(200 \pm 20 \mathrm{~g})$ were prepared and fractionated into mitochondria, microsomes, and cytosol as described in section 3.3. Two fractions of the mitochondria were extracted with $0.05 \% \mathrm{Na}-$ deoxycholate ( $\mathrm{pH} 7.0$ ) and $\mathrm{KCl}(125 \mathrm{mM} \mathrm{KCl} / 1 \mathrm{mM}$ EDTA/ $10 \mathrm{mM} \mathrm{K}-$ phosphate, $\mathrm{pH}$ 6.0). Finally, the $\mathrm{KCl}$ extracted mitochondria were extracted with deoxycholate as well. The obtained fractions and mitochondrial extracts were used for immunological quantitation of FABPs. The extraction procedures are described in section 3.3 .

Preparation of antigens.

Rat heart FABP was purified from $105,000 \times \mathrm{g}$ supernatants by gel filtration on Sephacryl $s-200$ and DEAE-cellulose anionexchange chromatography as described in chapter 4. Rat liver FABP was purified according to Glatz et al. [85], with some minor modifications.

Preparation of antisera.

Antisera were obtained from New Zealand White rabbits, that were immunized by intracutaneous injections of $100 \mathrm{\mu g}$ FABP at 3week intervals. Final exsanguination was performed by cardiac punction. Sera were isolated and stored at $-20^{\circ} \mathrm{C}$. A detailed description of the immunization procedure is given in section 3.5. IgG-fractions of the antisera were prepared with protein-A Sepharose as described by Goudswaard et al. [266].

ELISA procedures.

Titer determinations.

Blood samples were taken every 3 weeks for titer determinations. Antibody titers were determined in ELISA with pure FABPs attached to the solid-phase, using successive 2-fold 
dilutions of the sera. Peroxidase-conjugated swine anti-rabbit IgG was used for detection of the bound antibodies, with orthophenylene diamine as substrate. The product of the peroxidase reaction was determined at $492 \mathrm{~nm}$ with a Titertek Multiscan. Details of the procedure are given in section 3.5. Titers were determined from titration curves, constructed of a semi-log plot of absorbance at $492 \mathrm{~nm}$ versus serum dilution, and were defined as the reciprocal values of the serum dilution required to obtain $50 \%$ maximal reaction.

ELISA for quantitation of FABPs.

Measurements of cytosolic FABP content were carried out with a quantitative ELISA, performed as described in section 3.5. In short, calibration curves (0-7 ng FABP) and samples (50 and 100 ng cytosolic protein) were used for overnight coating at $20^{\circ} \mathrm{C}$. IgG-fractions of the antisera were appropriately diluted in PBSTween ( $5.4 \mathrm{mM}$ Na-phosphate/ $1.3 \mathrm{mM} \mathrm{K}$-phosphate/ $150 \mathrm{mM} \mathrm{NaCl,} \mathrm{pH}$ 7.4/ 0.05\% Tween-20), to produce linear standard curves. The microtitre plates were treated as described before (section 3.5). The amount of immune-reactive protein in the samples was determined from calibration curves calculated from linear regression analysis. Molecular masses used in all calculations were 14,992 Da for heart FABP [110] and 14,273 Da for liver FABP [90].

Quantitation of $\alpha$-fetoprotein.

$\alpha$-Fetoprotein content of cytosols was determined in ELISA, similarly to the measurements of FABP. Antiserum to rat $\alpha$-fetoprotein and $\alpha$-fetoprotein standard were kindly donated by Dr. J. Uriel (Laboratoire de Chimie des Protéines, Institut de Recherches scientifiques sur le cancer, CNRS, Villejuif, France). A molecular mass of 70,000 Da for $\alpha$-fetoprotein [290] was used in calculations.

Electrophoresis and Western blotting.

Cytosolic protein samples $(50 \mu \mathrm{g})$ were separated by polyacrylamide slabgel electrophoresis in $0.1 \%$ SDS at pH 8.8 with 7.5-20\% acrylamide gradient gels (0.7 $\mathrm{mm}$ thick). Immediately afterwards, the proteins were transferred electrophoretically to nitrocellulose paper. After blotting the nitrocellulose sheets were dried. Immunostaining was carried out after blocking of all remaining binding sites on the nitrocellulose with bovine serum albumin. Antigens were detected with the double antibody technique, using peroxidase-conjugated swine-anti rabbit IgG as 
second antibody and 4-chloro-1-naphthol as precipitating substrate [269]. Details are described in section 3.6.

\subsection{RESULTS.}

FABPs were isolated from cytosolic protein preparations of rat heart and liver by gel filtration and anion-exchange chromatography. Purity of the isolated FABP preparations was confirmed by SDS-polyacrylamide gel electrophoresis and ultrathin-layer isoelectric focusing. Protein-A purified IgG fractions of antisera to rat heart and liver FABP raised in rabbits were used for immunochemical investigations of FABP content and distribution of heart and liver FABP types.

The liver and heart forms of FABP have a clearly different tissue distribution within the rat. On Western blots, liver FABP is predominantly detected in liver and intestine (Fig. 6.1A). Rat

A

B

$\mathrm{Mr}$

(Da)

$94000-$

$68000-$

$43000-$

30000-

20100-

14400-

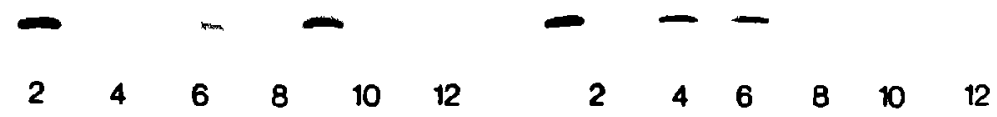

Fig. 6.1. Immunostained Western blots of rat tissue cytosols. Panel A: after incubation with anti-ret liver FABP; panel B: Incubated with anti-rat heart FABP. Cytosols: heart (lane 1); l iver (2); m.quadriceps (3); m soleus (6); m.extensor digitorum longus (5); diaphragm (6); kidney (7); adrenal (8); intestıne (9); spleen (10); adipose tissue (11); lung (12) and brain (lane 13 ). Slots were loaded with $50 \mu g$ of cytosolic protein. Blotting and staining was performed as described in section 3.6 . 


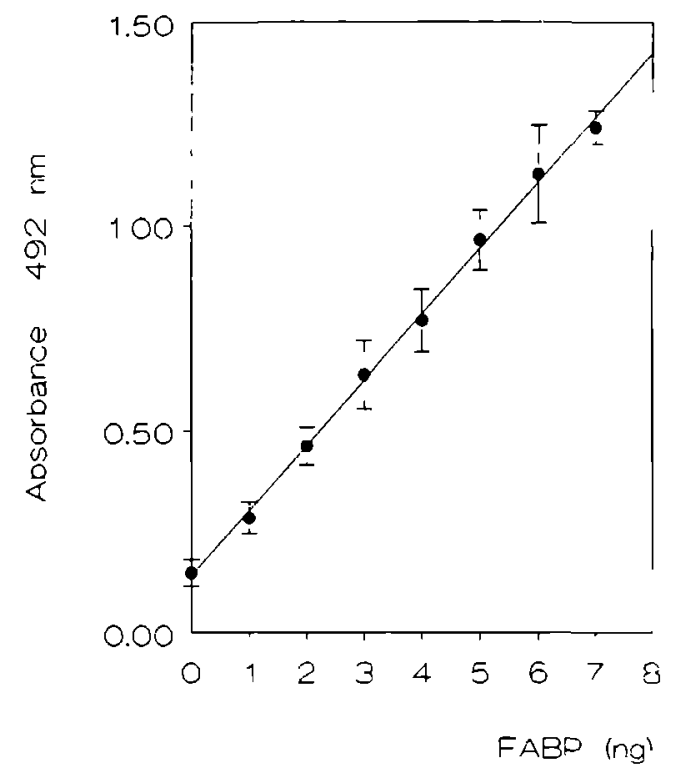

fig. 6.2. Calibration curve of ELISA for the quant $i$ tative determination of rat heart FABP. liver cytosol also appears to contain minor amounts of an immune-reactive protein of approximately 30 kDa. This band was not present in the pure FABP preparation that was used for immunization, but it is found in liver FABP preparations that were repeatedly thawed and refrozen. Sheridan et al. [238] observed a similar phenomenon. Cytosols of lung and some types of muscle only showed reactivity with proteins of molecular mass higher than FABP. Blotting analysis with antiserum raised against another liver FABP preparation showed that the reactivity in the 30 kDa range was no artifact.

The significance of these proteins is not clear.

on Western blots of tissue cytosols, reactions with antibodies against heart FABP were only observed in heart, m. soleus, m.extensor digitorum longus, diaphragm, kidney, and weakly in $\mathrm{m}$. quadriceps (Fig. $6.1 \mathrm{~B}$ ), all in the $15 \mathrm{kDa}$ region. Reactivity with proteins of other molecular weight was not seen.

The FABP content of rat tissue cytosols was determined as the amount of anti-FABP-reactive protein with a quantitative enzyme-linked immunosorbent assay (ELISA). The antigens were directly adsorbed to a polystyrene surface, allowing the use of very small amounts of cytosolic protein (i.e. 50-100 ng). Incubation with whole rabbit antisera gave insufficient reproducibility. This problem was overcome by using IgG-fractions of the antisera. IgG solutions were diluted to produce linear calibration curves, as demonstrated for rat heart FABP in Fig. 6.2. The assay has a sensitivity limit of $5 \mathrm{ng} / \mathrm{ml}$. Recovery of pure FABP added to cytosolic protein samples was $92 \pm 13 \%$ (mean \pm SD of 3 determinations). The antisera against heart FABP cross-react only very weakly with liver FABP in ELISA (less than $1 \%$ ), as do anti-liver FABP antibodies with heart FABP $(2 \%)$. 
Table 6.1.

Tissue distribution of heart and liver type fABP.

\begin{tabular}{|c|c|c|}
\hline \multirow[t]{2}{*}{ Tissue } & \multicolumn{2}{|c|}{ Proteln reactive with } \\
\hline & enti-heart fABP & ant $i-l i$ ver FABP \\
\hline Heart & $57.1 \pm 5.7(7)$ & $1.9 \div 0.7(4)$ \\
\hline Liver & $6.0 \pm 4.3(6)$ & $34.3 \pm 6.9(6)$ \\
\hline M.quadriceps & $23.1 \pm 3.9(7)$ & \\
\hline M.soleus & $43.5 \pm 10.2(6)$ & \\
\hline M.extensor digitorum longus & $21.0 \pm 8.4(6)$ & \\
\hline Diaphragm & $36.9 \pm 7.2(6)$ & \\
\hline Kidney & $11.5 \pm 2.6(7)$ & $0.4 \pm 0.2(4)$ \\
\hline Adrenal & $4.4 \pm 0.5(3)$ & $2.2 \pm 0.5(3)$ \\
\hline Intestine & $3.3 \pm 2.3(3)$ & $6.4 \pm 2.0(5)$ \\
\hline Spleen & $8.7 \pm 0.4(3)$ & $1.0 \pm 0.2(3)$ \\
\hline Adipose tissue & $6.2 \pm 0.9(3)$ & $6.9 \pm 2.2(3)$ \\
\hline Lung & $20.2 \pm 3.5(3)$ & \\
\hline Brain & $12.3 \pm 7.1(4)$ & $2.4 \pm 0.4(3)$ \\
\hline
\end{tabular}

Protein reactive with anti-heart and anti-liver FABP IgG was measured in cytosol of tissues of male, adult, fed rats by a quantitative immonoassay. Data were obtained from multiple determinations at 2 concentrations of cytosolic protein for each sample. Values are expressed as FABP content in $\mu \mathrm{g} / \mathrm{mg}$ protein and are given as means \pm SD of the number of separate preparatıons indicated within parentheses.

The tissue distribution of heart and liver FABP is summarized in Table 6.1. The amount of anti-liver FABP reactive protein in lung and skeletal muscles was omitted, because this only represents reactions with non-FABP proteins as observed on immunoblots. In ELISA, as on the western blots, liver FABP is found in liver and intestine, and furthermore in adipose tissue cytosol. The content of liver FABP in rat intestine is smaller than found in jejunum [150]. This is probably due to the use of a more distal part of the intestine in this study, since FABP concentration is highest at the proximal end [146]. With brain cytosol, only a minor reactivity was observed with antibodies to rat liver FABP.

The ELISA results show that heart FABP has a much wider distribution than the liver type. It was detected in high quantities in heart, diaphragm and m.soleus, and in lower concentrations in the other skeletal muscles and lung. Smaller amounts were found in kidney, brain and spleen. Blood plasma and high speed supernatants of lysed erythrocytes did not react with either antiserum.

Cellular FABP distribution was assessed by measurement of the FABP content of mitochondrial, microsomal and cytosolic fractions after cell fractionation. Mitochondria were also extracted 


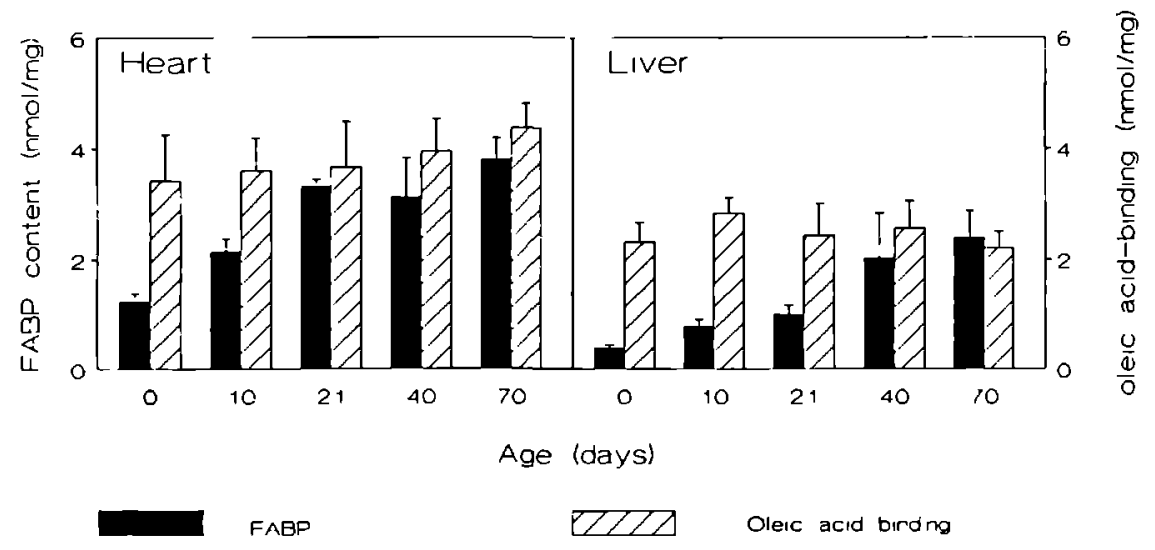

Fig. 6.3. Postnatal development of FABP content (immonossay) and oleic acid-binding capacity (Lipidex essay) of rat heart and liver cytosol.

with either $\mathrm{KCl}$ solution or deoxycholate to differentiate between FABP associated with the mitochondrial outer membrane and FABP located within the mitochondria. In both heart and liver, FABP was located solely in the cytosol (96 2 and $99 \pm 1 \%(n=3)$, respectively). A slight amount of FABP was found in the microsomal fraction $(3.2$ and $0.8 \%)$, probably due to some residual cytosol, since this fraction was not washed. The mitochondria and mitochondrial extracts did not contain detectable FABP.

The FABP content shows a

Table 6.2.

Postnatal development of a-fetoprotein content of rat heart and liver cytosol

\begin{tabular}{|c|c|c|}
\hline \multirow{2}{*}{$\begin{array}{c}\text { Age } \\
\text { (days) }\end{array}$} & \multicolumn{2}{|c|}{ a-Fetoprotein content } \\
\hline & Hea & Liver \\
\hline 0 & $0.10 \pm 0.03^{a}$ & $0.12 \pm 0.01^{a}$ \\
\hline 10 & $0.08 \pm 0.01^{\mathrm{a}}$ & $0.06 \pm 0.01^{\mathrm{a}}$ \\
\hline 21 & $0.01 \pm 0.00$ & $0.03 \pm 0.01$ \\
\hline 40 & $0.00 \pm 0.00$ & $0.02 \pm 0.01$ \\
\hline 70 & $0.01 \pm 0.00$ & $0.02 \div 0.01$ \\
\hline
\end{tabular}

Statistical significance of values versus 70 day-old animals: $p<0.001$. values were determined for male, fed rats by quantitative immunoassay. All values are given in $\mathrm{mmol} / \mathrm{mg}$ cytosolic protein, as means \pm SD of 4-7 samples. marked increase during postnatal development (Fig. 6.3), reaching adult values around day 21 in heart and between 40 and 70 days in liver, respectively. These data are contrary to the constant fatty acidbinding capacity observed during postnatal development in both heart and liver cytosol (Fig. 6.3., binding data from Ref 158). The FABP content of livers of prenatal animals shows a rise from less than 0.1 at 18 days of gestation to about $0.3 \mathrm{nmol} / \mathrm{mg}$ protein at term ( 22 days of gestation). 
The fatty acid binding capacity (after dealbuminization) of the cytosols of developing animals can not entirely be assigned to FABP, as for adult tissues. The difference may be due to another soluble protein that decreases in concentration during development, reciprocally to the increase in FABP concentration. This protein may be $\alpha$-fetoprotein, which is synthesized by the fetal liver and is known to bind unsaturated fatty acids with high affinity $[290,291]$. To assess the possible involvement of $\alpha$-fetoprotein in the fatty acid-binding capacity, the a-fetoprotein content of liver and heart cytosol was determined by immunochemical quantitation (Table 6.2). The data show a postnatal decline of $\alpha$-fetoprotein content of both tissue cytosols that is reciprocal to the increase of the FABP content. Rat $\alpha$-fetoprotein has one high affinity binding site and 12 or 13 binding sites with lower affinity for arachidonic acid 12901 . At the fatty acid concentrations used with the Lipidex assay these binding sites will not all be occupied. In addition to the $2.5 \mathrm{~mol}$ endogenously bound fatty acid per mol protein, $\alpha$-fetoprotein bound only about 2 mol exogenous fatty acid/mol when incubated with 9 fatty acids

Table 6.3.

Effect of various physiological parameters on FABP content and fatty acid-binding capacity of rat heart and liver cytosol.

\begin{tabular}{llll}
\hline Tissue & Animal & $\begin{array}{c}\text { FABp } \\
\text { content }\end{array}$ & $\begin{array}{c}\text { Olelc acid- } \\
\text { binding capacity }\end{array}$ \\
\hline Heart & Control & $3.81 \pm 0.38$ & $4.38 \pm 0.43$ \\
& Female & $4.87 \pm 0.51^{\mathrm{a}}$ & $5.94 \pm 0.79^{\mathrm{a}}$ \\
& Starved (66h) & $2.84 \pm 0.87$ & $4.02 \pm 1.37$ \\
& Clofibrate-fed & $3.12 \pm 0.76$ & $3.29 \pm 0.31^{\mathrm{b}}$ \\
& Derk phase & $2.87 \pm 0.52^{\mathrm{b}}$ & $2.59 \pm 0.40^{\mathrm{b}}$ \\
& & & \\
Liver & Control & $2.40 \pm 0.48$ & $2.21 \pm 0.30$ \\
& Female & $3.08 \pm 0.44$ & $3.44 \pm 0.71^{\mathrm{a}}$ \\
& Starved (66h) & $2.46 \pm 0.25$ & $3.25 \pm 0.64$ \\
& Clofibrate-fed & $3.32 \pm 0.36^{\mathrm{a}, \mathrm{c}}$ & $4.71 \pm 0.58^{\mathrm{b}}$ \\
& Dark phase & $277 \pm 0.39$ & $3.12 \pm 0.45^{\mathrm{b}}$ \\
\hline
\end{tabular}

Statistical significance of differences vs control: $P<0.01 ; D<0.001$. Statistical significance of differences between FABP content and oleic acid-binding capacity: ${ }^{c}$ p<0.01. FABP content was measured immunologically in cytosolic protein samples. Oleic acid-binding capacity yas derived from Scatchard plot analysis of binding isotherms at $37^{\circ} \mathrm{C}$ of dealbuminized, del ipidated cyrosolic protein preperations [158]. All values (expressed in $\mathrm{mol} / \mathrm{mg}$ cytosolic protein) are means \pm SO of $4-9$ samples. Control animals were male, adult, fed rats and were sacrificed in the light phase. 
Table 6.4.

Differences in liver FABP content among 7 inbred strains of rats.

\begin{tabular}{lcc}
\hline Strain & $\begin{array}{c}\text { Body weight } \\
(\mathrm{g})\end{array}$ & $\begin{array}{c}\text { FABP content } \\
(\mathrm{nmol} / \mathrm{mg})\end{array}$ \\
\hline Histar & $200 \pm 20$ & $2.40 \pm 0.48$ \\
HEK & $286 \pm 10$ & $4.44 \pm 0.40^{\mathrm{a}}$ \\
BN & $383 \pm 33$ & $3.46 \pm 0.23^{\mathrm{a}}$ \\
Brat & $318 \pm 38$ & $3.52 \pm 0.40^{\mathrm{b}}$ \\
SHR & $326 \pm 26$ & $3.21 \pm 0.30^{\mathrm{b}}$ \\
SD & $417 \pm 43$ & $2.77 \pm 0.07$ \\
S3 & $300 \pm 9$ & $2.99 \pm 0.77$
\end{tabular}

Statistical significance versus rats of Wistar strain $p<0.001{ }^{b} p<0.01$. values are given as means $t$ SO for 5 or 6 (male) enimals, with exception of the 53 group, which consisted of 3 animals. Wistar rats were 10-11 weeks old, all other animals were aged 15-96 weeks. at a concentration of 1.1-1.4 mol each/mol a-fetoprotein [292]. Even when all 14 binding sites would be occupied, the rather low absolute values of $\alpha$-fetoprotein content may only account for a part of the difference between FABP content and fatty acid-binding capacities of postnatal rat heart and liver.

The immunologically determined FABP content and the fatty acid-binding capacity determined with $\left[{ }^{14} \mathrm{C}\right]$ oleic acid [158] show a good agreement under all physiological conditions for adult animals (Table 6.3), except in liver of clofibrate-fed animals. The FABP

content of both heart and liver cytosol is higher in female than in male animals. Clofibrate treatment for 8-10 days does not affect the FABP content of heart, but induces a $38 \%$ increase in liver. The FABP content of rat liver is not influenced by starvation, or by the diurnal cycle. In heart, a slight decrease of FABP content is observed at mid-dark phase, and after a $66 \mathrm{~h}$ starvation period.

When seven inbred strains of rats were examined for their hepatic FABP content (Table 6.4), statistically significant inter-strain differences were found. The wistar rats were a few weeks younger than the other animals, but FABP content does not increase at older age in wistar rats $[238,239,519.6 .31$.

Much more drastic effects were found on liver FABP content than on $\mathrm{SCP}_{2}$ content in rats maintained for 3 weeks on diets supplemented with agents that are known to modify lipid metabolism (Table 6.5). Except for clofibrate, all agents cause a marked decrease of hepatic FABP content. In contrast to the marked decrease now observed after 3 weeks of cholestyramine feeding, we previously found a rise of liver FABP content upon addition of cholestyramine for 5-7 days $(164,293)$. Addition of clofibrate to the diet gave a comparable increase of liver FABP as clofibrate administered by oral canula (Table 6.3). Others observed a somewhat stronger effect of clofibrate on liver FABP content 25,150 , $228,284]$, but this may relate to a higher clofibrate dose. 
Table 6.5 .

Influence of various agents on the FABP and $\mathrm{SCP}_{2}$ content of liver.

\begin{tabular}{|c|c|c|}
\hline Treatment & $\begin{array}{l}\text { FABP content } \\
\text { (nmol/mg protein) }\end{array}$ & $\begin{array}{c}\mathrm{SCP}_{2} \text { content } \\
\text { (mol/ming proteln) }\end{array}$ \\
\hline Contral & $2.30 \pm 0.24$ & $0.036 \div 0.002$ \\
\hline Cholesterol & $0.94 \pm 0.29^{\mathrm{a}}$ & $0.035 \div 0.002$ \\
\hline Cholestyramine (2\%) & $0.51 \neq 0.11^{8}$ & $0.037 \pm 0.002$ \\
\hline Mevinolin & $066 \pm 0.18^{8}$ & $0.031 \pm 0.004$ \\
\hline Clofibrate & $2.85 \pm 0.23$ & $0.027 \pm 0.001$ \\
\hline Cholate & $0.94 \pm 0.17^{\circ}$ & $0.028 \pm 0.001$ \\
\hline
\end{tabular}

Statistical significance of data versus control: a p<0.0001. Cytosolic FABP content was measured by immunoassay. Data were obtained from 11-weekold Wistar rats, which had received the indicated agent together with $5 \%$ ol ive oil for 21 days. Control animals were fed a diet containing only $5 \%$ olive 011 . Values are given as means \pm SD of 5 animals. SCP 2 data are derived from Geelen et al. [288]

\subsection{DISCUSSION.}

The absence of cross-reactivity of FABPs from heart and liver with their respective antisera in ELISA and on Western blots established the earlier proven existence of discrete liver and heart FABP types. Most of our data on the distribution of heart and liver FABP are comparable with the results obtained by others with ELISA [152] or immunodiffusion [151,155,157]. The contents of liver FABP and heart FABP in liver and heart agree quite well with the values determined immunochemically by others [87,150-152] . Comparison of our data on oleic acid-binding capacity [158] and FABP content shows that fatty acid-binding capacities are markedly higher in brain and kidney. Adrenal cytosol contains almost no detectable heart or liver FABP, but has a relatively high oleic acid-binding capacity [158]. These observations imply the presence in these tissues of some other protein(s) that account for the high fatty acid-binding capacity. Bass et al. [161] described the presence of two FABPs in brain, the minor component of which reacted with antiserum to liver FABP. Whole brain cytosol did not react, however [161]. Senjo et al. [96] did not find a cross-reactivity of antiserum to liver FABP with FABP from rat brain. Fujii et al. [294] recently showed that rat kidney contains a type of FABP that is different from liver FABP. FABPs of lung and adipose tissue were reported to be closely related to liver FABP [89,162]. By contrast, we found a reaction of antibodies to heart FABP with a protein of about $15 \mathrm{kDa}$ in lung cytosol. Antiliver FABP only reacted with protein(s) of higher molecular mass 
in lung cytosol.

The observed presence of heart and liver FABP types in various tissues is compatible with the distribution of rat heart and liver FABP mRNA. Relatively high levels of heart FABP mRNA were found in slow twitch muscle (e.g. soleus), intermediate levels in fast twitch skeletal muscle, and low levels in kidney, brain and adrenal $[123,124]$. Rat liver FABP $m R N A$ is present in high concentrations in liver and intestine [167]. At most, trace amounts were detected in other tissues investigated.

At cell fractionation of heart as well as liver, FABP was solely found in the cytosol. Others made similar observations for liver FABP, on the basis of immunocytochemical studies [169], and for heart FABP with ELISA [152]. Ockner \& Manning [146] found 16\% of rat intestinal FABP associated with various intracellular membranes. For rat heart a gradient-like distribution of FABP (with 158 present in mitochondria) was suggested, based on immunoelectron microscopical observations [165]. The group of spener $[176,1 \mathrm{~m}$ observed binding of FABP to bovine liver and heart mitochondria by gold-label electron microscopy and immunodiffusion. The closely related cellular retinol-binding protein of rat liver is confined to the cytosol [295]. The subcellular distribution of FABP differs clearly from that of non-specific lipid transport protein or $\mathrm{SCP}_{2}$ and phosphatidylcholine transfer protein, 70 and $60 \%$ of which are located in the cytosol, respectively $[180-182]$.

Our values on postnatal development agree with those of ockner et al. [87,223], who described a comparable increase of rat liver FABP content between 30 and 60 days of age. Measurements of bromosulfophthalein binding [239] also indicated an increasing FABP content in liver, only the maximal value was reached between 20 and 30 days of age. An approximately 10-fold increase of rat liver FABP content was observed with a fluorescence-enhancement method [238], although with lower absolute values. Developmental changes of FABP content of heart were also reported by Crisman et al. [152]. The increase of heart FABP content parallels the change in the palmitate oxidation capacity of heart from 0 to 70 days after birth [231]. In rat 1 iver, the palmitate oxidation capacity increases from birth up to 3 weeks and then decreases almost 2-fold [231], while the FABP content rises further after 3 weeks.

The reciprocal changes of FABP and $\alpha$-fetoprotein contents in both liver and heart of postnatal rats may account to some extent for the constant fatty acid-binding capacities [158]. The decrease of $\alpha$-fetoprotein IRNA in liver after birth [296] is compatible with the observed decrease of $\alpha$-fetoprotein concentration. 
Until now, no data were available on the presence of this protein in heart. Trojan and Uriel [297] reported the presence of $\alpha$-fetoprotein in the cytosol of a number of other tissues in newborn rats, and its disappearance during the first weeks after birth. It is interesting to note that agents known to modify lipid metabolism, as well as different physiological conditions, affect the hepatic FABP content. The agreement of FABP content and fatty acid-binding capacity in adult rats at most physiological conditions supports a $1: 1$ stoichiometry of fatty acid binding to FABP. On the other hand, this agreement may also indicate a regulation of FABP concentration at the transcriptional and/or translational level, and not by a rapidly acting activation/ deactivation mechanism. A similar conclusion was drawn from measurements of FABP mRNA production [150,167], and turnover studies (227).

Discrete functions of heart and liver FABP types are clearly suggested by the structural differences of the proteins $125,27,79,85$, $90,110,1171$. Their different response to physiological variations, their tissue distribution and the clearcut difference in concomitant changes of FABP content and fatty acid oxidation capacity of heart and liver are other indications in this respect.

In conclusion, assay of fatty acid-binding capacity may not always give an accurate measure of the FABP content of dealbumirized cytosols, due to the presence of other proteins with fatty acid-binding ability. It should be emphasised that immunochemical data have to be based on two procedures, e.g. Western blotting and ELISA, to ensure the specificity of the immunoassay. Combination of data of fatty acid-binding capacity and of qualitative and quantitative FABP content may help to gain more insight into the number of different FABP types, and their tissue and functional specificity.

\subsection{SUMMARY.}

Antisera against rat heart and liver FABP were applied in Western blotting analysis and ELISA, to assess their tissue and intracellular distribution, and the influence of development, physiological conditions and several agents on the FABP content of tissue cytosols. The data obtained are compared with the oleic acid-binding capacity. Heart FABP is found in high concentrations in heart, skeletal muscles, diaphragm and lung, and in lower concentrations in kidney, brain and spleen, whereas liver FABP is limited to liver and intestine. In heart and liver, FABP is 
only present in the cytosol. The FABP content of both heart and liver shows a progressive increase during the first weeks of postnatal development, in contrast to their constant oleic acidbinding capacity. The reciprocally declining a-fetoprotein content of both tissues may partially account for the complementary fraction of the fatty acid-binding capacity. The FABP content and the fatty acid-binding capacity of adult heart and liver were in good accordance under various physiological conditions. Addition of clofibrate to the diet induces an increase of liver FABP content, whereas feeding of cholesterol, cholestyramine, mevinolin or cholate caused a marked decrease. The significance of the combined determination of fatty acid-binding capacity and FABP content (by immunochemical quantitation and blotting analysis) is indicated. 


\section{Distribution of liver and heart FABP types} in human and porcine tissues.*

\subsection{INTRODUCTION.}

Long-chain fatty acids are an important energy source in many mammalian tissues, and take part in various biosynthetic processes. Due to their hydrophobic nature, carrier systems are essential for transport of these substances through the aqueous environments of the organism. Within the cell fatty acid-binding proteins (FABPs) are postulated to assume this carrier function [28]. FABPs are present in the cytosol of (nearly) all mammalian tissues, and have a molecular mass of 14-15 kDa and a high affinity for long-chain fatty acids as common features. A number of different FABP types exist, each with its own ligand specificity and chemical structure. Until now five distinct FABP types have been identified: hepatic, cardiac, intestinal, adipose tissue and renal FABP $[25,26,28,102]$. The tissue distribution of the liver and heart FABP types was mainly studied in the rat by immunochemical [150-153] and immunohistochemical methods [170,173,243] and by dot-blot analysis of specific mRNAs $[123,124,167$. These studies showed a rather complex distribution pattern, in which the presence of each type is not restricted to one tissue. In intestine and kidney, there even is a simultaneous expression of two FABP types. Studies of the amino acid and CDNA sequences of FABPs established a considerable homology between the FABPs from homologous tissues of different species (for a recent review see [28] ) .

Comparison of the tissue distribution of corresponding FABP types in different species may help to get a better insight into the relation of the distinct types of this protein to the (tis-

- This chapter was adapted from Paulussen et al., 1989 [148]. 
sue-related) differences in fatty acid metabolism. Data on the FABP content of human tissues amy also become useful reference values for investigations in pathological conditions. Therefore we studied the immunological cross-reactivity of liver and heart FABPs from man, pig and rat, and the tissue distribution of liver and heart FABP types in man and pig.

\subsection{METHODS.}

origin of tissues and preparation of cytosols.

Human tissue samples were either obtained from autopsies conducted within $20 \mathrm{~h}$ after death, or from biopsies taken at open surgery. Placentas were obtained shortly after delivery. Samples of pig tissues were collected fresh at the slaughterhouse, placenta at the farm. The materials were either stored at $-70^{\circ} \mathrm{C}$ or used immediately. Rat tissues were obtained from fed, male albino Wistar rats $(200 \pm 20 \mathrm{~g})$. Cytosols were prepared as described in section 3.3 .

Human umbilical cord artery endothelial cells were cultured as described [298], and obtained from Dr. Van Hinsbergh (Gaubius Institute TNO, Leiden, The Netherlands). Cultured rat coronary microvascular endothelial cells were obtained from Dr. H. Piper (Dept. Physiology, University Dusseldorf, FRG).

Isolation of FABPs.

Heart FABPs were isolated from heart cytosols by gel filtration on Sephacryl s-200 and DEAE-cellulose anion-exchange chromatography as described [B4]. Additionally, traces of myoglobin were removed from the preparations by CM-cellulose chromatography in $20 \mathrm{mM} \mathrm{K}$-phosphate/ $154 \mathrm{mM} \mathrm{KCl} \mathrm{(pH} \mathrm{6.0).} \mathrm{Liver} \mathrm{FABPs}$ were obtained by the procedure described by Peeters et al. [83]. FABPs from muscle were purified by gel filtration, anion- and cation-exchange chromatography [260]. FABP from rat kidney was isolated by gel filtration and DEAE-cellulose anion-exchange chromatography as described for rat heart FABP (B4). It was eluted with $50 \mathrm{mM}$ Tris $-\mathrm{HCl}(\mathrm{pH} 8,0)$, and further purified by filtration on Sephadex G-50. Its specific binding activity amounted to 25 nmol/mg protein at $1 \mu M\left(1-{ }^{14} \mathrm{C}\right]$ oleic acid. 
Preparation of antisera.

Antisera against FABPs were raised in New zealand white rabbits. The immunization procedure and the determination of antibody titers are described in section 3.5. IgG-fractions of the antisera were prepared with protein-A Sepharose as described by Goudswaard et al. [266].

Enzyme-linked immunosorbent assays.

Cross-reactivities of FABPs with anti-FABP sera were determined from stepwise dilutions of the antiserum with $250 \mathrm{ng}$ FABP coated per well. Cross-reactivity was determined as the reciprocal of the serum dilution required to obtain half maximal absorbance, and expressed as percentage of the value obtained with the specific antigen-antibody combination.

The enzyme-linked immunosorbent assay for quantitative measurements of FABP concentrations were performed as described in section 3.5. Cytosolic protein (50 and $100 \mathrm{ng}$ ) was adsorbed to 96-well microtitre plates by overnight incubation at $20^{\circ} \mathrm{C}$. The cytosolic FABP was probed with anti-FABP IgG, and peroxidaseconjugated swine-anti rabbit Igg was used as second antibody. The complex was visualised by incubation with o-phenylene diamine. The reaction was terminated by addition of $0.5 \mathrm{vol} . \mathrm{H}_{2} \mathrm{SO}_{4}(12.5 \%$, $v / v)$, and the product of the reaction was measured at $492 \mathrm{~nm}$ with a Titertek Multiscan. Results were determined by reference to a standard curve (0-7 ng FABP). Recovery of $2 \mathrm{ng}$ FABP added to 100 ng cytosolic protein was $105 \pm 16 \%(n=11)$. Molecular masses used in all calculations were 14,768 Da for human heart FABP [109], and $14,178 \mathrm{Da}$ for human liver FABP [105]. Estimates of 14,800 and 14,200 Da were used for pig heart and liver FABP, respectively.

Electrophoresis and immunoblotting.

Polyacrylamide slabgel electrophoresis was carried out according to Laemmi 1267$]$ with 7.5-20\% acrylamide gradient gels $(0.7 \mathrm{~mm}$ thick) in $0.1 \%$ SDS at $\mathrm{pH} 8.8$. Gels were immediately used for blotting of the proteins to nitrocellulose paper, followed by immunostaining. The procedures are described in section 3.6 . 
FABP preparations were isolated from tissue cytosols of human, porcine and rat origin by gel filtration and ion-exchange chromatography, and used to raise polyclonal antisera in rabbits. IgG fractions of the antisera were isolated, and their specificity was confirmed on Western blots of cytosols.

The cross-reactivities of the various FABPs were assessed with their antisera. Based on the reactivities of FABPs from rat tissues, the hepatic and cardiac types are clearly distinguishable. Similarly to rat, the FABPs from heart and liver of man and pig do not cross-react with their respective antisera (Table 7.1). The reactivity of the FABP preparation from rat kidney with anti-rat heart FABP $(98 \pm 19 \%)$, and the cross-reaction of rat heart FABP with antibodies against the FABP from rat kidney (58 $\pm 6 \%$ ) indicate a strong homology of these two proteins. Recent$1 Y$, it was established that kidney contains two distinct FABPs, one of which is identical to the heart type [102].

The interspecies cross-reactivity of heart and liver FABPs from man, pig and rat with their antisera is shown in Table 7.1. Although obviously related, there are considerable species differences with the heart and liver FABP types. The epitopes shared by the three hepatic FABPs apparently are the most immunogenic sites of pig liver FABP, resulting in a comparable reactivity of anti-pig liver FABP IgG towards all three liver FABPs. Anti-human

Table 7.1.

Cross-reactivity between FABPs from human, pig and rat heart and liver and their antisera.

\begin{tabular}{|c|c|c|c|c|c|c|c|}
\hline \multirow[b]{2}{*}{ FABP } & & \multicolumn{4}{|c|}{ Antiserum against FABP from } & \multicolumn{2}{|c|}{ rat } \\
\hline & & heart & liver & heart & liver & heart & liver \\
\hline \multirow[t]{2}{*}{ Human } & heart & 100 & 8 & $\pi$ & 2 & 9 & $\ll 1$ \\
\hline & liver & 4 & 100 & 3 & 104 & 2 & 76 \\
\hline \multirow[t]{2}{*}{ Pig } & heart & 72 & 1 & 100 & 2 & 4 & $<1$ \\
\hline & liver & 2 & 34 & 1 & 100 & $<1$ & 63 \\
\hline \multirow[t]{2}{*}{ Rat } & heart & 16 & 4 & 14 & $<1$ & 100 & 2 \\
\hline & liver & 12 & 58 & 2 & 81 & $<1$ & 100 \\
\hline
\end{tabular}

Antiserum dilutions at which half maximal binding was obtained in an ELISA were taken os measure for the immunochemical cross-reactivity of the FABPs. Per well $0.25 \mu \mathrm{g}$ FABP was used. Values are means of at least 2 determinations, and given as percentage of the binding of the the specific antiserum to its specific antigen. 
Table 7.2 .

Tissue distribution of human heart and liver faBp types.

\begin{tabular}{|c|c|c|}
\hline \multirow[t]{2}{*}{ Tissue } & \multicolumn{2}{|c|}{ Protein reactive with } \\
\hline & ant1-heart FABP & anti-liver FABP \\
\hline Heart & $20.8 \pm 1.5(3)$ & $3.3 \pm 1.3(3)$ \\
\hline Liver & $2.8 \pm 1.2(3)$ & $33.0 \pm 5.7(9)$ \\
\hline M.gastrocnemius & 12.6 & \\
\hline M.gluteus & $7.1 / 6.2(2)$ & \\
\hline M.quodr Iceps & $10.6 \pm 2.2(14)$ & $1.1 \pm 1.4(9)$ \\
\hline M.psoas & $9.6 \pm 1.9(5)$ & $1.1 \pm 1.7(7)$ \\
\hline Kidney - whole & $6.1 \pm 1.3(4)$ & $2.6 \pm 0.6(4)$ \\
\hline - cortex & $7.1 \pm 3.0(5)$ & $3.4 \pm 0.9$ (5) \\
\hline - medulla & $5.8 \pm 2.8(6)$ & $3.1 \pm 1.3(6)$ \\
\hline Brain - cortex & $5.5 \pm 2.1(5)$ & $3.3 \pm 0.3(3)$ \\
\hline Placenta & $2.8 / 5.2(2)$ & $37 / 4.3(2)$ \\
\hline
\end{tabular}

The FABP content of eytosols was determined in a quantitative ELISA as the amount of protein reactive with IgG-fractions of antisera against human heart and liver FABP. Data were obtained from multiple determinations of each sample at two cytosolic protein concentrations. Values are expressed in $\mu \mathrm{g} / \mathrm{mg}$ protein and are means I SD of the number of samples indicated within parentheses.

liver FABP relatively is the most species-specific. Antisera against cardiac FABPs showed a larger cross-reactivity between man and pig than between rat and man or pig.

To study the tissue distribution of the distinct FABP types, we determined the reactions of $1 \mu \mathrm{g}$ cytosolic protein from a large series of tissues with serial dilutions of specific antiFABP sera, as a relative measure for the occurrence of different FABPs $[82,277]$. The values are, however, biased by the combination of variations in cross-reactivities of the FABP types towards the antisera, and differences in the FABP content between tissues. To get more accurate information on the presence of distinct FABPs and their concentrations in different tissues of man and pig, a quantitative ELISA procedure was applied, that was previously used for the assessment of FABP concentrations of rat tissue cytosols [153].

The concentrations of liver FABP in human and pig tissues (Tables 7.2 and 7.3 ) are comparable to those found in the rat tissues [153]. Some minor reactivities were found in other tissues, but hepatic FABPs are only found in significant amounts in liver 
Table 7.3.

Tissue distribution of pig heart and liver FABP types.

\begin{tabular}{llr}
\hline Tissue & \multicolumn{2}{c}{ Protein reactive with } \\
\cline { 2 - 3 } Heart & $15.7 \pm 0.3(4)$ & $5.7 \pm 2.0(3)$ \\
Liver & $3.4 \pm 1.3(3)$ & $59.9 \pm 12.1(3)$ \\
Skeletal muscle & $9.3 \pm 1.5(3)$ & $2.7 \pm 0.4(3)$ \\
Kidney & $5.2 \pm 1.5(5)$ & $2.8 \pm 1.6(3)$ \\
Brain & $5.3 \pm 0.7(3)$ & $1.7 \pm 0.3(3)$ \\
Spleen & $3.0 \pm 0.1(3)$ & $1.8 \pm 0.1(3)$ \\
Lung & $6.5 \pm 1.2(3)$ & $1.6 \pm 0.1(3)$ \\
Placenta & $8.4 \pm 0.9(6)$ & $1.8 \pm 0.3(6)$
\end{tabular}

The FABP content of cytosols was determined in a quantitative ELISA, as described in Table 7.2. Values are expressed in $\mu \mathrm{g} / \mathrm{mg}$ protein, and are means \pm SD of the number of samples indicated with in parentheses.

itself and in intestine. In a biopsy sample of the proximal part of human jejunum, the hepatic FABP content $(29.1 \mu \mathrm{g} / \mathrm{mg}$ cytosolic protein) was comparable to that of liver. This observation agrees quite well with the relative hepatic FABP content of rat small intestine [151]. The large intestine of rat contains less FABP [151.153]. Kamisaka et al. [159] found concentrations of $0.86,0.28$, 0.18 and $0.13 \mathrm{mg}$ immunereactive protein/g tissue with anti-liver FABP in human liver, kidney, heart and jejunum, respectively. Pig liver bound 71 pmol palmitoyl-COA per $\mathrm{mg}$ protein [234]. This value is much lower than the FABP content $(4.22 \mathrm{nmol} / \mathrm{mg}$ protein) we found. The FABP content of bovine liver cytosol [179] is comparable to our data on liver of man, pig and rat.

Heart FABPs are found in high concentrations in heart and skeletal muscles, lower amounts are present in kidney, and brain (Tables 7.2 and 7.3). The concentrations are, however, generally higher for rat [153], than for man and pig. Rat heart contains about $55 \mu \mathrm{g} / \mathrm{mg}$ cytosolic protein [152,153], but only $3.2 \mu \mathrm{g} \mathrm{FABP} / \mathrm{mg}$ protein was reported for bovine heart cytosol [178]. The finding of FABP in pig muscle is in contrast with its reported absence on basis of palmitoyl-COA binding [234].

Concomitantly with the lower FABP concentration, the palmitate oxidation capacity of human heart is also considerably lower than that of rat heart [231]. The FABP concentrations of human 
heart, m.quadriceps and m.gluteus correspond with the fatty acid oxidation capacity of these tissues. Fatty acid oxidation capacity [231] and FABP content $[153,157,158,260]$ of rat slow-twitch muscles are higher than of fast-twitch muscles. These differences in FABP content are in accordance with the distribution of cardiac FABP mRNA $[123,124]$. The average amount of protein of m.quadriceps cytosol reactive with anti-heart $F A B P$ corresponds with the value determined with anti-muscle FABP [260]. These observations, and the high degree of similarity of human heart and muscle FABP [260], put some doubt to the existence of a muscle specific FABP type, as was suggested by some authors $[299,300]$.

The comparable reaction of cytosol from human kidney cortex and medulla with anti-human heart FABP is consistent with the equal distribution of the heart FABP type in rat kidney [102]. The renal FABP type, that is predominantly located in the cortex [102], is not detected by this antibody. Both types could be isolated from human kidney cortex (Maatman and veerkamp, to be published).

The cytosol of human and porcine brain contains a comparable amount of protein reactive with antibodies against heart FABP as rat brain cytosol [153]. Since fatty acids may deliver only a minor contribution to energy production in brain 1231,3011, the presence of FABP in this tissue indicates a role for these proteins in other processes than $\beta$-oxidation.

The FABP contents of pig spleen and lung are lower than in these tissues of rat [153]. With anti-pig liver FABP antibodies, only a slight reactivity was found. Haq et al. [162], however, reported rat lung FABP to be immunologically related to the liver type. Bass et al. (151) found only a slight reaction of lung with antibodies against rat heart FABP, but could not detect any FABP in spleen immunologically. Heuckeroth et al. [124] did not observe heart FABP mRNA in spleen or lung, but others [167] found low concentrations of mRNA sequences homologous to rat liver and intestinal FABP cDNA in rat spleen and lung cytosol.

In human placenta, the content of anti-FABP reactive protein was low. In pig placenta, the FABP content appears to be higher, and its structure closer related (possibly similar) to cardiac than to hepatic FABP. Based on fatty acid binding, FABP was previously found in placenta of rat [302] and rabbit [303), but not of man (303) and pig [304]. Recently FABP was purified from human placenta [305]. Its characteristics were more comparable to the hepatic than to the cardiac type, but only heart FABP mRNA was found in rat placenta $[117,124]$. FABP may be important for the high utero-placental fatty acid transfer observed in some species, as man and rat [306]. In other species, this process appears to be 
limited, e.g. in pig [307]. However, fatty acid oxidation and synthesis take place in placenta of all species by the end of gestation [300].

With anti-heart FABP antibodies, FABP could be detected in cultured human endothelial cells in approximately one third of the concentration in heart $(8.7$ and $6.1 \mathrm{\mu g} / \mathrm{mg}$ cytosolic protein, 2 samples). Rat heart FABP type was found in cultured rat endothelial cells in a comparable concentration. The presence of FABP in endothelial cells may have important implications for the understanding of the transport of fatty acids from the capillaries to the tissue cells. Albumin is believed to play an important role in this process. Albumin-fatty acid complexes can pass the endothelial cells by transcytosis, a process that possibly involves specific albumin-binding proteins $[29,30]$. Albumin may also function as a fatty acid-carrier through the interstitial fluid [31]. Scow and colleagues proposed a model in which fatty acids are transferred by lateral movement in membranes [32]. Neither view encompasses a role for intracellular FABP in endothelial cells.

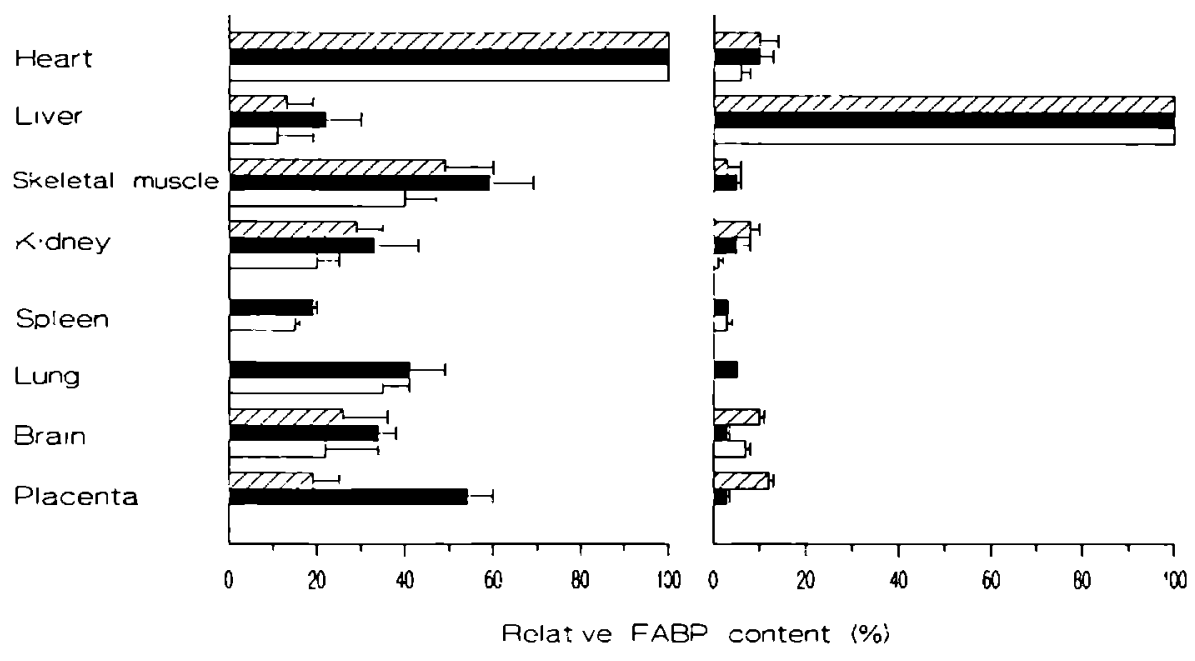

EPA $\operatorname{man}$
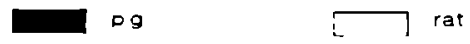

Fig. 7.1. Relative content of heart and liver FABP types in human, pig and rat tissues. The FABP concentrations of cytosols of various $t$ issues were determined as the anount of protein reactive with antibodies against heart (upper panel), or liver faBp (lower panel) from the same species. Values are expressed as percentages, relative to the FABP content of heart or liver. 
Immunocytochemical studies showed that FABP was present in all compartments of rat heart, the capillary endothelium, the intercellular spaces and the myocytes [165]. The presence of heart FABP and its mRNA in rat aortic tissue were established with polyclonal antibodies and a cDNA probe [166]. The concentration of FABP in the interstitial fluid of rat heart, however, appeared to be very low [309]. Therefore its role is likely to be confined to the intracellular compartments of the various heart cells.

The data presented in this and our previous study [153] demonstrate a similar tissue distribution of the distinct FABP types in man, pig and rat. Although the absolute concentrations vary, a clear analogy among these three species appears when the heart and liver FABP contents of the various tissues are expressed relative to their concentration in heart or liver (Fig. 7.1). The apparent evolutionary preservation of the association of distinct FABP types with specific tissues, with their specific patterns of fatty acid utilization, supports the assignment of a major role for these FABPs. The different FABP types may perform distinct roles in intracellular fatty metabolism.

\subsection{SUMMARY.}

Antisera against heart and liver FABPs were used in ELISA to study the cross-reactivity between these FABP types of man, pig and rat, and to assess their tissue distribution in man and pig. No cross-reactivities were found of heart FABPs with antiliver FABP-sera and vice-versa. With the liver FABPs, marked species differences were found, but the three proteins are clearly related. Human and pig heart FABP are immunochemically closer related to each other than to this protein from rat heart. The tissue distribution of heart and liver FABP types is similar in man, pig and rat. Liver FABP is only found in liver and intestine, and heart FABP is present in heart, skeletal muscle, kidney, lung, brain and placenta. Cardiac FABP is also found in cultured human and rat endothelial cells. The FABP content of human and pig liver is comparable to that of rat liver, but the tissue concentrations of heart FABP are lower in man and pig than in rat. When the latter values are expressed relative to the FABP content in heart, analogous distribution patterns are observed in man, pig and rat. 

Fatty acid-binding protein(s) (FABPs) are believed to play a crucial role in the intracellular transport and storage of long-chain fatty acids and acyl-derivatives. The presence of FABPs in most mammalian tissues in relatively high concentrations, is a clear indication for an important role of these proteins in intracellular fatty acid metabolism. In Chapter 2 the current state of knowledge on these proteins is presented. Chapter 3 gives the materials and general procedures applied during this study. The subsequent chapters of this thesis describe investigations that deal with the characteristics of FABPs from heart (Chapter 4), the influence of various conditions on FABP content (Chapters 5 and 6 ), and the tissue distribution of heart and liver FABP types in man, pig and rat (Chapters 6 and 7 ).

FABPs were isolated from heart cytosols of man, rat and pig by gel filtration and anion-exchange chromatography (Chapter 4). The heart FABPs can be clearly distinguished from their liver counterparts on basis of their physico-chemical characteristics (molecular mass, isoelectric point, amino acid composition, and their immunochemical properties), and their ligand specificity. only long-chain fatty acids and their CoA- and carnitine-derivatives bind to heart FABP, whereas liver FABPs bind a variety of low-molecular-weight hydrophobic ligands.

The cytosolic fatty acid-binding capacity of rat tissues was estimated as a measure for their FABP content (Chapter 5). After removal of residual albumin by immuno-affinity chromatography, and delipidation, this capacity was determined by a radiochemical binding assay, using Lipidex 1000 to separate free and proteinbound ligand. Based on the oleic acid-binding capacity, FABP is present in high concentrations in liver, heart, skeletal muscle, 
brain, kidney, diaphragm and adrenal. The FABP content of these tissues amounts to 2-6\% of total cytosolic protein. During postnatal development, the fatty acid-binding capacity does not change appreciably in heart and liver cytosol. The oleic acidbinding capacity is higher of cytosolic proteins of heart and liver from female than from male rats. The cytosolic fatty acidbinding capacity is markedly influenced by starvation and clofibrate treatment in liver, but not in heart. The diurnal rhythm has only a minor effect in heart and liver.

Antisera against FABPs from human, porcine and rat tissues were used to study the degree of immunochemical cross-reactivity and tissue distribution of FABP types. An enzyme-linked immunosorbent assay was developed for the quantitation of heart and liver FABPs in human, pig and rat tissue cytosols (Chapters 6 and 7).

The tissue distribution of heart and liver FABP types is similar in all three species. The presence of hepatic FABP is limited to liver and intestinal mucosa, only minor reactivities with the antibodies were observed in other tissues. Cardiac FABP has a much wider tissue distribution, and is found in heart, skeletal muscles, kidney, lung, brain and placenta. The observed tissue distribution of the heart and liver FABP types is in good agreement with the reported distribution of liver and heart FABP mRNAS.

The cytosolic content of cardiac FABP decreases in the order heart > slow-twitch muscle > fast twitch muscle > other tissues. The FABP concentration of liver is comparable in man, pig and rat. The absolute concentrations of heart FABP type are lower in tissues of man and pig than of rat, but when the concentrations are expressed relative to the concentration in heart, a similar distribution pattern is obtained for all three species. The observed FABP concentrations of heart and muscles are in accordance with the palmitate oxidation capacities of the tissues. There is a good agreement between the FABP content (Chapter 6) and the cytosolic fatty acid-binding capacity of rat tissues (Chapter 5) for liver, heart and muscle, but not for brain, lung, kidney, diaphragm and adrenal. These differences indicate the existence of more tissue-specific FABP types than the liver and heart types. During postnatal development the FABP content of rat heart and liver markedly increased, but the oleic acid-binding capacity is already at adult level at birth. $\alpha$-Fetoprotein is present in the cytosols in a concentration that decreases reciprocally to the raising FABP content, but this can only partially explain the observed difference. 
The discrepancy between fatty acid-binding capacity and FABP content during postnatal development, and the differences in the cytosolic binding capacity and content of heart or liver FABP type of some tissues, imply an important warning against the use of a single parameter for quantitative measurements in these studies. The existence of (at least) five distinct FABP types, and the tissue-related differences in FABP content, oblige an intercomparison of several, independent, methods, to obtain reliable values on cytosolic FABP content.

In conclusion, FABPs are a group of low-molecular-weight cytosolic proteins, that are present abundantly in mammalian tissues. Although still no conclusive evidence is available for the role of these proteins, the accumulated knowledge indicates distinct functions for the different FABP types. Liver FABP type acts as a rather general intracellular carrier for hydrophobic compounds, whereas the cardiac type is a more specialized binding protein. The presence of the heart FABP type only in tissues that rely on fatty acids as their major energy source, suggests that the main physiological function of this protein is the delivery of fatty acids to the $\beta$-oxidation systems. The consistency of heart FABP content in response to various physiological conditions is compatible with this view. The marked changes in the liver FABP content may be related to other functions of this protein that are distinct from the role of the cardiac FABP type. The apparently limited tissue distribution of other FABP types indicates a relation of these proteins to tissue-specific processes. 

Hogere organismen hebben een zeer complexe struktuur, met organen en weefsels met sterk gespecialiseerde functies. Voor een gericht transport van regulerende stoffen, bouwstenen, en energie leverende verbindingen naar de cellen in het lichaam waar deze stoffen nodig zijn is een effectief mechanisme nodig. Ook intracellulair zijn gerichte transportprocessen van grote betekenis. In de laatste decennia $z i j n$ een aantal oplosbare eiwitten gevonden, die hierbij een belangrijke rol spelen. zo zijn in het bloed een groot aantal eiwitten betrokken bij vervoer van hormonen en vitaminen. Het serumalbumine is een meer algemeen transporteiwit voor slecht water-oplosbare verbindingen, en speelt een belangrijke rol bij het transport van vrije vetzuren. Vetzuren worden ook getransporteerd in triacylglycerolen, fosfolipiden en cholesterolesters, die deel uitmaken van lipoproteinen en chylomicronen.

In de cel vormt het cytoplasma een barrière voor vervoer van hydrofobe verbindingen tussen de plasmamembraan en de celorganellen waar die moleculen gemetaboliseerd worden. Om de passage door het cytoplasma mogelijk te maken bevat de cel een aantal specifieke bindingseiwitten, met een hoge affiniteit voor verschillende (groepen) verbindingen, als fosfolipiden, cholesterol, retinol. Tot deze groep intracellulaire transporteiwitten behoren de vetzuurbindende eiwitten (fatty acid-binding proteins, FABPs). Deze groep eiwitten is betrokken bij het transport van vetzuren en mogelijk hun coenzym A- en carnitine-esters. FABPs werden ontdekt aan het einde van de jaren zestig. sindsdien is veel bekend geworden over deze eiwitten. De aanwezigheid van FABPs in de meeste weefsels van zoogdieren, in relatief hoge concentraties, is een sterke aanwijzing voor een belangrijke rol voor deze eiwitten bij het vetzuurmetabolisme. Het onderzoek dat in dit 
proefschrift beschreven wordt, was erop gericht om meer kennis te verwerven over de struktuur en eigenschappen van de FABPs en hun functie in verschillende weefsels van de mens, het varken en de rat.

In Hoofdstuk 2 wordt een overzicht gegeven van de huidige kennis van FABPs (de resultaten van de in de latere hoofdstukken beschreven onderzoeken zijn hierin reeds verwerkt). Uit de literatuur wordt duidelijk dat er verschillende typen FABP bestaan, die in verschillende weefsels gevonden worden. In de nier en in darmepitheel komen zelfs tegelijkertijd twee typen van het eiwit voor. Waarschijnlijk zijn de verschillende typen van het FABP aangepast aan de verschillen in het vetzuurmetabolisme van de weefsels. In dit hoofdstuk wordt een gedetailleerde beschrijving gegeven van de struktuur en de eigenschappen van de verschillende typen.

Hoofdstuk 3 geeft de herkomst van de gebruikte materialen en een beschrijving van de toegepaste experimentele procedures. Hoofdstuk 4 behandelt de isolatie van FABPs uit hartweefsel van mens, varken en rat met behulp van gelfiltratie en anionenuitwisselings chromatografie en de karakterisering van deze eiwitten. De drie eiwitten verschillen wel in aminozuursamenstelling, maar lijken toch sterk op elkaar. Op basis van fysischchemische eigenschappen (molecuulgewicht, isoelektrisch punt, aminozuursamenstelling en immunochemische eigenschappen) en ligandspecificiteit kan het hart FABP type duidelijk onderscheiden worden van het lever type. Hart FABP bindt alleen vetzuren en vetzure esters, terwijl het lever FABP type ook andere hydrofobe liganden kan binden.

In Hoofdstuk 5 worden effecten van fysiologische condities en van postnatale ontwikkeling en clofibraat toediening op het cytosolisch FABP gehalte van weefsels van de rat bestudeerd. Als maat voor het FABP gehalte werd de vetzuurbindingscapaciteit van cytosolisch eiwit bepaald met een radiochemische methode. Voorafgaand aan de bepaling werd eventueel aanwezig serum albumine, dat ook vetzuren bindt, verwijderd door middel van immuno-affiniteitschromatografie. ook werden de endogeen gebonden vetzuren verwijderd. Met behulp van het hydrofobe chromatografie medium Lipidex 1000 werden vrije en eiwit-gebonden vetzuren gescheiden bij $0^{\circ} \mathrm{C}$. Op basis van de oliezuurbindingscapaciteit werden FABPs gevonden in lever, hart, skeletspier, hersenen, nieren, bijnieren en diafragna van de rat. In deze organen bestaat 2-6\% van het cytosolisch eiwit uit FABP. Het FABP gehalte van lever en hart van vrouwelijke ratten is hoger dan in mannelijke dieren. Tijdens de ontwikkeling van de geboorte tot volwassen dier blijkt de 
vetzuurbindingscapaciteit van hart en lever niet duidelijk te veranderen. De cytosolische vetzuurbindingscapaciteit van lever wordt beinvloed door onder andere vasten en het hypolipidemisch agens clofibraat, in tegenstelling tot de capaciteit in hart. Het dag-nacht ritme heeft slechts een beperkte invloed op de vetzuurbindingscapaciteit van beide weefsels.

Tegen FABPs uit verscheidene weefsels van mens, varken en rat werden antilichamen opgewekt in konijnen, waarmee de immunochemische kruisreactiviteit en de weefselverdeling van verschillende FABP typen bestudeerd werd. Een enzym immunoassay werd ontwikkeld voor de kwantitatieve bepaling van het FABP gehalte van weefselcytosolen van mens, rat en varken (Hoofdstukken 6 en 7).

De hart en lever FABP typen hebben een vergelijkbare weefselverdeling in de drie species. Lever FABP komt alleen voor in lever en in darmepitheel. Het hart type is aanwezig in hart, skeletspieren, nieren, longen, hersenen en placenta. Het hart FABP gehalte in oxidatieve spieren, die voor een belangrijk deel van vetzuren afhankelijk zijn voor de energievoorziening, is hoger dan in glycolytische spieren, waar vetzuren slechts een beperkte rol spelen voor energieproduktie. De hart FABP concentratie daalt in de reeks hart > oxidatieve spieren > glycolytische spieren > andere weefsels. De FABP concentratie in de lever is vergelijkbaar in mens, varken en rat. In hart $z i j n$ de gevonden concentraties voor mens en varken lager dan van de rat, maar uitgedrukt als percentage van de concentratie in hart ontstaat een zelfde weefselverdelingspatroon voor alle drie species. De gevonden FABP concentraties in hart en spieren zijn in overeensteming met de palmitinezuur oxidatiecapaciteit van deze weefsels. Het FABP gehalte (Hoofdstuk 6) en de cytosolische vetzuurbindingscapaciteit van ratteweefsels (Hoofdstuk 5) komen overeen voor lever, hart en spieren, maar niet voor hersenen, longen, diafragma, nieren en bijnieren. Deze verschillen duiden op het bestaan van meer weefselspecifieke FABP typen dan het lever en hart type. Het lagere FABP gehalte in het hart bij mens en varken komt overeen met de lagere vetzuuroxidatiecapaciteit van het hartweefsel van deze species vergeleken met de rat. Tijdens de postnatale ontwikkeling nemen het FABP gehalte en de vetzuuroxidatiecapaciteit duidelijk toe, terwijl de vetzuurbindingscapaciteit bij de geboorte al op hetzelfde niveau ligt als in volwassen dieren. Alfa-foetoproteine, een foetaal eiwit dat betrokken is bij vetzuurtransport, werd gevonden in lever en hart in een concentratie die afneemt met de toename van het FABP gehalte. De hoeveelheid alfa-foetoproteine was echter zo laag, dat dit slechts gedeeltelijk het verschil tussen de vetzuurbin- 
dingscapaciteit en het FABP gehalte kon verklaren.

De afwijking tussen de vetzuurbindingscapaciteit en de FABP concentratie tijdens postnatale ontwikkeling, en de verschillen in bindingscapaciteit en gevonden hoeveelheid hart of lever type FABP in verschillende weefsels, wijzen op een belangrijk risico van het gebruik van slechts éen parameter voor kwantitatieve FABP bepalingen in dit soort studies. Het bestaan van (tenminste vijf) verschillende FABP typen en de verschillen in FABP concentratie per weefsel maken een vergelijking van verschillende, onafhankelijke, bepalingsmethoden essentieel voor het verkrijgen van een betrouwbaar inzicht in de weefselverdeling en gehalten van deze eiwitten.

Samenvattend, vetzuurbindende eiwitten vormen een groep laag-moleculaire cytosolische eiwitten, die in relatief hoge concentraties voorkomen in weefsels. Hoewel nog steeds geen direct bewijs beschikbaar is, zijn op basis van de verzamelde kennis duidelijk verschillende functies aanwijsbaar voor de verschillende typen van dit eiwit. Lever FABP is betrokken bij intracellulair transport van een groot aantal hydrofobe verbindingen, terwijl hart FABP een meer specifiek vetzuurbindingseiwit is. De aanwezigheid van het hart type in weefsels die voor een belangrijk deel afhankelijk $z i j n$ van vetzuren voor hun energievoorziening duidt op vetzuurtransport naar $\beta$-oxidatie systemen als hoofdfunctie voor dit eiwit. De beperkte invloed van allerlei fysiologische condities op het hart FABP gehalte is in overeensteming met die rol. De veel grotere variabiliteit van het lever FABP gehalte is waarschijnlijk gerelateerd aan andere functies van dit FABP type dan de rol bij energieproduktie. De andere FABP typen komen slechts in een beperkt aantal weefsels voor (het nier type alleen in de nieren, en darm FABP alleen in het darmepitheel), hetgeen een rol van deze eiwitten bij weefselspecifieke processen suggereert. 
1. Baumann, G., Amburn, K.D. and Buchanan, T.A. (1987) J.Clin. Endocrinol.Metab. 64, 657-660

2. Daughaday, W.H., Ward, A.P., Goldberg, A.C., Trivedi, B. and Kapadia, M. (1982) J.Clin.Endocrinol.Metab. 55, 916

3. Siiteri P.K., Murai, J.T., Hammond, G.L., Nisker, J.A., Raymoure, W.J. and Kuhn, R.W. (1982) Rec.Progr.Horm.Res. 38, 457-503

4. Bridges, C.D.B., Peters, T.,Jr., Smith, J.E., Goodman, D.S., Fong, S.-L., Griswold, M.D. and Musto, N.A. (1986) Fed.Proc. 45, 2291-2303

5. Chen, W.Y.J., James, H.O. and Glover, J. (1986) Biochem.Soc. Trans. 14, 925-928

6. Spector, A.A. and Fletcher, J.E. (1978) in "Disturbances in lipid and lipoprotein metabolism" (Dietschy, J.M., Gotto, A.M. and Ontko, S.A., eds.) pp. 229-249, williams and Wilkins Co., Baltimore, USA

7. Spector, A.A. (1975) J.Lipid Res. 16, 165-179

8. Kostner, G.M. (1983) Adv.Lipid Res. 20, 1-43

9. Mahley, R.W., Innerarity, T.L., Rall, S.C.,Jr. and Weisgraber, K.H. (1984) J.Lipid Res. 25, 1277-1294

10. Breslow, J.L. (1988) Physiol.Rev. 68, 85-132

11. Chan, L. (1989) Klin. Wochenschr. 67, 225-237

12. Tall. A.R. (1986) J.Lipid Res. 27, 361-367

13. Chytil, F. and Ong, D.E., (1987) Ann.Rev.Nutr. 7, 321-335

14. Verdon, C.P. and Blumberg J.B. (1988) Anal.Biochem. 169, $109-120$

15. Parikh, I., Rajendran, K.G., Su, J.-L., Lopez, T. and Sar, M. (1987) J. Steroid Biochem. 27, 185-192

16. Sasaki, T., (1985) Chem. Phys.Lipids 38, 63-77

17. Stolz, A., Takikawa, H., Ookhtens, M. and Kaplowitz, N. (1989) Ann.Rev.Physiol. 51, 161-176

18. Scallen, T.J., Pastuszyn, A., Noland, B.J., Chanderbhan, R., Kharroubi, A. and Vahouny, G.V. (1985) Chem. Phys.Lipids 38, 239-261

19. Vahouny, G.V., Chanderbhan, R., Kharroubi, A., Noland, B.J., Pastuszyn, A. and Scallen, T.J. (1987) Adv.Lipid Res. 22, 83-113

20. Akeroyd, R. and Wirtz, K.W.A. (1982) in: "Membranes and transport, Vol. I" (Martonosi, A, ed.), pp. 93-98, Plenum Publishing Corp., New York, USA

21. Wetterau, J.R. and Zilversmit, D.B. (1984) Methods Biochem. Anal. 30, 199-226

22. Helmkamp, G.M.,Jr. (1986) J.Bioenerget.Biomembr. 18, 71-91

23. Aussel, C. and Massayeff, R. (1983) Biochim.Biophys.Acta $752,324-328$

24. Aussel, C. and Massayeff, R. (1983) Res.Commun.Chem.Pathol. Pharmacol. 42, 261-269 
25. Bass, N.M. (1985) Chem.Phys.Lipids 38, 95-114

26. Glatz, J.F.C., Paulussen, R.J.A. and Veerkamp, J.H. (1985) Chem. Phys. Lipids 38, 115-129

27. Sweetser, D.A., Heuckeroth, R.O. and Gordon, J.I. (1987) Ann.Rev.Nutr. 7, 337-359

28. Paulussen, R.J.A. and Veerkamp. J.H. in: Subcellular Biochemistry, Vol. 16 (Hilderson, H.J.J. ed.), Plenum Publishing Corp., New York, USA, in press.

29. Milici, A.J., Watrous, N.E., Stukenbrok, H. and Palade, G.E. (1987) J.Cell Biol. 105, 2603-2612

30. Ghinea, N., Fixman, A., Alexandru, D. Popov, D., Hasu, M., Ghitescu, L., Eskenasy, simionescu, M. and Simionescu, N. (1988) J.Cell Biol. 107, 231-239

31. Julien, P., Dagenais, G.R., Gailis, J. and Roy, P.E. (1978) Can.J.Physiol. Pharmacol. 56, 1041-1046

32. Scow, R.O. and Blanchette-Mackie, E.J. (1985) Prog.lipid Res. 24, 197-241

33. Wetzel, M.G. and Scow, R.O. (1984) An.J.Physiol. 246, C467C485

34. Spector, A.A., Fletcher, J.E. and Ashbrook, J.D. (1971) Biochemistry 10, 3229-3232

35. Wosilait, W.D. and Soler-Argilaga, C. (1977) FEBS Lett. 73, 72-76

36. Rauch, B., Bode, Ch., Piper, H.M., Hutter, J.F., zimmermann, R., Braunwell, E., Hasselbach, W. and Kubler, W. (1987) J.Mol.Cell.Cardiol. 19, 159-166

37. Samuel, D., Paris, S. and Ailhaud, G. (1976) Eur.J.Biochem. $64,583-595$

38. Spector, A.A., Steinberg, D. and Tanaka, A. (1965) J.Biol. Chem. 240, 3747-3753

39. Soler-Argilaga, C., Infante, R., Renaud, G. and Polonovski, J. (1974) Biochimie 56, 757-761

40. Renaud, G., Bouma, M.E., Foliot, A. and Infante, R. (1985) Arch. Int. Physiol.Biochim. 93, 313-319

41. Morand, O., Fibach, E. and Gatt, S. (1982) Biochim.Biophys. Acta $693,143-150$

42. Dietschy, J.M. (1978) in "Disturbances in lipid and lipoprotein metabolism" (Dietschy, J.M., Gotto, A.M. and ontko, S.A., eds.) pp. 1-28, williams and Wilkins Co., Baltimore, USA

43. Hamilton, J.A. and Cistola, D.P. (1986) Proc.Natl.Acad.Sci. USA $83,82-86$

44. Rose, C.P. and Goresky, C.A. (1977) Circ.Res. 11, 534-545

45. Van Der Vusse, G.J., Roemen, T.H.M., Flameng, W. and Reneman, R.S. (1983) Biochim.Biophys.Acta 752, 361-370

46. Kushlan, M.C., Gollan, J.L., Ma, W-L. and Ockner, R.K. (1981) J.Lipid Res. 22, 431-436

47. Noy, N., Donnelly, T.M., Cooper, R.B. and Zakim, D. (1989) Biochim.Biophys.Acta 1003, 125-130

48. Ockner, R.K., Weisiger, R.A. and Gollan, J.L. (1983) Am.J. Physiol. 245, G13-G18 
49. Weisiger, R.A. and Ma, W-L. (1987) J.Clin.Invest. 79, 10701077

50. Spector, A.A. (1969) J.Lipid Res. 10, 207-215

51. Daniels, C., Noy, N. and Zakim, D. (1985) Biochemistry 24, 3286-3292

52. Noy, N., Donnelly, T.M. and Zakim, D. (1986) Biochemistry 25, 2013-2021

53. Cooper, R., Noy, N. and Zakim, D. (1987) Biochemistry 26, 5890-5896

54. Weisiger, R.A., Fitz, J.G. and scharschmidt, B.F. (1989) J.Clin. Invest. 83, 411-420

55. Weisiger, R.A., Gollan, J.L. and Ockner, R.K. (1981) Science 211, 1048-1051

56. Brandes, R., Ockner, R.K., Weisiger, R.A. and Lysenko, N. (1982) Biochem.Biophys.Res.Commun. 105, 821-827

57. Stremmel, W., Potter, B.J. and Berk, P.D. (1983) Biochim. Biophys.Acta 756, 20-27

58. Abumrad, N.A., Perkins, R.C., Park, J.H. and Park, C.R. (1981) J.Biol.Chem. 256, 9183-9191

59. Abumrad, N.A., Park, J.H. and Park, C.R. (1984) J.Biol.Chem. $259,8945-8953$

60. Schwieterman, W., Sorrentino, D., Potter, B.J., Rand, J., Kiang, C-L., Stump, D. and Berk, P.D. (1988) Proc.Natl.Acad. SCi.USA $85,359-363$

61. Stremmel, W., and Berk, P.D. (1986) Proc.Natl.Acad.Sci.USA, 83, 3086-3090

62. Stremmel, W., Strohmeyer, G. and Berk, P.D. (1986) Proc. Nat1.Acad.Sci.USA 83, 3584-3588

63. Stremmel, W. and Thielmann, L. (1986) Biochim.Biophys.Acta 877, 191-197

64. Stremmel, W. (1988) J.clin.Invest. 81, 844-852

65. Sorrentino, D., Stump, D., Potter, B.J., Robinson, R.B., White, R., Kiang, C.-L. and Berk, P.D. (1988) J.Clin. Invest. 82, 928-935

66. Stremmel, W. (1988) J.Clin. Invest. B2, 2001-2010

67. Stremmel, w. (1987) J.Biol.Chem. 262, 6284-6289

68. Stremmel, W., Kochwa, S. and Berk, P.D. (1983) Biochem. Biophys.Res.Commun. 112, 88-95

69. Stremmel, W., Strohmeyer, D., Borchard, F., Kochwa, S. and Berk, P.D. (1985) Proc.Natl.Acad.Sci.USA 82, 4-B

70. Potter, B.J., Stump, D., Schwieterman, W., Sorrentino, D., Jacobs, L.N., Kiang, C-L., Rand, J.H. and Berk, P.D. (1987) Biochem. Biophys.Res.Commun. 148, 1370-1376

71. Stremmel, W., Lotz, G., Strohmeyer, G. and Berk, P.D. (1985) J.Clin. Invest. 75, 1026-1076

72. Nunn, W.D., Colburn, R.W. and Black, P.N. (1986) J.Biol. Chem. 261, 167-171

73. Levi, A.J., Gatmaitan, Z. and Arias, I.M. (1969) J.Clin. Invest. 48, 2156-2167

74. Ockner, R.K., Manning, J.A., Poppenhausen, R.B. and Ho, W.K.L. (1972) Science 177, 56-58 
75. Mishkin, S., Stein, L., Gatmaitan, Z, and Arias, I.M. (1972) Biochem. Biophys.Res.Commun. 47, 997-1003

76. Ketterer, B., Tipping, E., Hackney, J.F. and Beale, D. (1976) Biochem.J. 155, 511-521

77. Mogensen, I.B., Schulenberg, H., Hansen, H.O., Spener, F. and Knudsen, J. (1987) Biochem.J. 241, 189-192

78. Mikkelsen, J., Hojrup, P., Nielsen, P.F., Roepstorff, P. and Knudsen, J. (1987) Biochem.J. 245, 857-861

79. Glatz, J.F.C. and Veerkamp, J.H. (1985) Int.J.Biochem. 27, 13-22

80. Bernier, I. and Jollès, P. (1987), Biochimie 69, 1127-1152

81. Bass, N.M. (1988) Int.Rev.Cytol. 111, 143-183

82. Veerkamp, J.H. and Paulussen, R.J.A. (1987) Biochem.Soc. Trans. 15, 331-336

83. Peeters, R.A., In 't Groen, M.A.P.M., De Moel, M.P., Van Moerkerk, H.T.B. and Veerkamp, J.H. (1989) Int.J.Biochem. 21, 407-418

84. Paulussen, R.J.A., Van Der Logt, C.P.E. and Veerkamp, J.H. (1988) Arch.Biochem.Biophys. 264, 533-545

85. Glatz, J.F.C., Janssen, A.M., Baerwaldt, C.C.F. and Veerkamp, J.H. (1985) Biochim.Biophys.Acta 837, 57-66

86. Offner, G.D., Troxler, R.F. and Brecher, P. (1986) J.Biol. Chem. $261,5584-5589$

87. Ockner, R.K., Manning, J.A. and Kane, J.P. (1982) J.Biol. Chem. 257, 7872-7878

88. Fournier, N.C., Geoffroy, M. and Deshusses, J. (1978) Biochim.Biophys.Acta 533, 457-464

89. Haq, R.U., Christodoulides, L., Ketterer, B. and Shrago, E. (1982) Biochim.Biophys.Acta 713, 193-198

90. Takahashi, K., Odani, S. and Ono, T. (1983) Eur.J.Biochem. $136,589-601$

91. Lee, L. and Wiggert, B. (1984) J.Neurochem. 12, 47-53

92. Kamisaka, K., Hirano, M. and Tsuru, M. (1978) Experientia 34, 1265-1266

93. Trulzsch, D. and Arias, I.M. (1981) Arch.Biochem.Biophys. $209,433-440$

94. Senjo, M., Ishibashi, T., Imai, Y., Takahashi, K. and Ono, T. (1985) Arch.Biochem.Biophys. 236, 662-668

95. Haunerland, N., Jagschies, G. Schulenberg, H. and Spener, F. (1984) Hoppe-Seyler's Z.Physiol.Chem. 365, 365-376

96. Jagschies, G., Reers, M., Unterberg, C. and Spener, F. (1985) Eur.J.Biochem. 152, 537-545

97. Unterberg, C., Heidl, G., Von Bassewitz, D.-B. and Spener, F. (1986) J.Lipid Res. 27, 1287-1293

98. Billheimer, J.T. and Gaylor, J.L. (1980) J.Biol.Chem. 255, 8128-8135

99. Takahashi, K., Odani,s. and Ono, T. (1982) FEBS Lett. 140, 63-66

100. Avanzati, B. and Catala, A. (1983) Arch.Int.Physiol.Biochem. 91, 103-108 
101. Alpers, D.H., Strauss, A.W., Ockner, R.K., Bass, N.M. and Gordon, J.I. (1984) Proc.Natl.Acad.Sci.USA 81, 313-317

102. Lam, K.T., Borkan, S., Claffey, K.P., Schwartz, J.H., Chobanian, A.V. and Brecher, P. (1988) J.Biol.Chem. 263, $15762-15768$

103. Gordon, J.I., Alpers, D.H., Ockner, R.K. and strauss, A.W. (1983) J.Biol.Chem. 258, 3356-3363

104. Flinta, C., Persson, B., Jornvall, H. and Von Heijne, G. (1986) Eur.J.Biochem. 154, 193-196

105. Chan, L., Wei, C-F., Li, W-H., Yang, C-Y., Ratner, P., Pownall, H., Gotto, A.M.jr and Smith, L.C. (1985) J.Biol. Chem. 260, 2629-2632

106. Lowe, J.B., Boguski, M.S., Sweetser, D.A., Elshourbagy, N.A., Taylor, J.M. and Gordon, J.I. (1985) J.Biol.Chem. $260,3413-3417$

107. Sweetser, D.A., Birkenmeier, E.H., Klisak, I.J., Zollman, S., Sparkes, R.S., Mohandas, T., Lusis, A.J. and Gordon, J.I. (1987) J.Biol.Chem. 262, 16060-16071

108. Billich, S., Wissel, T., Kratzin, H., Hahn, U., Hagendorff, B., Lezius, A.G. and Spener, F. (1988) Eur.J.Biochem. 175, $549-556$

109. Offner, G.D., Brecher, P., Sawlivich, W.B., Costello, C.E. and Troxler, R.F. (1988) Biochem.J. 252, 191-198

110. Sacchettini, J.C., Said, B., Schulz, H. and Gordon, J.I. (1986) J.Biol.Chem, 261,8218-8223

111. Bernlohr, D.A., Angus, C.W., Lane, M.D., Bolanowski, M.A. and Kelly, T.J. (1984) Proc.Natl.Acad.Sci.USA 81, 5468-5472

112. Suzuki, M., Kitamura, K., Sakamoto, Y. and Uyemura, K. (1982) J.Neurochem. 39, 1759-1762

113. Kitamura, K., Suzuki, M., Suzuki, A. and Uyemura, K. (1980) FEBS Lett. 115, 27-30

114. Bohmer, F.D., Kraft, R., Otto, A., Wernstedt, C., Hellman, U., Kurtz, A., Muller, T., Rohde, K., Etzold, G., Lehmann, W., Langen, P., Heldin, C-H. and Grosse, R. (1987) J.Biol. Chem. 262, 15137-15143

115. Sundelin, J., Anundi, H., Tragardh, L., Eriksson, U., Lind, P., Ronne, H., Peterson, P.A. and Rask, L. (1985) J.Biol. Chem. 260, 6488-6493

116. Li, E., Demmer, L.A., Sweetser, D.A., Ong, D.E. and Gordon, J.I. (1986) Proc.Natl.Acad.Sci.USA 83, 5779-5783

117. Gordon, J.I. and Lowe, J.B. (1985) Chem.Phys.Lipids 38, $137-158$

118. McLachlan, A.D. and Walker, J.E. (1977) J.Mol.Biol. 112, 543-558

119. Westerman, J. and Wirtz, K.W.A. (1985) Biochem.Biophys.Res. Commun. 127, 333-338

120. Akeroyd, R., Moonen, P., Westerman, J., Puyk, C. and wirtz, K.W.A. (1981) Eur.J.Biochem. 114, 385-391

121. Chou, P.Y. and Fasman, G.D. (1979) Biophys.J. 26, 367-384

122. Sweetser, D.A., Lowe, J.B. and Gordon, J.I. (1986) J.Biol. Chem. 261, 5553-5561 
123. Claffey, K.P., Herrera, V.L., Brecher, P. and Ruiz-opazo, N. (1987) Biochemistry 26, 7900-7904

124. Heuckeroth, R.O., Birkenmeier, E.H., Levine, M.S. and Gordon, J.I. (1987) J.Biol.Chem. 262, 9709-9717

125. Lowe, J.B., Strauss, A.W. and Gordon, J.I. (1984) J.Biol. Chem. 259, 12696-12704

126. Lowe, J.B., Sacchettini, J.C., Laposata, M., McQuillan, J.J. and Gordon, J.I. (1987) J.Biol.Chem. 262, 5931-5937

127. Hunt, C.R., Ro, J.H-S., Dobson, D.E., Min, H.Y. and Spiegelman, B.M. (1986) Proc.Natl.Acad.Sci.USA B3, 3786-3790

128. Demmer, L.A., Birkenmeier, E.H., Sweetser, D.A., Levin, M.S., Zollman, S., Sparkes, R.S., Mohandas, T., Lusis, A.J. and Gordon, J.I. (1987) J.Biol.Chem. 262, 2458-2467

129. Sundelin, J., Eriksson, U., Melhus, H., Nilsson, M., Lundval1, J., Bavik, C.o., Hansson, E., Laurent, B. and Peterson, P.A. (1985) Chem.Phys.Lipids 38, 175-185

130. Sacchettini, J.C., Gordon, J.I. and Banaszak, L.J. (1988) J.Biol. Chem. 263, 5815-5819

131. Sacchettini, J.C., Meininger, T.A., Lowe, J.B., Gordon, J.I. and Banaszak, L.J. (1987) J.Biol.Chem. 262, 5428-5430

132. Newcomer, M.E., Jones, T.A., Aqvist, J., Sundelin, J., Eriksson, U., Rask, L. and Peterson, P.A. (1984) EMBo J. 3, 1451-1454

133. Holden, H.M., Rypniewski, W.R., Law, J.H. and Rayment, I. (1987) EMBO J. 6, 1565-1570

134. Huber, R., Schneider, M., Epp, O., Mayr, I., Messerschmidt, A., Pflugrath, J. and Kayser, H. (1987) J.Mol.Biol. 195, 423-434

135. Papiz, M.z., Sawyer, L., Eliopoulos, E.E., North, A.C.T., Findlay, J.B.C., Sivaprasadarao, R., Jones, T.A., Newcomer, M.E. and Kraulis, P.J. (1986) Nature 324, 383-385

136. Godovac-Zimmermann, J. (1988) TIBS 13, 64-66

137. Brown, J.R. and Shockley, P. (1982) in "Lipid-protein interactions" (Jost, P.C. and Griffith, O.H., eds.), 1, pp. 2568 , Wiley and Sons, New York

138. Boguski, M.S., Elshourbagy, N., Taylor, J.M. and Gordon, J.I. (1984) Proc.Natl.Acad.Sci.USA 81, 5021-5025

139. Schulenberg-Schell, H., Schafer, P., Keuper, H.J., stanislawski, B., Hoffmann, E., Ruterjans, H. and Spener, F. (1988) Eur.J.Biochem. 170, 565-574

140. Keuper, H.J.K., Klein, R.A. and Spener, F. (1985) Chem.Phys. Lipids 38, 159-173

141. Storch, J., Kleinfeld, A. and Bass, N.M. (1987) Fed.Proc. 46,1417

142. Akeroyd, R., Lange, L.G., Westerman, L. and Wirtz, K.W.A. (1981) Eur.J.Biochem. 121, 77-81

143. Cistola, D.P., Walsh, M.T., Corey, R.P., Hamilton, J.A. and Brecher, P. (1988) Biochemistry 27, 711-717

144. Cistola, D.P., Sacchettini, J.C., Banaszak, L.J., Walsh, M.T. and Gordon, J.I. (1989) J.Biol.Chem. 264, 2700-2710 
145. Cistola, D.P., Small, D.M. and Hamilton, J.A. (1987) J.Biol. Chem. 262, 10980-10985

146. Ockner, R.K. and Manning, J.A. (1974) J.Clin.Invest. 54, $326-338$

147. Van Amerongen, A., Teerlink, T., Van Heusden, G.P.H. and Wirtz, K.W.A. (1985) Chem.Phys.Lipids 38, 195-204

148. Paulussen, R.J.A., Van Moerkerk, H.T.B. and Veerkamp, J.H. (1989), submitted. (chapter 7 of this thesis)

149. Matarese, V. and Bernlohr, D.A. (1988) J.Biol.Chem. 263, 14544-14551

150. Bass, N.M., Manning, J.A., Ockner, R.K., Gordon, J.I., Seetharam, S. and Alpers, D.H. (1985) J.Biol.Chem. 260, $1432-1436$

151. Bass, N.M. and Manning, J.A. (1986) Biochem.Biophys.Res. Commun. 137, 929-935

152. Crisman, T.S., Claffey, K.P., Saouaf, R., Hanspal, J., and Brecher, P. (1987) J.Mol.Cell.Cardiol. 19, 423-43I

153. Paulussen, R.J.A., Geelen, M.J.H., Beynen, A.C. and Veerkamp, J.H. (1989) Biochim.Biophys.Acta 1001, 201-209

154. Said, B. and Schulz, H. (1984) J.Biol.Chem. 259, 1155-1159

155. Fukai, F., Kase, T., Shidotani, T., Nagai, T. and Katayama, T. (1987) Biochem.Biophys.Res.Commun. 147, 899-903

156. Vincent, S.H., Bass, N.M., Snider, J.M. and Muller-Eberhard, U. (1987) Biochem.Arch. 3, 443-451

157. Miller, W.C,. Hickson, R.C. and Bass, N.M. (1988) Proc.Soc. Exp.Biol.Med. 189, 183-188

158. Paulussen, R.J.A., Jansen, G.P.M. and Veerkamp, J.H. (1986) Biochim. Biophys. Acta 877, 342-349

159. Kamisaka, K., Maezawa, H., Inagaki, T. and Okano, K. (1981) Hepatology 1, 221-227

160. Rústow, B., Risse, S. and Kunze, D. (1982) Acta Biol.Med. Germ. 41, 439-445

161. Bass, N.M., Raghupathy, E., Rhoads, D.E., Manning, J.A. and Ockner, R.K. (1984) Biochemistry 23, 6539-6544

162. Haq, R.U., Shrago, E., Christodoulides, L. and Ketterer, B. (1985) Exp. Lung Res. 9, 43-55

163. Jones, P.D., Caine, A., Bass, N.M. and Grigor, M.R. (1988) Biochem.J. 251, 919-925

164. Glatz, J.F.C., Baerwaldt, C.C.F., Veerkamp, J.H. and Kempen, H.J.M. (1984) J.Biol.Chem. 259, 4295-4300

165. Fournier, N.C. and Rahim, M. (1985) Biochemistry 24, 23872396

166. Sarzani, R., Claffey, K.P., Chobanian, A.V. and Brecher, P. (1988) Proc.Natl.Acad.Sci.USA 85, 7777-7781

167. Gordon, J.I., Elshourbagy, N., Lowe, J.B., Liao, S., Alpers, D.H. and Taylor, J.M. (1985) J.Biol.Chem. 260, 1995-1998

168. Sweetser, D.A., Birkenmeier, E.H., Hoppe, P.C., McKeel, D.W. and Gordon, J.I. (1988) Genes Devel. 2, 1318-1332

169. Capron, F., Coltoff-Schiller, B., Johnson, A.B., Fleischner, G.M. and Goldfischer, S. (1979) J.Histochem.Cytochem. 27, 961-966 
170. Suzuki, T. and Ono, T. (1987) J.Pathol. 153, 385-394

171. Bass, N.M., Barker, M.E., Manning, J.A., Jones, A.J. and Ockner, R.K. (1989) Hepatology 9, 12-21

172. Bass, N.M. and Ockner, R.K. (1987) in "Drugs affecting lipid metabolism" (Paoletti, R., Kritchevsky, D. and Holmes, w.L., eds.) pp 105-110, Springer Verlag

173. Shields, H.M., Bates, M.L., Bass, N.M., Best, C.J., Alpers, D.H. and Ockner, R.K. (1986) J.Lipid Res. 27, 549-557

174. Iseki, S., Hitomi, M., Ono, T. and Kondo, H. (1989) Anat. Rec. $223,283-291$

175. Iseki, S., Kondo, H., Hitomi, M. and Ono, M. (1988) Histochemistry $89,317-322$

176. Bordewick, U., Schulenberg, H., Schäfer, P., and Spener, F. (1986) Fette.Seifen.Anstrichmittel 88, 588-592

177. Rudel, H., Unterberg, C. and Spener, F. (1985) Fette.Seifen. Anstrichmittel $87,561-567$

178. Börchers, T., Unterberg, C., Rüdel, H., Robenek, H. and Spener, F. (1989) Biochim.Biophys.Acta 1002, 54-61

179. Bordewick, U., Heese, M., Borchers, T., Robenek, H. and Spener, F. (1989) Biol.Chem.Hoppe-Seyler 370, 229-238

180. Teerlink, T., Van Der Krift, T.P., Post, M. and Wirtz, K.W.A. (1982) Biochim.Biophys.Acta 713, 61-67

181. Megl1, F.M., De Lisi, A., Van Amerongen, A., Wirtz, K.W.A. and Quagliariello, E. (1986) Biochim.Biophys.Acta 861, 463470

182. Teerlink, T., Van Der Krift, T.P., Van Heusden, G.P.H. and Wirtz, K.W.A. (1984) Biochim.Biophys.Acta 793, 251-259

183. Van Amerongen, A., Van Noort, M., Van Beckhoven, J.C.R.M., Rommerts, F.F.G., OrlY, J. and Wirtz, K.W.A. (1989) Biochim. Biophys. Acta 1001, 243-248

184. Burnett, D.A., Lysenko, N., Manning, J.A. and ockner, R.K. (1979) Gastroenterology 77, 241-249

185. Rüstow, B., Hodi, J., Kunze, D., Reichmann, G. and Egger, E. (1978) FEBS Lett. 95, 225-228

186. Jagschies, G. (1984) Ph.D.Thesis, University of Munster, Munster, FRG

187. Mishkin, S. and Turcotte, R. (1974) Biochem.Biophys.Res. Commun. 57, 918-926

188. Burrier, R.E., Manson, C.R. and Brecher, P. (1987) Biochim. Biophys.Acta 919, 221-230

189. Wilkinson, T.C.I. and wilton, D.C. (1987) Biochem.J. 247 , 485-488

190. Dutta-Roy, A.K., Gopalswamy, N. and Trulzsch, D.V. (1987) Eur.J.Biochem. 162, 615-619

191. Glatz, J.F.C. and Veerkamp, J.H. (1983) Anal.Biochem. 132, 89-95

192. Fournier, N.C., Zuker, M., Williams, R.E. and Smith, I.C.P. (1983) Biochemistry 22, 1863-1872

193. Fournier, N.C. and Richard, M.A. (1988) J.Biol.Chem. 263, 14471-14479 
194. Vincent, S.H. and Muller-Eberhard, U. (1985) J.Biol.Chem. $260,14521-14528$

195. Takikawa, H. and Kaplowitz, N. (1986) Arch.Biochem.Biophys. $251,385-392$

196. Burrier, R.E. and Brecher, P. (1986) Biochim.Biophys.Acta B79, 229-239

197. Tipping E. and Ketterer, B. (1981) Biochem.J. 195, 441-452

198. Renaud, G., Foliot, A. and Infante, R. (1978) Biochem. Biophys. Res. Commun. B0, 327-334

199. Ockner, R.K. and Manning, J.A. (1976) J.Clin.Invest. 58, $632-641$

200. Goresky, C.A., Daly, D.S., Mishkin, S. and Arias, I.M. (1978) Am.J.Physiol. 234, E542-E553

201. Mishkin, S., Stein, L., Fleischner, G., Gatmaitan, Z. and Arias, I.M. (1975) Am.J.Physiol. 228, 1634-1640

202. Peeters, R.A., Veerkamp, J.H. and Demel, R.A. (1989) Biochim. Biophys. Acta 1002, 8-13

203. McCormack, M. and Brecher, P. (1987) Biochem.J. 244, 717723

204. Catala, A. and Avanzati, B. (1983) Lipids 18, 803-807

205. Barbour, R.L. and Chan, S.H.P. (1979) Biochem.Biophys.Res. Commun. 89, 1168-1177

206. Grinstead, G.F., Trzaskos, J.M., Billheimer, J.T. and Gaylor, J.I. (1983) Biochim.Biophys.Acta 751, 41-51

207. Lunzer, M.A., Manning, J.A. and Ockner, R.K. (1977) J.Biol. Chem. 252, 5483-5487

208. Wu-Rideout, M.Y.C., Elson, C. and Shrago, E. (1976) Biochem. Biophys.Res.Commun. 71, 809-816

209. Noy, N. and Zakim, D. (1985) Biochemistry 24, 3521-3525

210. Mishkin, S. and Turcotte, R. (1974) Biochem.Biophys.Res. Commun. 60, 376-381

211. O'Doherty, P.J.A. and Kuksis, A. (1975) FEBS Lett. 60, 256258

212. Iritani, N., Fukuda, E. and Inoguchi, K. (1980) J.Nutr.Sci. Vitaminol. 26, 271-277

213. Roncari, D.A.K. and Mack, E.Y.W. (1981) Can.J.Biochem. 59, 944-950

214. Haq, R.U., Tsao, F. and Shrago, E. (1987) J.Lipid Res. 28, 216-220

215. Das, T. Sa, G. and Mukherjea, M. (1989) Biochim.Biophys.Acta $1002,164-172$

216. Gutknecht, J. (1988) J.Membrane Biol. 106, 83-93

217. Van Der Vusse, G.J., Roemen, T.H.M., Prinzen, F.W., Coumans, W.A. and Reneman, R.S. (1982) Circ.Res. 50, 538-546

218. Glatz, J.F.C., Van Bilsen, M., Paulussen, R.J.A., Veerkamp, J.H., Van Der Vusse, G.J. and Reneman, R.S. (1988) Biochim. Biophys.Acta $961,148-152$

219. Bassuk, J.A., Tsichlis, P.N. and Sorof, S. (1987) Proc.Natl. Acad.Sci.USA 84, 7547-7551

220. Giguere, V., Ong, E.S., Segui, P. and Evans, R.M. (1987) Nature $330,624-629$ 
221. Chytil, F. and Ong, D.E. (1987) Ann.Rev.Nutr. 7, 321-335

222. Bernlohr, D.A., Bolanowski, M.A., Kelly, T.A.jr. and Lane, M.D. (1985) J.Biol.Chem. 260, 5563-5567

223 . Ockner, R.K., Lysenko, N., Manning, J.A. and Monroe, S.E. (1980) J.Clin. Invest. 65, 1013-1023

224. Kawashima, Y., Nakagawa, S. and Kozuka, H. (1982) J.Pharm. Dyn. 5, 771-779

225. Brandes, R. and Arad, R. (1983) Biochim.Biophys.Acta 750, 334-339

226. Stein, L.B., Mishkin, S., Fleischner, G., Gatmaitan, Z. and Arias, I.M. (1976) Am.J.Physiol. 231, 1371-1376

227. Bass, N.M., Manning, J.A. and Ockner, R.K. (1985) J.Biol. Chem. 260, 9603-9607

228. Kawashima, Y., Nakagawa, S., Tachibana, Y. and Kozuka, H. (1983) Biochim.Biophys.Acta 754, 21-27

229. Wilkinson, T.C.I. and Wilton, D.C. (1987) Biochem.J. 242, 913-917

230. McTigue, J., Taylor, J.B., Craig, R.K., Christodoulides, L. and Ketterer, B. (1985) Biochem.Soc.Trans. 13, 896-897

231. Veerkamp, J.H. and Van Moerkerk, H.T.B. (1986) Biochim. Biophys.Acta 875, 301-310

232. Glatz, J.F.C., Van Der Vusse, G.J. and Veerkamp, J.H. (1988) NIPS 3, 41-43

233. Haq, R.U. and Shrago, E. (1983) Nutr.Res. 3, 329-333

234. St.John, L.C., Rule, D.C., Knabe, D.A., Mersmann, H.J. and Smith, S.B. (1987) J.Nutr. 117, 2021-2026

235. Pignon, J.P., Bailey, N.C., Baraona, E. and Lieber, C.S. (1987) Hepatology 7, 865-871

236. Reyes, H., Levi, A.J., Gatmaitan, Z. and Arias, I.M. (1971) J.Clin. Invest. 50, 2242-2252

237. Dutta-Roy, A.K., Trinh, M.V., Sullivan, T.F. and Trulzsch, D.V. (1988) J.Nutr. 118, 1116-1119

238. Sheridan, M., Wilkinson, T.C.I. and Wilton, D.C. (1987) Biochem.J. 242, 919-922

239. Foliot, A., Housset, E., Ploussard, J.P., Petite, J.P. and Infante, R. (1973) Biomedicine 19, 488-491

240. Crisman, T.S., Claffey, K.P., Labrie, E.D. and Brecher, P. (1988) FASEB J. 2, A1037

241. Levi, A.J., Gatmaitan, Z. and Arias, I.M. (1970) N.Engl.J. Med. 283, 1136-1139

242. Levi, A.J., Gatmaitan, 2. and Arias, I.M. (1969) Lancet II, $139-140$

243. Suzuki, T. and ono, T. (1988) Acta Pathol.Jpn. 38, 979-987

244. Simoneau, J.-A. and Pette, D. (1988) Pflugers Arch.Eur.J. Physiol. 412, 86-92

245. Kaufmann, M., Simoneau, J.-A., Veerkamp, J.H. and Pette, D. (1989) FEBS Lett. 245, 181-184

246. Custer, R.P. and Sorof, S. (1984) Proc.Natl.Acad.Sci.USA 81, 6738-6742

247. McGuire, D.M., Olson, C.D., Towle, H.C. and Dempsey, M.E. (1984) J.Biol.Chem. 259,5368-5371 
248. Scallen, T.J, Noland, B.J., Gavey, K.L., Bass, N.M., Ockner, R.K., Chanderbhan, R. and Vahouny, G.V. (1985) J. Biol.Chem. $260,4733-4739$

249. Vahouny, G.V., Chanderbhan, R., Kharroubi, A., Noland, B.J., Pastuszyn, A. and Scallen, T.J. (1987) Adv.Lipid Res. 22, 83-113

250. Sheridan, M. and Wilton, D.C. (1989) Biochem.Soc.Trans. 17, 173

251. Levin, M.S., Pitt, A.J.A., Schwartz, A.L., Edwards, P.A. and Gordon, J.I. (1989) Biochim.Biophys.Acta 1003, 293-300

252. Thomas, C.R., Lowy, C. and Evans, J.L. (1986) Diabetologia $29,600 A-601 A$

253. Fujii, S., Kawaguchi, H., Okamoto, H., Togashi, H., Saito, H. and Yasuda, H. (1988) J.Hypertension 6, 671-675

254. Mishkin, S. and Halperin, M.L. (1977) Adv.Exp.Med.Biol. 92, 583-605

255. Knowlton, A.A., Apstein, C.S., Saouaf, R. and Brecher, P. (1987) Circ.Res. 76, IV-425

256. Chen, S.H., Vantuinen, P., Ledbetter, D.H., Smith, L.C. and Chan, L. (1986) Som.Cell Mol.Genet. 12, 303-306

257. Minghetti, P.P., Ruffner, D.E., Kuang, W.J., Dennison, O.E., Hawkins, J.W., Beattie, W.G. and Dugaiczyk, A. (1986) J.Biol.Chem. 261, 6747-6757

258. Ingram, R.S., Scott, R.W. and Tilghman, S.M. (1981) Proc. Natl.ACad.Sci.USA 78, 4694-4698

259. Gibson, B.W., Yu, Z., Aberth, W., Burlingame, A.L. and Bass, N.M. (1988) J.Biol.Chem. 263, 4182-4185

260. Peeters, R.A., In 't Groen, M.A. and Veerkamp, J.H. (1989) Arch.Biochem.Biophys. in press

261. Kamisaka, K., Listowsky, I., Gatmaitan, Z. and Arias, I.M. (1975) Biochim.Biophys.Acta 393, 24-30

262. Morrow, F.D., Allen, C.E. and Martin, R.J. (1979) Fed.Proc. 38,280

263. Nilsson, K. and Mosbach, K. (1981) Biochem.Biophys.Res. Commun. 102, 449-457

264. Hudson, L. and Hay, F.C. (1980) Practical Immunology, 2nd. Edn.; Blackwell Scientific Publications, Oxford

265. Scatchard, G. (1949) Ann.N.Y.Acad.Sci. 51, 660-672

266. Goudswaard, J., Van Der Donk, J.A., Noordzij, A., Van Ham, R.H. and Vaerman, J.P. (1978) Scand.J.Immunol. 8, 21-28

267. Laemmli, U.K. (1970) Nature 227, 680-685

268. Morrisey, J.H. (1981) Anal.Biochem. 117, 307-310

269. Towbin, H., Staehelin, T. and Gordon, J. (1979) Proc.Natl. Acad.Sci.USA 76, 4350-4354

270. Lowry, O.H., Rosebrough, N.J., Farr, A.L., and Randall, R.J. (1951) J.Biol.Chem. 193, 265-275

271. Bensadoun, A. and Weinstein, D. (1976) Anal.Biochem. 70, 241-250

272. Reers, M., Elbracht, R., Rüdel, H. and Spener,F. (1984) Chem. Phys.Lipids 36, 15-28 
273. Brecher, P., Saouaf, R., Sugarman, J.M., Eisenberg, D. and LaRosa, K. (1984) J.Biol.Chem. 259, 13395-13401

274. Edelhoch, H. (1967) Biochemistry 6, 1948-1954

275. Corr, P.B., Gross, R.W. and Sobel, B.E. (1984) Circ.Res. 55, $134-154$

276. Neely, J.R. and Feuvray, D. (1981) Am.J.Pathol. 102, 282291

277. Veerkamp, J.H. and Paulussen, R.J.A. (1987) in: "Drugs affecting lipid metabolism" (Paoletti, R., Kritchevsky, D. and Holmes, w.L., eds.) pp. 98-104, Springer Verlag, Berlin

278. Ockner, R.K., Burnett, D.A., Lysenko, N. and Manning, J.A. (1979) J.Clin. Invest. 64, 172-181

279. Morrow F.D. and Martin, R.J. (1983) J.Lipid Res. 24, 324331

280. Wilkinson, T.C.I. and Wilton, D.C. (1986) Biochem.J. 238, 419-424

281. Dempsey, M.E. (1984) Curr.Top.Cell.Regul. 24, 63-86

282. Kawashima, Y., Tachibana, Y., Nakagawa, S. and Kozuka, H. (1984) Lipids 19, 481-487

283. Wagenmakers, A.J.M., Schepens, J.T.G. and Veerkamp, J.H. (1984) Biochem.J. 223, 815-821

284. Fleischner, G., Meijer, D.K.F., Levine, W.G., Gatmaitan, Z., Gluck, R. and Arias, I.M. (1975) Biochem.Biophys.Res. Commun. 67, 1401-1407

285. Thielmann, L., Stollman, Y.R., Arias, I.M. and Wolkoff, A.W. (1984) Hepatology 4, 923-926

286. Berge, R.K., Hosoy, L.H. and Farstad, M.N. (1984) Int.J. Biochem. 16, 403-410

287. Berge, R.K. and Aarsland, A. (1985) Biochim.Biophys.Acta 837, 141-151

288. Geelen, M.J.H., Beynen, A.C. and Wirtz, K.W.A. (1987) Int.J.Biochem. $19,619-623$

289. Noland, B.J., Arebalo, R.E., Hansbury, E. and Scallen, T.J. (1980) J.Biol.Chem. 255, 4282-4289

290. Aussel, C. and Masseyeff, R. (1983) Res.Commun.Chem. Pathol. Pharmacol. 12, 261-269

291. Aussel, C. and Masseyeff, R. (1983) Biochim.Biophys.Acta $752,324-328$

292. Benassayag, C., Valette, G., Delorme, J., Savu, L. and Nunez, E.A. (1980) oncodev.Biol.Med. 1, 27-36

293. Kempen, H.J.M., Glatz, J.F.C., De Lange, J. and Veerkamp, J.H. (1983) Biochem.J. 216, 511-514

294. Fujii, S., Kawaguchi, H. and Yasuda, H. (1987) Arch. Biochem. Biophys. 254, 552-558

295. Harrison E.H., Blaner, W.S., Goodman, D.S. and Ross, A.C. (1987) J.Lipid Res. 28, 973-983

296. Muglia, L. and Locker, J. (1984) Nucl.Acids Res. 12, 67516762

297. Trojan, J. and Uriel, J. (1986) Colloques INSERM 149, 483496 
298. Van Hinsbergh, V.W.M., Mommaas-Kienhuis, A.M., Weinstein, R., and Maciag, T. (1986) Eur.J.Cell Biol. 12, 101-110

299. Smith, S.B., Ekeren, P.A. and Davis, S.K. (1988) FASEB J. 2, A639

300. Said, B. and Schulz, H. (1985) Fed.Proc. 44, 1415 (abstract)

301. Sokoloff, L., Fitzgerald, G.G. and Kaufman, E.E. (1977) in: "Nutrition and the brain" (Wurtman, R.J. and Wurtman, J.J., eds.) pp. 87-139, Raven Press, New York, USA

302. Brandes, R., Arad, R. and Barash, V. (1987) Placenta 8, 347-350

303. Evans, J., Lowy, C. and Thomas, C. (1986) Placenta 7, 464

304. Walsh Hentges, L.S. and Martin, R.J. (1986) Fed.Proc. 45, 1025, abstract 5065

305. Das, T., Sa, G. and Mukherjea, M. (1988) Lipids 23, 528-533

306. Hull, D. and Stammers, J.P. (1985) Biochem.Soc.Trans. 13, $821-822$

307. Thulin, A.J., Allee, G.L., Harmon, D.L. and Davis, D.L. (1989) J.Anim.Sci. 67, 738-745

308. Zimmermann, T., Hummel, L., Moller, U. and Kinzl, U. (1979) Biol. Neonate 36, 109-112

309. Húlsmann, W.C., De Wit, L.E.A., Dubelaar, M.-L. and stam, H. (1987) Basic Res.Cardiol. 82, Suppl. 1, 3-9 
APPENDICES.

Append $1 \times 1$.

Ligand-binding affinities of FABPS

\begin{tabular}{|c|c|c|c|}
\hline$\overline{\text { Origin }}$ & Ligand & $\begin{array}{c}\text { Kd value } \\
(\mu M)\end{array}$ & Refs. \\
\hline \multicolumn{4}{|l|}{$\overline{\text { RAT }}$} \\
\hline liver & $\begin{array}{l}\text { palmitic acid } \\
\text { palmitoyl-CoA } \\
\text { stearic acid } \\
\text { oleic acid } \\
\text { oleoyl-coA } \\
\text { linoleic acid } \\
\text { orachidonic acid } \\
\text { erucic acid } \\
\text { retinol } \\
\text { retinyl palmitate } \\
\text { heme } \\
\text { hematin } \\
\text { lysophosphatidylcholíne } \\
\text { prostaglandin-E1 } \\
\text { bromosulfophthalein } \\
\text { bilirubin } \\
11 \text {-(dansylamino)- } \\
\text { undecanoic acid } \\
\text { 16-anthroyloxy- } \\
\text { palmitic acid } \\
\text { 1-pyrene-dodecanole acid } \\
\text { oestrone sulphate } \\
\text { dehydroepiandrosterone }\end{array}$ & $\begin{array}{l}0.6 \quad 1.0 \\
0.14-2.8 \\
0.7 \\
0.07-1.5 \\
1.2-2.0 \\
0.5 \\
0.6,0.92 \\
0.9 \\
21 \\
14 \\
015 ; 15 \\
0.07 \\
15 \\
0.037 \\
0.69 \\
027 ; 1.10 \\
0.24,0.03 \text { and } 0.5 \\
0.72 \\
064 \\
30 \\
20\end{array}$ & $\begin{array}{l}25,76,85 \\
25,76,187 \\
25 \\
25,83,85,190,194,195,248 \\
25,188 \\
25 \\
25,85 \\
25 \\
194 \\
155 \\
25,194 \\
195 \\
196 \\
190 \\
195 \\
194,195 \\
83,189 \\
83 \\
83 \\
76 \\
76\end{array}$ \\
\hline heart & $\begin{array}{l}\text { myristic acid } \\
\text { palmitic acid } \\
\text { palmitoyl-cod } \\
\text { palmitoyl-carnitine } \\
\text { oleic acid } \\
\text { arachidonic acid } \\
11 \text {-(dansylamino)- } \\
\text { undecanoic acid } \\
\text { 16-enthroyloxy- } \\
\text { palmitic acid } \\
\text { 1-pyrene-dodecanoic acid }\end{array}$ & $\begin{array}{l}095 \\
078 ; 102 \\
0.51 \\
0.59 \\
0.38 \\
0.16 \\
1.84 \\
\\
133 \\
0.22\end{array}$ & $\begin{array}{l}84 \\
84,85 \\
84 \\
84 \\
83,84 \\
84 \\
83 \\
83 \\
83\end{array}$ \\
\hline kidney & $\begin{array}{l}\text { palmitic scid } \\
\text { olele acid } \\
\text { arachidonic acid }\end{array}$ & $\begin{array}{ll}1.0 \\
10 \\
09 \\
\end{array}$ & $\begin{array}{l}294 \\
294 \\
294 \\
\end{array}$ \\
\hline
\end{tabular}


Appendix I (continued).

\begin{tabular}{|c|c|c|c|}
\hline Origin & L I gand & $\begin{array}{c}\text { Kd value } \\
(\mu \mathrm{M})\end{array}$ & Refs. \\
\hline \multicolumn{4}{|l|}{$\overline{\text { MAN }}$} \\
\hline liver & $\begin{array}{l}\text { hematin } \\
\text { bromosul fophthalein } \\
\text { bilirubin } \\
\text { oleic acid } \\
11 \text { - (dansylamino)- } \\
\text { undecenole acid } \\
\text { 16-anthroyloxy- } \\
\text { palmitic acid } \\
\text { 1-pyrene-dodecenoic acid }\end{array}$ & $\begin{array}{l}0.97 \\
0.25 \\
0.78 \\
0.04: 0.62 \\
0.38 \\
028 \\
0.65\end{array}$ & $\begin{array}{l}195 \\
195 \\
195 \\
83,199 \\
83 \\
83 \\
83\end{array}$ \\
\hline heart & $\begin{array}{l}\text { myristic acid } \\
\text { palmitic acid } \\
\text { palmitoyl-CoA } \\
\text { palmitoyl-carnitine } \\
\text { oleic acid } \\
\text { arachidonic acid }\end{array}$ & $\begin{array}{ll}0 & 88 \\
0 & 60 \\
0.50 \\
0 & 42 \\
0 & 20 \\
0 & 17\end{array}$ & $\begin{array}{l}84 \\
84 \\
84 \\
84 \\
84 \\
84\end{array}$ \\
\hline \multicolumn{4}{|l|}{ PIG } \\
\hline liver & $\begin{array}{l}\text { oleic acid } \\
11 \text { (dansylamino)- } \\
\text { undecanoic acid } \\
16 \text { anthroyloxy- } \\
\text { palmitic acid } \\
1 \text { pyrene-dodecanoic acid }\end{array}$ & $\begin{array}{l}0.63 \\
044 \\
0.25 \\
0.39\end{array}$ & $\begin{array}{l}83 \\
83 \\
83 \\
83\end{array}$ \\
\hline heart & $\begin{array}{l}\text { myristic acid } \\
\text { palmitic acid } \\
\text { oleic acid } \\
\text { arachidonic acid } \\
12 \text {-doxylstearic acid } \\
11 \text {-(densylemino)- } \\
\text { undecanoic acid } \\
\text { 16-anthroyloxy- } \\
\text { palmitic acid } \\
1 \text {-pyrene-dodecanoic acid }\end{array}$ & $\begin{array}{ll}1.81 \\
1.26 \\
0 & 43 \\
0 & 24 \\
0 & 85 \\
1 & 62 \\
0 & 69 \\
0 & 25\end{array}$ & $\begin{array}{l}84 \\
84 \\
83,84 \\
84 \\
192 \\
83 \\
83 \\
83\end{array}$ \\
\hline CATTLE & & & \\
\hline liver & oleic acid & $0.24 ; 2.15$ & 139 \\
\hline heart & $\begin{array}{l}\text { palmitic acid } \\
\text { oleic acid } \\
\text { arachidonic acid }\end{array}$ & $\begin{array}{l}0.90 \\
0.39 \\
030\end{array}$ & $\begin{array}{l}186 \\
186 \\
186\end{array}$ \\
\hline
\end{tabular}


Appendix II.

Response of FABP content and fatty acid-binding capacity to physiological conditions and drugs

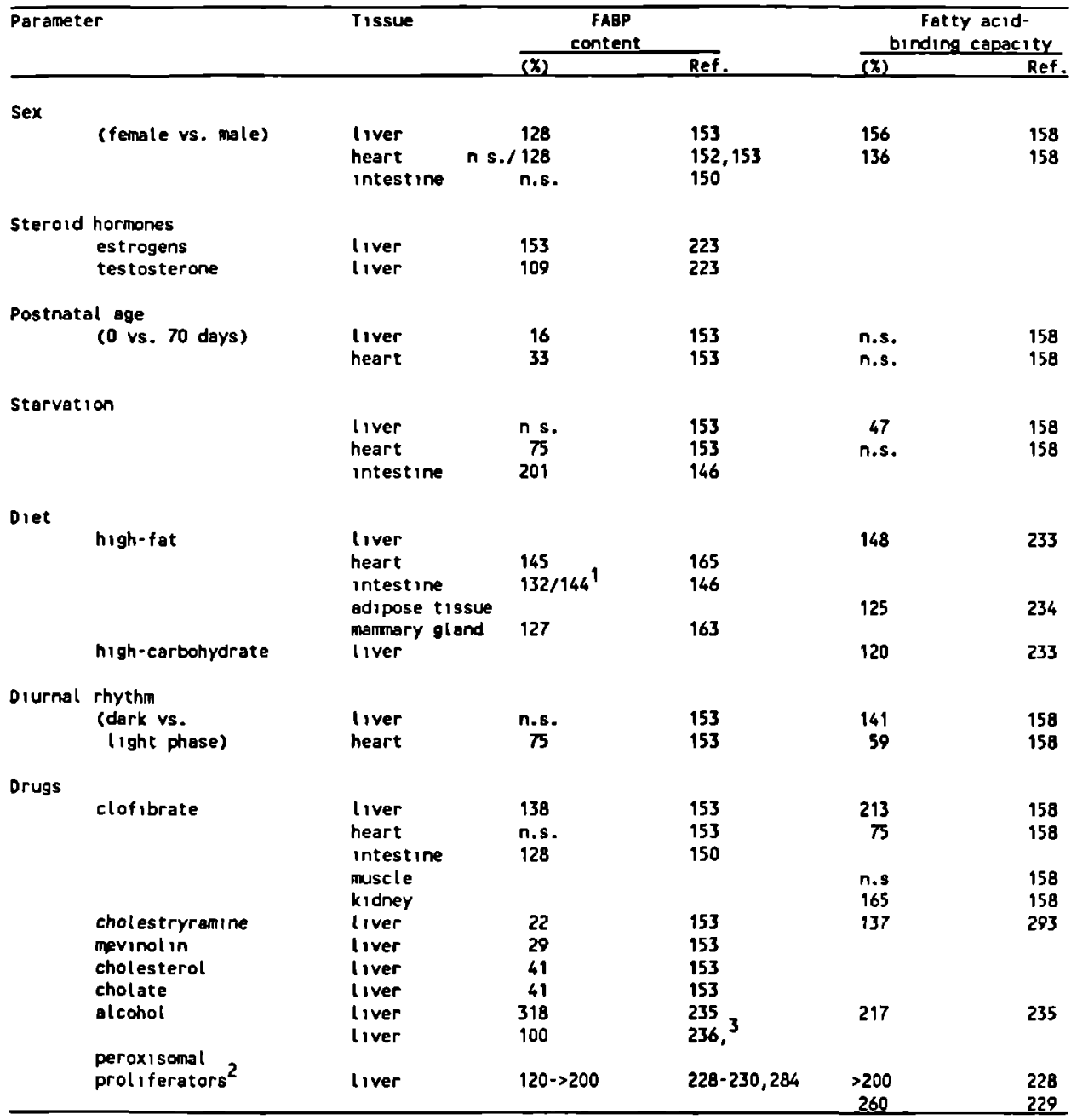

Values were derived from data in mol/mg protein, and expressed relative to those of control, adult, male fed animals (100\%).

n.s., no significant change

1 in middle and distal part of intestine, respectively.

(No significant effect in proximal section).

2 Tiadenol, nafenopin, phthalic acid esters, acetylsalicylic acid.

3 J.H. Veerkamp et al., unpubl ished results. 
1. Glatz, J.F.C., Paulussen, R.J.A. and Veerkamp, J.H. (1985) Fatty acid-binding proteins from heart. Chem.Phys.Lipids $38,115-129$

2. Paulussen, R.J.A., Jansen, G.P.M. and Veerkamp, J.H. (1986) Fatty acid-binding capacity of cytosolic proteins of various rat tissues: effect of postnatal development, starvation, sex, clofibrate feeding and light cycle. Biochim. Biophys. Acta $877,342-349$

3. Veerkamp, J.H. and Paulussen, R.J.A. (1987) Fatty acid transport in muscle: the role of fatty acid-binding proteins. Biochem.Soc.Trans. 15, 331-336

4. Veerkamp, J.H. and Paulussen, R.J.A. (1987) Fatty acidbinding proteins of various tissues. In: "Drugs affecting lipid metabolism" (Paoletti, R., Kritchevsky, D. and Holmes, W.L., eds.) pp. 98-104, Springer Verlag, Berlin

5. Paulussen, R.J.A., Van Der Logt, C.P.E. and Veerkamp, J.H. (1988) Characterization and binding properties of fatty acid-binding proteins from human, pig and rat heart. Arch. Biochem. Biophys. 264, 533-545

6. Glatz, J.F.C., Van Bilsen, M., Paulussen, R.J.A., Veerkamp, J.H., Van Der Vusse, G.J. and Reneman, R.S. (1988) Release of fatty acid-binding protein from isolated rat heart subjected to ischemia and reperfusion or to the calcium paradox. Biochim.Biophys.Acta 961, 148-152

7. Paulussen, R.J.A., Geelen, M.J.H., Beynen, A.C. and Veerkamp, J.H. (1989) Immunochemical quantitation of fatty acid-binding proteins. I. Tissue and intracellular distribution, postnatal development and influence of physiological conditions on rat heart and liver FABP. Biochim.Biophys.Acta 1001, 201-209

8. Paulussen, R.J.A., Van Moerkerk, H.T.B. and Veerkamp, J.H. (1989) Immunochemical quantitation of fatty acid binding proteins. II. Distribution of liver and heart FABP types in human and porcine tissues. Submitted for publication.

9. Paulussen, R.J.A. and Veerkamp. J.H. (1990) Intracellular fatty acid-binding proteins, characteristics and function. In: Subcellular Biochemistry, Vol. 16 (Hilderson, H.J.J. ed.), Plenum Publishing Corp., New York, USA, in press. 

René J.A. Paulussen werd op 2 september 1958 geboren te Rotterdam. In 1976 werd het eindexamen Atheneum B behaald aan het Titus Brandsma College te Dordrecht en begon hij met de studie Biologie aan de Rijksuniversiteit utrecht. In september 1980 werd het kandidaatsexamen (B1) afgelegd. Het doctoraalexamen volgde in juni 1983 en omvatte een hoofdvak Moleculaire Biologie (Vakgroep Moleculaire Celbiologie, Dr. W.J.C. Amesz, Prof. Dr. H.O. Voorma) en een bijvak Biochemie (Vakgroep Biochemie, Dr. B. Roelofsen, Prof. Dr. L.L.M. van Deenen). Moleculaire Genetica werd, als tweede hoofdvak, bewerkt aan de Erasmus Universiteit te Rotterdam (Vakgroep Celbiologie en Genetica, Dr. A.H.M. Geurts van Kessel, Prof. Dr. D. Bootsma).

Van 1 september 1983 tot 1 september 1987 was hij als wetenschappelijk assistent aangesteld bij de afdeling Biochemie, Medische Faculteit, van de Katholieke Universiteit Nijmegen. In die periode werd, onder leiding van Prof. Dr. J.H. Veerkamp, het in dit proefschrift beschreven onderzoek uitgevoerd.

Sinds 1 september 1987 is hij als wetenschappelijk medewerker in dienst bij de Rijksdienst voor de keuring van vee en vlees (RVV) en gedetacheerd bij de afdeling Biofarmaceutische Analyse van het Rijks-kwaliteitsinstituut voor Land- en tuinbouwprodukten (RIKILT) te Wageningen. 




